Power Map Explorer: uma ferramenta para visualização e previsão de vazões

Henderson Amparado de Oliveira Silva 



\title{
Power Map Explorer: uma ferramenta para visualização e previsão de vazões
}

\author{
Henderson Amparado de Oliveira Silva
}

Orientadora: Prof ${ }^{a}$. Dr ${ }^{a}$. Rosane Minghim

Dissertação apresentada ao Instituto de Ciências Matemáticas e de Computação - ICMC/USP, como parte dos requisitos para a obtenção do título de Mestre em Ciências de Computação e Matemática Computacional.

USP - São Carlos

Julho de 2007 

Dedico este trabalho

Aos meus pais Hélio e Edna

Aos meus irmãos Hélida, Helessandre e Helinho

À minha querida namorada Ana Paula pelos valores que todos representam. 



\section{Agradecimentos}

À Deus, seja onde ele estiver.

À professora Rosane Minghim, orientadora, pela oportunidade, apoio, parceria, compreensão, amizade e direção na realização deste projeto.

Ao professor Marinho Gomes de Andrade Filho, por me honrar com seus conhecimentos, pela paciência e competência no transcorrer deste trabalho.

Aos professores Luis Gustavo Nonato, Maria Cristina Ferreira de Oliveira, Guilherme Telles, Graça Nunes, pelos ensinamentos.

Aos meus colegas do grupo de Visualização de Informação, Wagner, Fernando, Márcio, Pinho e Aretha, pela cooperação. Aos companheiros de futebol, pelos momentos de distração. Também aos amigos Murilo, Lucas, Valter, Fábio, Geraldo, Leandro, Ivan e a todos que de alguma maneira contribuíram para os bons momentos aqui vividos.

Aos funcionários do ICMC-USP, pela disposição em sempre bem atender.

À minha família, meus pais e irmãos, pelo carinho e incondicional apoio no transcorrer desta caminhada.

Em especial, à Ana Paula, namorada e companheira, pela compreensão nos momentos difícieis, pela disposição em sempre bem ajudar e principalmente por todo carinho e amor.

Ao ICMC-USP, pela oportunidade de realizar o curso de Pós-Graduação.

Ao CNPq, pelo apoio financeiro dado a este trabalho. 

"Para estar junto não é preciso estar perto, e sim do lado de dentro."

Leonardo da Vinci 

1 Introdução 1

1.1 Contextualização . . . . . . . . . . . . . . . . . . . . . . . 1

1.2 Motivação e Objetivos . . . . . . . . . . . . . . . . . . . . . 3

1.3 Organização . . . . . . . . . . . . . . . . . . 4

2 Fundamentação Teórica $\mathbf{5}$

2.1 Considerações Iniciais . . . . . . . . . . . . . . . . . . . 5

2.2 Visualização Interativa . . . . . . . . . . . . . . . . . . . . . . . 6

2.3 Visualização Espaço-Temporal . . . . . . . . . . . . . . . . . . 8

2.3.1 Características Espaço-Temporais . . . . . . . . . . . . 8

2.4 Visualização de Séries Temporais . . . . . . . . . . . . . . . . . 11

2.4.1 Técnicas de Visualização . . . . . . . . . . . . . . . . . . . . . 12

2.4 .2 Métricas de Distância . . . . . . . . . . . . . . . 17

2.4.3 Modelos de Previsão de Séries Temporais . . . . . . . . . . . . . . 20

2.5 Considerações Finais . . . . . . . . . . . . . . . . . . . . 25

3 Descrição do Sistema $\quad 27$

3.1 Considerações Iniciais . . . . . . . . . . . . . . . . . . . . 27

3.2 Estrutura de Desenvolvimento do Power Map Explorer . . . . . . . . . . 28

3.2.1 Arquitetura do Sistema . . . . . . . . . . . . . . . 28

3.2.2 Ferramentas de Desenvolvimento . . . . . . . . . . . . . . . 29

3.2 .3 Módulo de Interface . . . . . . . . . . . . . . . . . . 31

3.3 Módulo de Visualização . . . . . . . . . . . . . . . . . . . 31

3.3.1 Distribuição Espacial ou Mapa . . . . . . . . . . . . . . . . . 32

3.3 .2 Comportamentos Locais . . . . . . . . . . . . . . . 33

3.3.3 Time Manager e Animação em Mapa . . . . . . . . . . . . . . . . . 34

3.3.4 Comparação Visual em Mapa . . . . . . . . . . . . . . . . 35 
3.3.5 Gráficos Temporais . . . . . . . . . . . . . . . . . 36

3.3.6 Variação Temporal Uni-Escala . . . . . . . . . . . . . . . . . . . . 38

3.3.7 Projeção por Similaridades . . . . . . . . . . . . . . . . . . . 40

3.4 Módulo de Previsão . . . . . . . . . . . . . . . . . . . . . . . . . . . . . . . 42

3.4.1 Análise Preliminar . . . . . . . . . . . . . . . . . . . 42

3.4 .2 Parâmetros de Previsão . . . . . . . . . . . . . . . . . . . 43

3.4 .3 Resultados da Previsão . . . . . . . . . . . . . . . . . . . 45

3.5 Considerações Finais . . . . . . . . . . . . . . . . . . . . . 47

4 Aplicação do Sistema $\quad 49$

4.1 Considerações Iniciais . . . . . . . . . . . . . . . . . . . . . . . . . . 49

4.2 Visualização de Dados de Vazões Mensais . . . . . . . . . . . . . . . . . . 49

4.2.1 Definição da distribuição do atributo vazão sobre o território Brasileiro 50

4.2.2 Determinação de padrões, comportamentos e fenômenos embutidos nos dados . . . . . . . . . . . . . . . . . . . 55 55

4.2 .3 Detecção de similaridades entre usinas . . . . . . . . . . . . . 58

4.3 Previsão de Vazões Mensais . . . . . . . . . . . . . . . . . . . . . 62

4.3.1 Análise e Previsão dos Dados de Vazão para Sobradinho . . . . . . 62

4.4 Considerações Finais . . . . . . . . . . . . . . . . . . . . . 69

$\begin{array}{lll}5 & \text { Conclusões } & 71\end{array}$

$\begin{array}{ll}\text { Referências Bibliográficas } & 74\end{array}$

$\begin{array}{ll}\text { APÊNDICE } & 81\end{array}$

A Symbolic Aggregate ApproXimation - SAX $\quad 81$

$\begin{array}{ll}\text { B Estrutura dos Arquivos XML } & 87\end{array}$ 


\section{Lista de Figuras}

1.1 Sistema do sudeste Brasileiro . . . . . . . . . . . . . . . . . 2

2.1 Interação: modificações, realizadas pelo usuário, das informações obtidas $\quad 7$

2.2 Conceito de dados espaço-temporais de Peuquet . . . . . . . . . . . . . . . 9

2.3 Visualização Clássica de Minard da campanha do exército de Napoleão contra Rússia (Minard 1844-70) . . . . . . . . . . . . . . . . . . . 13

2.4 PowerWord Simulator: linhas de transmissão de alta voltagem . . . . . . . . 14

2.5 O mapa compara a taxa de desempregados entre as regiões da Itália nos anos de 1983 e 1990. Pode ser visto um padrão espacial de transformação: diminuição na taxa nos estados do norte (indicado pela cor azul) e aumento no sul onde o marrom prevalece. O cinza corresponde áreas sem dados . . . 14

2.6 Gráficos de dados dependentes do tempo. Esquerda: Pie Chart, Centro: Stacked Bar Chart, Direita: Circle Graph . . . . . . . . . . . . . . . . . 15

2.7 Exemplos de técnicas para a visualização de dados de séries temporais georeferenciadas . . . . . . . . . . . . . . . . . . 16

2.8 Calendar View: Clusters de dados de consumo de energia baseados em observações diárias em Potsdam, durante o ano 1997 . . . . . . . . . . . . 16

2.9 ThemeRiver: Visualização para 100 anos de dados climáticos . . . . . . . . 17

2.10 Noção intuitiva da distância Euclidiana, que pode ser vista como uma soma das linhas cinzas entre dois pontos. . . . . . . . . . . . . . . . . 18

3.1 Arquitetura do sistema. . . . . . . . . . . . . . . . . . . . . 28

3.2 Diagrama geral das principais classes do Power Map Explorer. . . . . . . . 30

3.3 Janela principal do Power Map Explorer. . . . . . . . . . . . . . . . . . . . 32

3.4 Distribuição Espacial ou Mapa. . . . . . . . . . . . . . . . . . . . . . . 33

3.5 Comportamento Anual do atributo vazão sobre o mapa. . . . . . . . . . . . 34

3.6 Time Manager. . . . . . . . . . . . . . . . . . . . 35

3.7 Gráficos de tempo para análise dos comportamentos dos elementos do conjunto de dados. . . . . . . . . . . . . . . . . . . . . . . . 37 
3.8 Gráficos de bar charts e pie charts. . . . . . . . . . . . . . . . 37

3.9 Construção da representação visual Variação Temporal Uni-escala. . . . . . 38

3.10 Disposição dos dados na representação uni-escala. . . . . . . . . . . . . . 39

3.11 Divisão do retângulo para representação da escala mensal. . . . . . . . . . . 39

3.12 Representação uni-escala para os dados de vazões nas hidrelétricas. . . . . 40

3.13 Agrupamentos gerados para dados de vazões utilizando a distância euclidiana. 41

3.14 Interface gráfica do módulo de previsão. . . . . . . . . . . . . . . . . . . . 43

3.15 Gráficos de média, desvio padrão, coeficiente de variação e de variância versus média para os dados de vazões da usina hidrelétrica de Furnas. . . . 44

3.16 Gráfico de tempo das séries de vazões prevista e observada para a usina de Furnas a partir da previsão pelo modelo PARPMLE. . . . . . . . . . . . . 46

3.17 Gráficos de resíduos $a_{t}$ gerados pelo modelo PARPMLE. . . . . . . . . . . 47

4.1 Representação das usinas hidrelétricas como círculos coloridos plotados sobre o mapa . . . . . . . . . . . . . . . . . . . . 51

4.2 Análise das transformações nas taxas de vazão das usinas hidrelétricas do sistema: diferenças absolutas entre os meses de junho de 1987 e junho de 1986

4.3 Análise das transformações nas taxas de vazão das usinas hidrelétricas do sistema: diferenças relativas entre os meses de junho de 1987 e junho de 198654

4.4 Verificação numérica dos comportamentos e das transformações correntes nas usinas . . . . . . . . . . . . . . . . . . . . . 54

4.5 Vazão média nas usinas hidrelétricas para os últimos 75 anos. . . . . . . . 56

4.6 Vazão mensal nas usinas hidrelétricas da Bacia Hidrográfica do rio Paraná durante os últimos 10 anos. . . . . . . . . . . . . . . . . . . . . . . . 57

4.7 Comportamentos anuais da usina de Tucurui. . . . . . . . . . . . 57

4.8 Distribuição discreta mensal do atributo vazão para a usina de Sobradinho. 58

4.9 Comportamento anual das usinas hidrelétricas para o atributo vazão no ano de 1992. . . . . . . . . . . . . . . . . . . . . . . . 5 59

4.10 Comportamento anual das usinas hidrelétricas para o atributo vazão no ano de 1992. . . . . . . . . . . . . . . . . . . . . 6 60

4.11 Agrupamentos das usinas da bacia do rio São Francisco segundo a CDM 61

4.12 Agrupamentos das usinas da bacia do rio Paraná segundo a medida Euclidiana 62

4.13 Gráficos de média, desvio padrão, coeficiente de variação e de variância versus média para os dados de vazões da usina hidrelétrica de Sobradinho . 63

4.14 Séries prevista (em azul) e observada (em vermelho) a partir da previsão pelo modelo ARBOXCOX . . . . . . . . . . . . . . . . . . 64

4.15 Séries prevista (em azul) e observada (em vermelho) a partir da previsão pelo modelo PARPBC . . . . . . . . . . . . . . . . . . . . . . . . . 64 
4.16 Gráfico de tempo com as séries previstas pelos modelos PARPMLE, PARPBC, ARMLE e ARBOXCOX, mais a série original . . . . . . . . . . 66

4.17 Gráficos da série padronizada $z_{t}$ e dos resíduos $a_{t}$ gerados pelo modelo

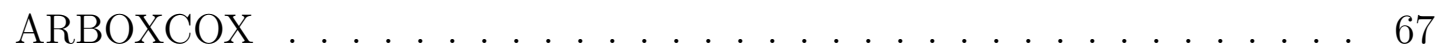

4.18 Tabelas com valores referentes a qualidade, erro e phich da previsão pelo modelo ARBOXCOX . . . . . . . . . . . . . . . . . . . . . 68

A.1 SAX: uma série temporal de tamanho 24 foi reduzida em uma string de

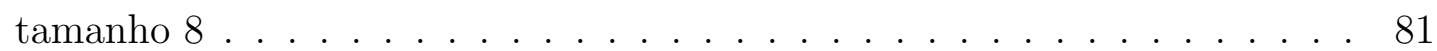

A.2 Aplicação da etapa do PAA com $w=8$ a uma série temporal de tamanho

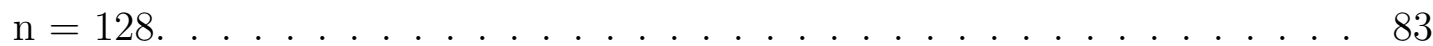

A.3 Uma série temporal é discretizada, primeiramente obtendo uma representação PAA, e depois utilizando breakpoints para mapear os segmentos PAA em símbolos. Neste caso, foi usado $w=8$ e $a=3$, obtendo-se a palavra $\widehat{C}$ $=\widehat{c_{1}}, \widehat{c_{2}}, \widehat{c_{3}}, \widehat{c_{4}}, \widehat{c_{5}}, \widehat{c_{6}}, \widehat{c_{7}}, \widehat{c_{8}}=$ baabccbc ........... 85 



\section{Lista de Tabelas}

2.1 Compression-Based Dissimilarity Measure (CDM)(Keogh et al., 2007). . . 19

4.1 Tabela com valores exatos das diferenças absoluta e relativa. . . . . . . . 53

A.1 Sumário de notações usadas no SAX . . . . . . . . . . . . . . . . . . 82

A.2 Tabela de breakpoints para a etapa de discretização de séries temporais normalizadas, com alfabeto variando de 3 a $10 . \ldots$. . . . . . . . . . . . . 84 



\section{Lista de Símbolos}

$\begin{array}{ll}\text { ARBOXCOX } & \text { Modelo auto-regressivo com transformação de Box-Cox } \\ \text { ARMLE } & \text { Modelo auto-regressivo com ajuste de máxima verossimilhança } \\ \text { PARPBC } & \text { Modelo periódico auto-regressivo de ordem P com transformação de } \\ & \text { Box-Cox } \\ \text { PARPMLE } & \text { Modelo periódico auto-regressivo de ordem P com ajuste pelo método } \\ & \text { de máxima verossimilhança } \\ X M L & \text { eXtensible Markup Language } \\ \text { ONS } & \text { Operador Nacional do Sistema }\end{array}$





\section{Resumo}

A complexidade inerente ao processo de produção de energia apresenta um desafio aos especialistas quando estes se deparam com o dimensionamento e operação de sistemas de recursos hídricos. A produção energética de um sistema hidroelétrico depende fundamentalmente das séries de vazões afluentes às diversas usinas hidrelétricas do sistema. No entanto, a incerteza das vazões futuras e sua aleatoriedade são obstáculos que dificultam todo o planejamento da operação do sistema energético brasileiro. A inexistência de um software específico para análise de séries de vazões ocorridas nas usinas hidrelétricas, associada à importância desse tipo de dado no contexto energético, motivou a concepção de uma ferramenta gráfica para visualização e previsão desses dados. Acredita-se que a visualização desses dados por meio de representações apropriadas e altamente interativas possa promover hipóteses e revelar novas informações dos fenômenos associados a essas quantidades, melhorando a qualidade das decisões de planejamento do sistema energético. Este trabalho de mestrado apresenta em detalhes o sistema desenvolvido, chamado Power Map Explorer, e das técnicas nele implementadas. 



\begin{abstract}
The complexity inherent to the process of energy production introduces a challenge to the experts when they are faced with dimension and operation of water resources systems. The energy production of a hidroeletric system depends on streamflow time series from hydroelectric plants located on different rivers of the system. However, the uncertainty and randomness of future streamflow series impose difficulties to the planning and operation of the brazilian energy system. The lack of a software suite to support the analysis of inflow series from hydroelectric plants, and the importance of this data in the energy context motivated the conception and implementation of a graphical tool to visualize and forecast this type data. The appropriate level of visualization and interaction with this type of data can spring new hypotheses and reveal new information, leading to performance improvement of the task of energetic planning. This work presents a software for visualization and forecast of inflow data series, the Power Map Explorer, in detail.
\end{abstract}




\section{Capítulo \\ 1 \\ Introdução}

\subsection{Contextualização}

A área de energia possui sem dúvida um papel estratégico para o desenvolvimento de qualquer país, e em especial, do Brasil. A dependência econômica da energia, em especial da elétrica, requer o uso mais racional e eficiente dos recursos disponíveis, principalmente dos não-renováveis e dependentes de condições climáticas, como os recursos hídricos. A energia elétrica atua como um fator de integração, e seu planejamento adequado é crucial para o desenvolvimento do país.

Neste contexto, o planejamento operacional de um sistema hidrotérmico ${ }^{1}$ de energia elétrica tem por objetivo determinar uma política de operação para as usinas hidroelétricas e termoelétricas do sistema que atenda a demanda de energia de forma mais econômica e confiável possível (Balinni, 2000).

Como estamos lidando com sistemas hidrotérmicos com predominância de geração hidroelétrica, situação do sistema brasileiro, com cerca de aproximadamente $76 \%$ de participação hidroelétrica, o planejamento da operação do sistema se torna imprescindível, pois as conseqüências de uma operação inadequada são graves (ANNEL, 2007).

A dificuldade do planejamento da operação de sistemas hidrotérmicos começa, portanto, pela necessidade de se analisar a operação ao longo de um "horizonte" de planejamento que permita avaliar o impacto futuro de decisões. Este horizonte depende fundamentalmente da capacidade de regulação dos reservatórios e das características hidrológicas do sistema (Fortunato e Araripe, 1990).

Além disso, o acoplamento hidráulico entre as usinas hidrelétricas situadas num mesmo rio torna as condições de operação de cada usina dependente da operação das demais, de

\footnotetext{
${ }^{1}$ Sistema constituído por usinas hidroelétricas e termoelétricas.
} 
modo que suas operações devem ser coordenadas. Assim, o parque hidrelétrico constituise num sistema interconectado de geração, ao contrário do termoelétrico, cujas unidades são independentes entre si. A figura 1.1 mostra parte do sistema do sudeste brasileiro, abrangendo a grande bacia do rio Paraná constituído pelos rios Paranaíba, Grande e Paraná, onde operam várias usinas hidrelétricas interligadas.

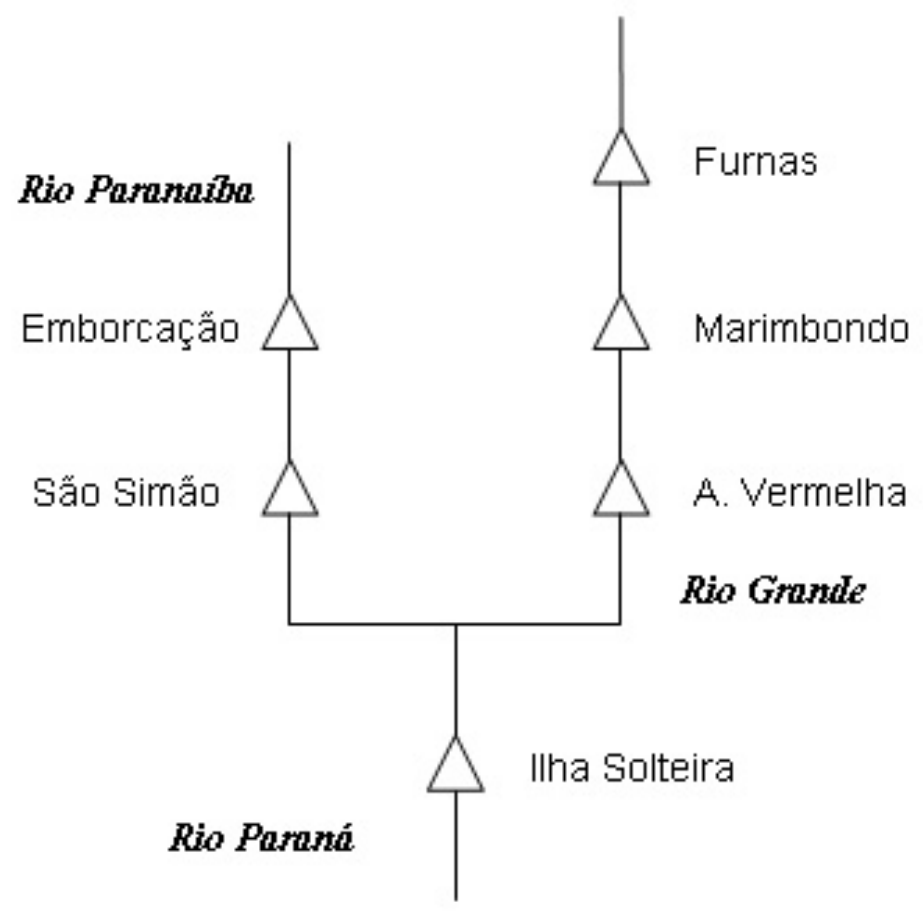

Figura 1.1: Sistema do sudeste Brasileiro.

Outros aspectos que dificultam o planejamento da operação de sistemas hidroelétricos são a incerteza das vazões futuras e a demanda de energia (ONS, 2007). A relativa aleatoriedade das vazões nos rios faz com que toda operação corra o risco da ineficiência. Segundo a ONS (Operador Nacional do Sistema) as vazões naturais são de fundamental importância para a atividade de planejamento do uso dos recursos hídricos, em particular, no caso do setor elétrico, para o planejamento da operação e expansão da geração hidroelétrica.

Da mesma forma, embora em menor grau, o crescimento e a modernização da economia brasileira nas últimas décadas geraram um enorme e sistemático aumento da demanda, principalmente nas grandes áreas urbanas e em regiões predominantemente industriais. Além do mais, o sistema energético brasileiro continua a crescer em um ritmo acelerado, e a tendência é em direção a uma maior complexidade, tornando a tomada de decisões cada vez mais complexa (ONS, 2007).

Como resultado destas tendências e transformações, é muito arriscado confiar em uma estratégia de gerenciamento baseada em tentativa e erro. Apesar do enorme auxílio e confiabilidade que sistemas de suporte podem oferecer, as decisões finais dependem sem- 
pre da análise e intervenção humana. Atualmente, estas tomadas de decisões são feitas baseadas em intuição e experiência, pois é muito difícil para engenheiros e operadores correlacionar a grande quantidade de dados existentes e suas diferentes características, como por exemplo, as localizações geográficas.

A forma clássica com que os dados para o planejamento energético são tratados, desde os dados de vazões nas hidrelétricas até o despacho, embute várias imprecisões e ineficiências. O grande volume de dados apresenta uma dimensão que dificilmente pode ser representada de forma legível e intuitiva apenas com o uso de diagramas comuns ou de tabelas convencionais.

Toda esta dificuldade freqüentemente resulta em erros nas tomadas de decisões - decisões que podem implicar em alto custo financeiro, social e ambiental. A solução tem sido utilizar o computador como ferramenta para auxiliar na execução de diversas tarefas, tais como obter modelos precisos e confiáveis do sistema, simular cenários de operação e programação, prever informações antecipadamente, visualizar e analisar dados, etc.

A idéia de se criar representações gráficas aparece como uma tentativa de oferecer aos especialistas uma interação com tais conjuntos de dados, possibilitando assim sua interpretação, bem como a dos processos e fenômenos que os geraram. Apesar de suas limitações, as técnicas de visualização são de grande ajuda a cientistas e outros profissionais que de outra forma ficariam impossibilitados de analisar e entender conjuntos de dados estritamente numéricos.

A solução dos problemas da área de energia elétrica tem se concentrado principalmente em duas grandes questões. Primeiro, como representar de forma legível e compatível o grande volume de dados existentes do sistema. Segundo, como prever antecipadamente informações do sistema elétrico de forma a facilitar as tomadas de decisões por parte dos responsáveis. O setor energético requer ainda muita pesquisa para obtenção de modelos de visualização e previsão eficientes.

\subsection{Motivação e Objetivos}

Apesar da grande importância de ferramentas computacionais para a eficiência e credibilidade do sistema energético, poucos recursos existem aplicados à área de energia, menos ainda relacionados com a visualização e previsão de dados de vazões nas hidrelétricas. É neste contexto que se espera que a Visualização, área que investiga estratégias capazes de explorar a capacidade humana de interpretar representações visuais para ganhar entendimento sobre os dados (Card et al., 1999; Wong, 1999), possa contribuir tanto para o apoio à geração e análise de resultados de previsões quanto à extração de informações úteis para a operação do sistema de energia.

Em anos recentes, dados com atributos espaciais e temporais têm adquirido cada vez mais importância no campo de Visualização de Informação. MacEachren e Kraak (2001) 
citam estimativas que sugerem que $80 \%$ dos dados gerados na época, em formato digital, incluíam referências espaciais, tais como coordenadas geográficas, endereços e código postal. O atributo espacial define o posicionamento relativo entre os objetos representados em conjunto de dados espaciais. A observação repetida, ao longo do tempo, de um mesmo objeto ou fenômeno espacial, estabelece uma componente temporal para os dados que representam o objeto ou fenômeno (MacEachren et al., 1999). A compreensão correta de fenômenos de natureza espacial e temporal em domínios como meio ambiente, energia, negócios e turismo, é importante para traçar estratégias de ação que beneficiam as comunidades afetadas por esses fenômenos. Neste sentido, estratégias de análise integrando abordagens visuais podem auxiliar especialistas a entender os resultados da análise, bem como a caracterizar os dados geradores e, com isso, aumentar a qualidade das análises e a confiança nos resultados, levando a previsões e planejamentos mais consistentes.

O objetivo central deste projeto de mestrado consistiu no desenvolvimento de um sistema gráfico, denominado Power Map Explorer, para visualização exploratória e previsão de dados de vazões nas usinas hidrelétricas. Para isso, técnicas da área de visualização espaço-temporal foram identificadas, adaptadas e integradas em um ambiente que agrega múltiplas visualizações interativas. Acredita-se que a visualização desses dados por meio de representações apropriadas e interativas possa promover hipóteses e revelar novas informações dos fenômenos associados a essas quantidades, melhorando a qualidade das decisões de planejamento do sistema energético. Além disso, foram reprogramados quatro modelos de previsão de vazões (dois modelos auto-regressivos (AR) e dois modelos periódicos auto-regressivos (PAR)) de autoria do prof. Marinho G. de Andrade Filho, do ICMC, e seus associados (Andrade, 2004). O Código existente foi convertido do ambiente estatístico Matlab para o ambiente integrado Java-Scilab, a fim de tornar o resultado final deste sistema de previsão e de visualização independente de software proprietário. Interfaces gráficas foram criadas para o acesso aos dados e para a apresentação e interação com os resultados.

\subsection{Organização}

No Capítulo 2 são apresentadas revisões relativas aos conceitos e conhecimentos necessários para o desenvolvimento deste projeto, incluindo uma abordagem sobre visualização de dados com atributos espaciais e temporais e modelos de previsão de séries temporais. O Capítulo 3 descreve em detalhes a ferramenta criada, especificando cada módulo, componentes visuais, recursos de interação e ferramentas utilizadas no desenvolvimento. Os testes de utilização realizados para validar o ambiente, bem como algumas informações extraídas dos dados são abordados no Capítulo 4. Finalmente, no Capítulo 5, são feitas as considerações finais deste trabalho, apresentando as conclusões e possibilidades de trabalhos futuros. 


\section{Capítulo \\ 2 \\ Fundamentação Teórica}

\subsection{Considerações Iniciais}

O desenvolvimento tecnológico, incorporando avanços em produtos e serviços, gerou condições para medições mais precisas, simulações mais velozes e registro de uma gama variada de tipos de dados, produzindo conjuntos de dados cada vez mais volumosos e complexos (Keim, 2001). O benefício da quantidade esbarra na natural dificuldade do ser humano em analisar tamanho volume de dados. A necessidade de extrair, analisar, descobrir e utilizar as informações embutidas em dados tem despertado o interesse de pesquisadores em áreas como Visualização, Inteligência Artificial, Estatística, Reconhecimento de Padrões e Banco de Dados (Wong, 1999; Fayad et al., 2002).

Em particular, o uso de representações visuais como instrumento de comunicação para transmitir idéias, resultados e conclusões é anterior ao surgimento dos computadores. Entretanto, o advento dos computadores com recursos gráficos propiciou a geração de imagens mais sofisticadas e complexas, e a manipulação direta das mesmas em tempo real (Tufte, 1990; Keim, 2000). Representações visuais manipuladas dinamicamente facilitam a interpretação dos dados pelo usuário, possibilitando a percepção de padrões, tendências, relacionamentos e exceções embutidos nos mesmos. É neste contexto que se insere a Visualização, área que busca aproveitar a capacidade visual humana para revelar informações até então desconhecidas em grandes quantidade de dados (Oliveira e Levkowitz, 2003).

Retomando a questão da análise de grandes volumes de informação, dados de natureza espacial e temporal representam hoje um desafio particular (Ester et al., 1999; Andrienko et al., 2000a). Muitas técnicas para visualização exploratória de dados com atributos espaciais e temporais foram propostas e implementadas, e têm adquirido importância (Andrienko et al., 2000b). A disseminação de bases de dados espaciais, como 
as relacionadas com sistemas de informação geográfica (GIS) e de sensoriamento remoto, provocou um crescente interesse em técnicas de visualização e mineração. Estimativas sugerem que $80 \%$ dos dados em formato digital apresentam referência espacial, tais como coordenadas geográficas e endereços (MacEachren e Kraak, 2001). Ecologia, saúde, energia, logística em negócios, turismo e controle de tráfego são exemplos de domínios para os quais tais técnicas são particularmente relevantes. Conjuntos de dados espaciais podem conter descrições de fenômenos ou eventos que se repetem ao longo do tempo, como séries de vazões nas usinas hidrelétricas. A presença de múltiplas instâncias, ou a variação de um fenômeno em decorrer do tempo, caracteriza a existência de uma série temporal no conjunto. Essa série fornece informações sobre o comportamento temporal do dado, que podem ajudar a descobrir e explicar relacionamentos e padrões nos dados (MacEachren et al., 1999).

O foco principal deste capítulo é o uso da visualização no processo de análise e descoberta de conhecimento. A seção 2.2 descreve a importância da visualização interativa para interpretação e extração de informação a partir dos dados sob análise. A seção 2.3 apresenta informações referentes à visualização de dados espaço-temporais. Dada a importância do componente temporal no contexto deste trabalho de mestrado, na seção 2.4, é apresentada uma revisão sobre a área de visualização de séries temporais, abordando algumas técnicas de visualização existentes na literatura para dados dependentes do tempo (geo-referenciados ou não), métricas de similaridades para detectar agrupamentos e relacionamentos entre séries, e modelos matemáticos para a previsão de séries temporais.

\subsection{Visualização Interativa}

Na perspectiva de Spence (2001), a visualização é uma atividade interna, de cognição do ser humano, que conduz à formação de um modelo mental com base em estímulo visual recebido através de uma imagem, facilitada por ferramentas computacionais para visualização. Um ponto complexo no projeto de tais ferramentas é o de unir representações visuais com controles interativos que confiram um certo grau de liberdade ao usuário em domínios e tarefas diversificadas.

O aumento da capacidade de processamento e armazenamento dos computadores, e o crescimento do número de sistemas de visualização disponíveis têm permitido o envolvimento do usuário nas várias etapas do processo de visualização (ver figura 2.1).

De acordo com Salvador (2003), para que os benefícios da visualização possam ser aproveitados num número crescente de aplicações, é preciso que projetistas de sistemas de visualização tenham em mente algumas questões importantes sobre o desenvolvimento de sistemas eficientes do ponto de vista do usuário, isto é, sistemas que possibilitem o entendimento de maior quantidade de informações. Uma dessas questões é o fornecimento 


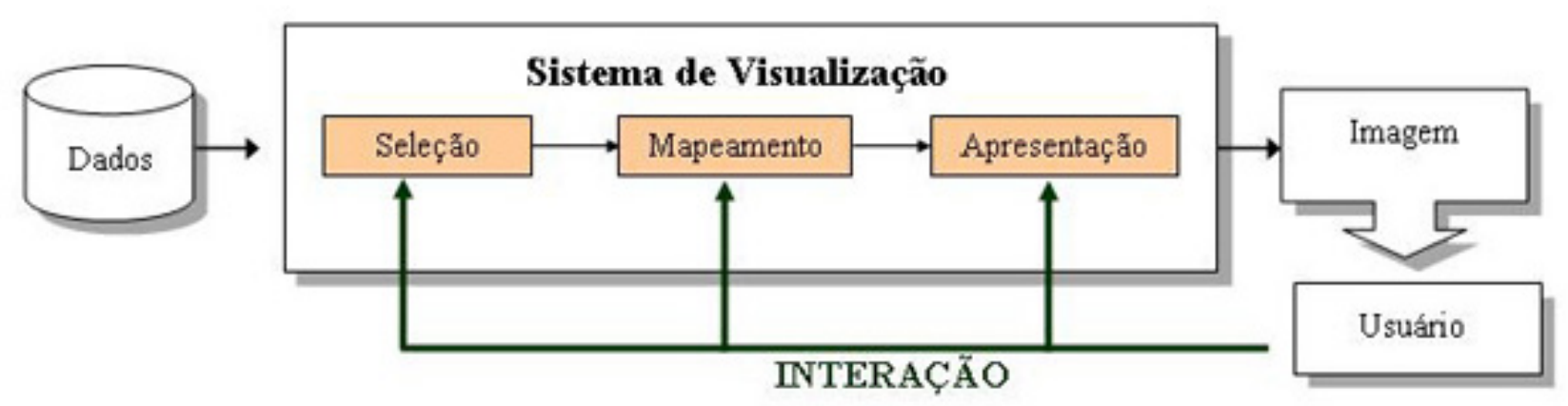

Figura 2.1: Interação: modificações, realizadas pelo usuário, das informações obtidas. [Modificado de Salvador (2003)]

de técnicas de interação para que o usuário possa manipular, explorar e analisar seus dados facilitando e agilizando sua interpretação.

Em geral, técnicas de visualização são usadas juntamente com técnicas de interação (Keim, 2000), uma vez que devem apresentar interfaces eficazes para atender às necessidades de interatividade e iteratividade do processo de descoberta, permitindo a exploração dinâmica dos dados. Keim (2001, 2002) identifica duas categorias de técnicas de interação. A primeira é composta por aquelas cujo princípio é prover uma visualização detalhada de uma porção dos dados, com o restante sendo visualizado em um nível de detalhe menor, mas possibilitando ainda a percepção do contexto global (técnicas de distorção). A segunda categoria é composta por técnicas que auxiliam uma exploração mais efetiva, permitindo que o usuário faça mudanças dinâmicas diretamente na visualização de acordo com os objetivos da exploração, como zooming, filtragem, detalhes sob demanda e linking-and-brushing. O zooming é uma técnica tradicional de interação que não somente aumenta os objetos da tela, mas também possibilita mudanças automáticas na representação dos dados para apresentar mais detalhes em um nível maior de zoom. A filtragem pode ser feita por meio de consultas dinâmicas a uma base de dados através de uma interface contendo, por exemplo, botões e barras de rolagem, enquanto os resultados são simultaneamente modificados na tela (Shneiderman, 1994). A técnica de detalhes sob demanda trabalha com dados previamente triados e, portanto, fáceis de serem inspecionados individualmente. Um bom exemplo disto é o simples clique do mouse em um item para abrir um pop-up com informações dos seus atributos (Shneiderman, 1996). O linking-and-brushing propõe múltiplas e diferentes visualizações do mesmo conjunto de dados e modificações feitas em uma delas refletem automaticamente nas outras (Keim, 2002). Algumas dessas técnicas descritas foram utilizadas no estudo e são assinaladas nos capítulos 3 e 4 .

A associação de técnicas de visualização e interação propiciou o desenvolvimento de vários sistemas de exploração visual de dados, dentre eles, pode-se destacar as ferramentas acadêmicas XmdvTool (Ward, 1994), XGobi (Swayne et al., 1998), Polaris (Stolte et al., 
2002), e as ferramentas comerciais IVEE/SpotFire (Ahlberg, 1996) e Inxight (Inxight, 2006). Em anos recentes, muitas técnicas de visualização e interação para dados com atributos espaciais e temporais foram desenvolvidas e assumiram importância nos mais diversos domínios de aplicação (Andrienko et al., 2000b).

A próxima seção procura descrever algumas características da visualização de dados espaço-temporais, destacando como a distinção dos seus componentes pode, conforme o objetivo desejado, auxiliar na escolha de estratégias apropriadas para análise e exploração desses dados.

\subsection{Visualização Espaço-Temporal}

A análise e interpretação de dados espaço-temporais representa um grande desafio atualmente (Ester et al., 1999; Andrienko et al., 2000a). Antes da década de noventa, os mapas tradicionais eram provavelmente as mais proeminentes ferramentas de visualização para pesquisadores estudarem esses tipos de dados. Para trabalhar com esses mapas, algumas técnicas eram desenvolvidas a fim de permitir a análise visual dos dados, bem como a revelação de padrões geo-espaciais, relacionamentos e tendências. Entretanto, o mapeamento visual de fenômenos que variam com o tempo sempre foi uma tarefa árdua para a maioria dos cartógrafos (Kraak, 2003).

Em anos recentes, a visualização de dados temporais geo-referenciados tem passado por importantes desenvolvimentos. Com o advento dos computadores modernos, e consecutivamente das facilidades com as novas tecnologias, a visualização de dados espaçotemporais ganhou bastante destaque em áreas como Visualização de Informação, Interação Humano-Computador e Estatística (Kraak, 2003).

Como resultado dessa evolução, os atuais softwares de visualização de dados espaçotemporais passaram a mesclar tecnologias fornecidas pelos modernos computadores e as heranças da cartografia convencional. Segundo Andrienko et al. (2003a), em comparação aos mapas tradicionais, estas ferramentas possuem duas novas propriedades: interatividade e dinamismo. Tais atributos possibilitam que algumas técnicas exploratórias possam ser aplicadas aos diversos tipos de dados espaço-temporais. A seguir são apresentadas algumas importantes características destes dados bastante utilizadas para seleção de técnicas e ferramentas apropriadas para o processo de análise e exploração.

\subsubsection{Características Espaço-Temporais}

O sucesso na análise exploratória de dados espaço-temporais depende crucialmente da seleção de técnicas de visualização apropriadas. A escolha certa depende das características dos dados e dos tipos de tarefas exploratórias que as técnicas podem suportar, em outras palavras, questões sobre os dados que elas podem responder. 
De acordo com Peuquet (1994), dados espaço-temporais são divididos em três grandes componentes: espacial (where), temporal (when) e temático (what). Cada componente consiste de elementos específicos que podem ter algumas propriedades e podem ser ligados por vários relacionamentos. Este conceito tornou-se importante no campo de pesquisa de dados espaço-temporais, pois a maioria dos problemas pode ser descrita em torno destes três componentes e das relações entre eles (Figura 2.2).

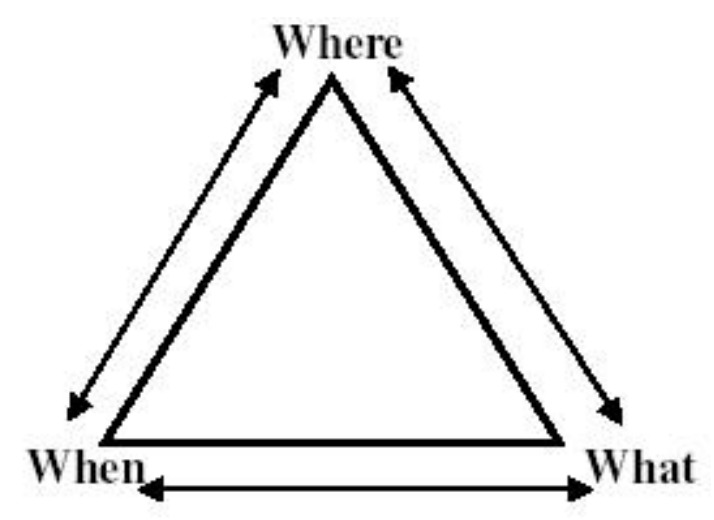

Figura 2.2: Conceito de dados espaço-temporais de Peuquet.

Na escolha de métodos para a análise de dados espaço-temporais, as características espaciais, temporais e temáticas possuem um papel fundamental. Assim, com relação às propriedades espaciais, objetos ou fenômenos podem ser classificados em pontos, linhas, áreas, e volumes (Slocum, 1999). Outra tipologia bastante utilizada classifica os mesmos de acordo com sua distribuição espacial: discreto ou contínuo (MacEachren, 1995). Fenômenos discretos ocorrem em localizações espaciais distintas ou em áreas restritas (ex. depósito de dinheiro e vazões), enquanto que fenômenos contínuos são definidos para todo território (ex. densidade populacional ou temperatura do ar).

As características temporais dos dados são classificadas segundo os tipos de transformações que ocorrem neles sobre o tempo (Blok, 2000):

- Transformações existenciais: aparecimento, desaparecimento. Refere-se ao surgimento (nascimento) de um novo fenômeno ou desaparecimento (morte) de um existente. Ex: tornado, vulcão, terremotos, etc.

- Transformações nas propriedades espaciais dos objetos: referem-se às transformações na posição ou geometria de um fenômeno. Ex: migração de gaivotas do norte para sul, etc.

- Transformações nas propriedades temáticas: refere-se às transformações que afetam os atributos de um fenômeno. Ex: série de vazão em uma usina hidrelétrica, força de um tornado, etc. 
$\mathrm{Na}$ maioria das vezes apenas um tipo de transformação é de interesse para um analista, mas, existem casos que é necessário lidar com vários tipos simultaneamente (Andrienko et al., 2003a).

Por último, as características temáticas são tipicamente distinguidas segundo os níveis de medida introduzidos por Stevens (1946): nominal, ordinal e numérico. Um fenômeno pode ter várias propriedades expressas por diferentes tipos de atributos. Por exemplo, observações de insetos raros podem ser descritas através dos seguintes atributos: as espécies dos insetos observadas (atributo nominal); estágio de desenvolvimento: ovo, larva, pupa, ou adulto (atributo ordinal); e o número de insetos encontrados (atributo numérico).

De acordo com os três componentes dos dados espaço-temporais, Peuquet (1994) definiu três possíveis tipos de questões sobre tais dados:

- when + where $\rightarrow$ what: descreve os objetos ou conjunto de objetos que estão presentes numa dada localização ou conjunto de localizações num dado tempo ou conjunto de tempos;

- when + what $\rightarrow$ where: descreve a localização ou conjunto de localizações ocupadas por um dado objeto ou conjunto de objetos num dado tempo ou conjunto de tempos;

- where + what $\rightarrow$ when: descreve o tempo ou conjunto de tempos que um dado objeto ou conjunto de objetos ocuparam uma dada localização ou conjunto de localizações.

Esta classificação é similar à noção de tipos de questões introduzidas por Bertin (1983), isto é, a quantidade de tipos de questões corresponde ao número de componentes na informação. Segundo Bertin, para cada tipo de questão existem três níveis de leitura: elementar, intermediário e total. Este nível indica se uma questão refere-se a um simples elemento, a um grupo de elementos ou a todo conjunto.

Koussoulakou e Kraak (1992) demonstram que, no caso específico de dados espaçotemporais, a noção de níveis de leitura podem ser aplicados independentemente para as dimensões espacial e temporal dos dados. Por exemplo, a questão "Qual a tendência de transformações da taxa de vazão na hidrelétrica de Furnas?" pertence ao nível elementar em relação ao componente espacial e total em relação ao componente temporal. Esta observação pode ser aplicada também para a dimensão temática.

Segundo Andrienko et al. (2003a), a vantagem desta tipologia proposta por Bertin (e especializada em dados espaço-temporais por Peuquet) é que ela relata diretamente as tarefas para componentes de dados, isto é, tendo um conjunto de dados particular, um programador pode antecipar as questões que podem potencialmente aparecer e utilizar técnicas apropriadas para encontrar respostas para elas.

Como já ressaltado na seção 2.1, o componente temporal possui um papel de grande importância no contexto deste trabalho, pois é o atributo principal dos dados utilizados 
no estudo. A próxima seção focaliza a análise deste componente, abordando técnicas de visualização, métricas de similaridades e modelos de previsão de séries temporais. Esta descrição procura revisar não somente estratégias para análise de séries temporais, georeferenciadas ou não, existentes na literatura, mas, também fundamentar sobre possíveis métodos utilizados neste trabalho.

\subsection{Visualização de Séries Temporais}

A análise de dados de séries temporais é um dos tópicos mais importantes em muitas áreas de pesquisa. Nos últimos anos, com o acúmulo crescente de dados dependentes do tempo, o número de métodos computacionais desenvolvidos para visualização de séries temporais aumentou significantemente. Pesquisadores em áreas como Visualização de Informação, Estatística e Interação Homem-Computador propuseram várias técnicas de visualização interativa para dados dessa natureza (Carlis e Konstan, 1998; Wijk e Selow, 1999; Hochheiser e Shneiderman, 2004; Tominski et al., 2004; Andrienko e Andrienko, 2005).

Nos últimos anos, a visualização tem sido utilizada como estratégia eficiente para análise de dados de séries temporais. Wijk e Selow (1999) destacam alguns objetivos importantes na análise desses dados: (i) investigar o mecanismo gerador da série; (ii) descrever o comportamento da série, verificando a existência de padrões, tendências e ciclos; (iii) fazer previsões futuras da série. Segundo MacEachren (1995), o mapeamento visual explora a habilidade humana em detectar estruturas escondidas nestes dados. Além disto, a visualização pode auxiliar o usuário a responder diversos tipos de questões escondidas em dados temporais, dentre elas:

- Um dado fenômeno pode ser observado em um período de tempo específico? (Existência de um fenômeno)

- Quando o fenômeno é observado no tempo? Existe algum comportamento cíclico? (Localização temporal)

- Qual é o intervalo de existência do fenômeno na série temporal? (Intervalo temporal)

- Qual é a freqüência de ocorrência do fenômeno na série temporal? (Textura temporal)

- Qual é a taxa de transformação do fenômeno na série temporal? (Taxa de transformação)

- Em que ordem os fenômenos aparecem? (Seqüência)

- Os fenômenos coexistem? (Sincronização) 
A visualização de dados dependentes do tempo possui uma longa história. A representação de séries temporais aparece pela primeira vez na ilustração de órbitas planetárias em um texto de um monastério no século 10 (Tufte, 1983). Na ciência, representações visuais de séries temporais têm sido observadas desde o século 18 (Muller e Schumann, 2003). Atualmente, um repertório mais amplo para visualização de séries temporais está disponível. No entanto, Keogh e Lin (2005) destacam várias dificuldades para se lidar com séries temporais, dentre elas, a grande dimensionalidade e o volume dos conjuntos temporais, e a miscelânea das séries, isto é, dados em diferentes formatos, escalas, taxas de amostragem, e com valores ausentes, etc.

Nesta seção estão sendo descritas diferentes técnicas para a análise de séries temporais embutidas tanto em conjunto de dados espaço-temporais quanto simplesmente temporais.

\subsubsection{Técnicas de Visualização}

O propósito da visualização de séries temporais é detectar e validar propriedades e características presentes nas séries, em particular, extrair padrões, tendências e informações desconhecidas com o objetivo de responder possíveis questões, como as apresentadas anteriormente.

A base para a visualização efetiva de dados foi preparada por Bertin (1983), que distinguiu 7 variáveis visuais: tamanho, valor, textura, cor, orientação, forma e localização, que podem ser utilizadas para codificar visualmente dados nominais, ordinais e quantitativos. Mackinlay (1986) descreve a utilização destas variáveis visuais para aumentar a percepção humana em processos de análise e extração de informação a partir de representações visuais. A maioria das técnicas de visualização de dados de séries temporais pode ser entendida como uma aplicação dos conceitos e observações reveladas por Bertin e Mackinlay (Muller e Schumann, 2003).

Um exemplo clássico é o mapa que retrata a marcha do exército de Napoleão na campanha contra a Rússia de Charles Minard (ver figura 2.3). Este gráfico é ainda considerado um dos melhores gráficos estatísticos já desenhados (Tufte, 1983). Esta representação mostra muitas variáveis visuais. Como em qualquer outro mapa existem localizações. Ligado à faixa de retirada (cor preta) está um diagrama indicando a temperatura. Adicionalmente, a representação mostra o tamanho das tropas pelos números e pela largura das faixas. Nomes indicam as maiores batalhas e importantes atributos geográficos. O tempo é ilustrado como uma distinção clara entre a faixa de ida (avançando em direção a leste) e a faixa de retirada (voltando para oeste) (Elvins, 1997).

OverBye e Weber (2000) descrevem um sistema denominado PowerWorld Simulator que utiliza animação em mapa para auxiliar na análise e extração de informações úteis do sistema de energia. Tal simulador permite visualizar o fluxo de energia corrente nas 


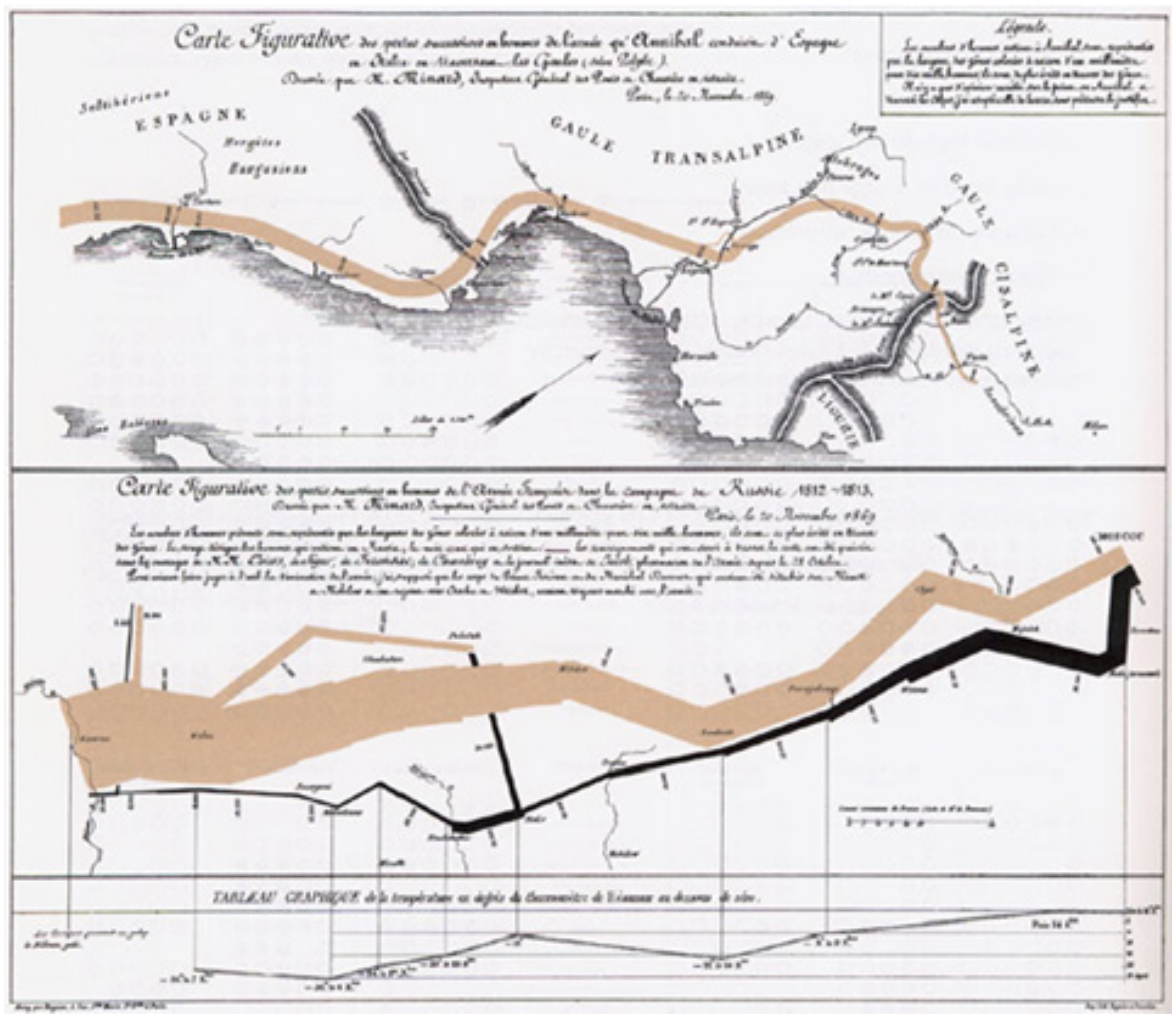

Figura 2.3: Visualização Clássica de Minard da campanha do exército de Napoleão contra Rússia (Minard 1844-70, Tufte (1983)).

linhas de transmissão através da variação no tamanho e nas cores das setas sobrepostas sobre as linhas (ver figura 2.4).

Uma possível técnica, herdada da cartografia tradicional, consiste em mostrar para cada localização a quantidade de transformações entre dois momentos diferentes no tempo. Em estudo realizado por Andrienko et al. (2000b), o método cloropleth map ${ }^{1}$ é utilizado para representar transformações nos atributos dos objetos. Neste mesmo sistema, é possível combinar esta técnica com animação, de forma que a cada passo da animação o mapa represente as diferenças entre momentos de tempo sucessivos, através da variação das cores em cada área. Uma outra operação permite estabelecer relações entre objetos, possibilitando uma comparação visual em relação ao momento anterior, a um momento fixado pelo usuário, a um objeto selecionado ou a algum valor constante (Figura 2.5).

Entretanto, o cloropleth map é pouco apropriado para a análise de transformações e tendências ocorridas em cada área em particular e menos apropriado para a comparação de transformações e tendências entre diferentes áreas.

Assim, adicionalmente, alguns métodos convencionais, baseados no mapeamento do tempo em uma escala quantitativa, são utilizados para tentar suprir essa deficiência. No caso de uma escala 1D, existem os gráficos seqüenciais, e no caso de $2 \mathrm{D}$ ou 3D, os

\footnotetext{
${ }^{1}$ De acordo com este método, o contorno de cada objeto geográfico é preenchido com alguma cor cuja intensidade corresponde à magnitude do valor de um atributo.
} 


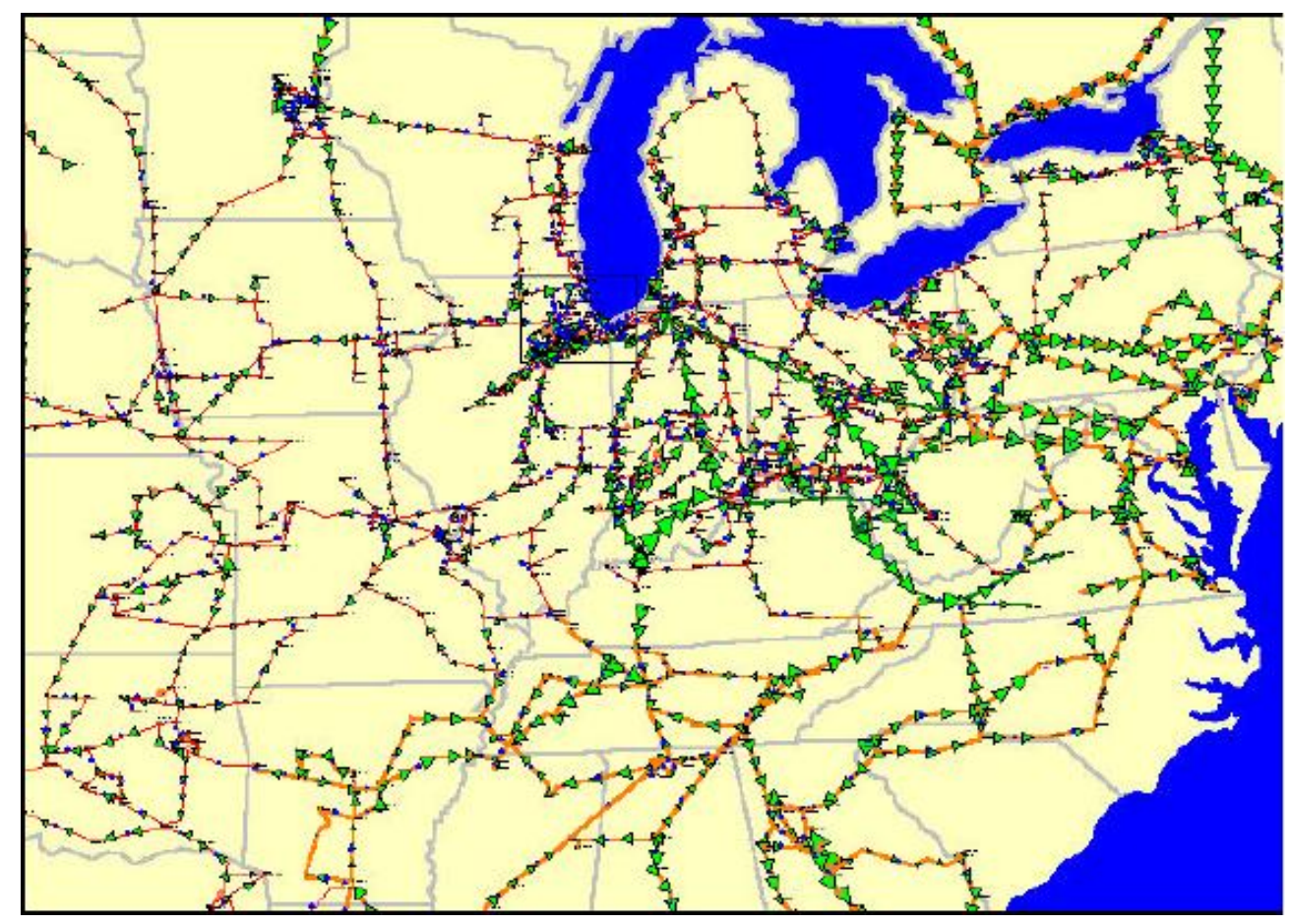

Figura 2.4: PowerWord Simulator: linhas de transmissão de alta voltagem (OverBye e Weber, 2000).

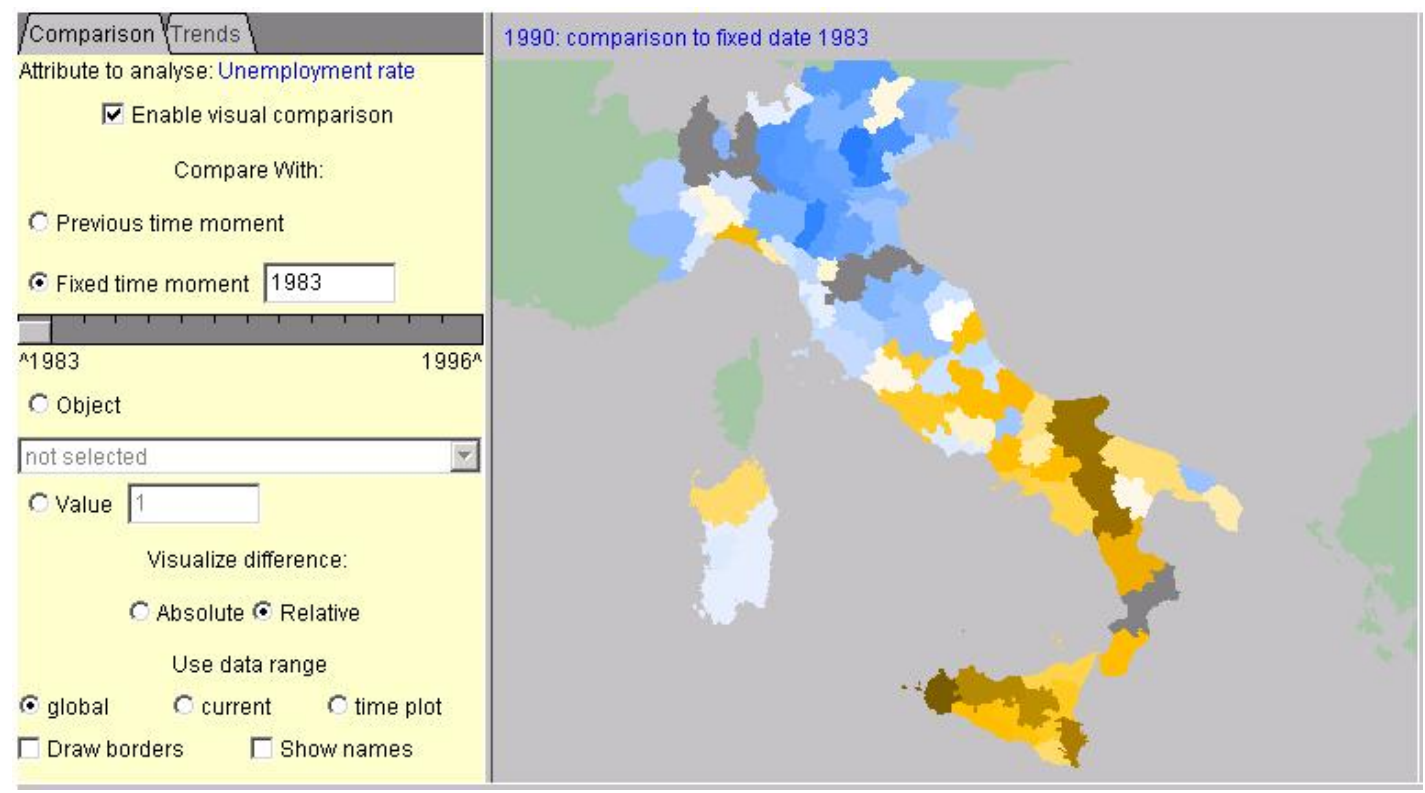

Figura 2.5: O mapa compara a taxa de desempregados entre as regiões da Itália nos anos de 1983 e 1990. Pode ser visto um padrão espacial de transformação: diminuição na taxa nos estados do norte (indicado pela cor azul) e aumento no sul onde o marrom prevalece. O cinza corresponde áreas sem dados (Fonte: http://www.ais.fraunhofer.de/and/time/italy.html). 
gráficos de tempo. A escolha de técnicas apropriadas depende do tipo de dado que será visualizado, por exemplo, gráficos de pontos (pie charts) para dados discretos, gráficos de linhas para dados contínuos, gráficos de barra (bar charts) para dados cumulativos, e gráficos circulares (circle graphs) para dados cíclicos (Harris (1996), ver figura 2.6 como exemplo).

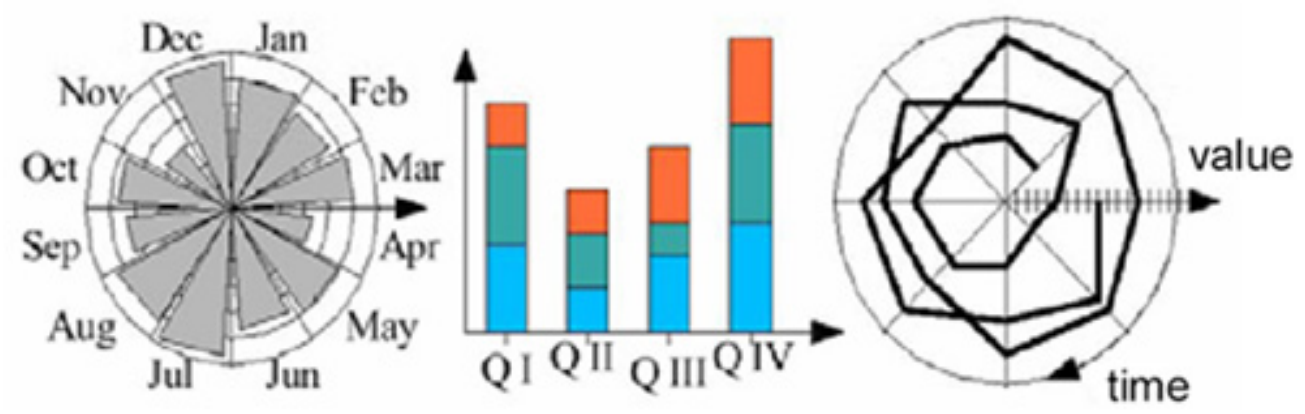

Figura 2.6: Gráficos de dados dependentes do tempo. Esquerda: Pie Chart, Centro: Stacked Bar Chart, Direita: Circle Graph (Harris, 1996).

Representações mais complexas podem ser geradas a partir de representações convencionais mais simples, de forma a permitir a visualização do comportamento temporal de vários itens do dado simultaneamente. Exemplos são os Change Charts, que apresentam o comportamento ou evolução de cada fenômeno em função do tempo, e os Stacked Bar Charts, que representam a quantidade total do item do dado como uma simples barra, e retratam o aumento em cada instante de tempo pela cor ou textura. Nesta mesma categoria, Andrienko e Andrienko (2005) apresentam métodos para a visualização de séries temporais distribuídas espacialmente, de forma que a série de cada item do dado é apresentada em conjunto com as demais na mesma representação visual (figura 2.7). Esta estratégia permite descobrir possíveis relações entre as séries, além de estabelecer clusters entre os itens do dado.

Uma outra maneira de apresentar dados dependentes do tempo é através de metáforas visuais especiais. Uma metáfora visual bastante intuitiva está presente na técnica Calendar View (Wijk e Selow, 1999). Esta técnica combina a representação de padrões e clusters diários em uma mesma visualização. Os padrões são retratados como gráficos e os clusters são representados em um calendário. Como um exemplo, a figura 2.8 mostra o resultado de uma análise de clusters de dados de consumo de energia baseados em observações diárias durante o ano 1997. À direita, os clusters são apresentados como gráficos coloridos, e à esquerda, cada dia no calendário é colorido de acordo com o cluster a que ele pertence. Tal técnica é considerada uma excelente opção para análise de dados de séries temporais, pois permite a extração de padrões e clusters embutidos nos dados de forma automática. 

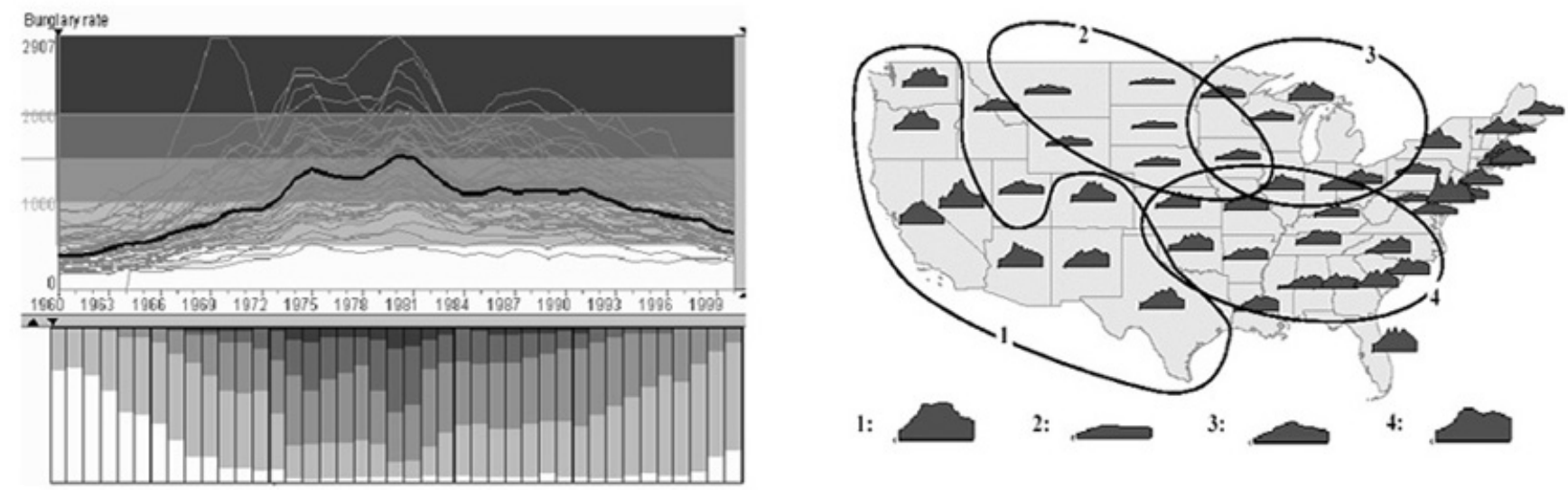

Figura 2.7: Exemplos de técnicas para a visualização de dados de séries temporais georeferenciadas. Esquerda: Gráfico de Tempo representando múltiplos comportamentos temporais. Direita: Cluster espacial dos itens do dado (neste caso, estados americanos) com comportamentos temporais similares (Andrienko e Andrienko, 2005).

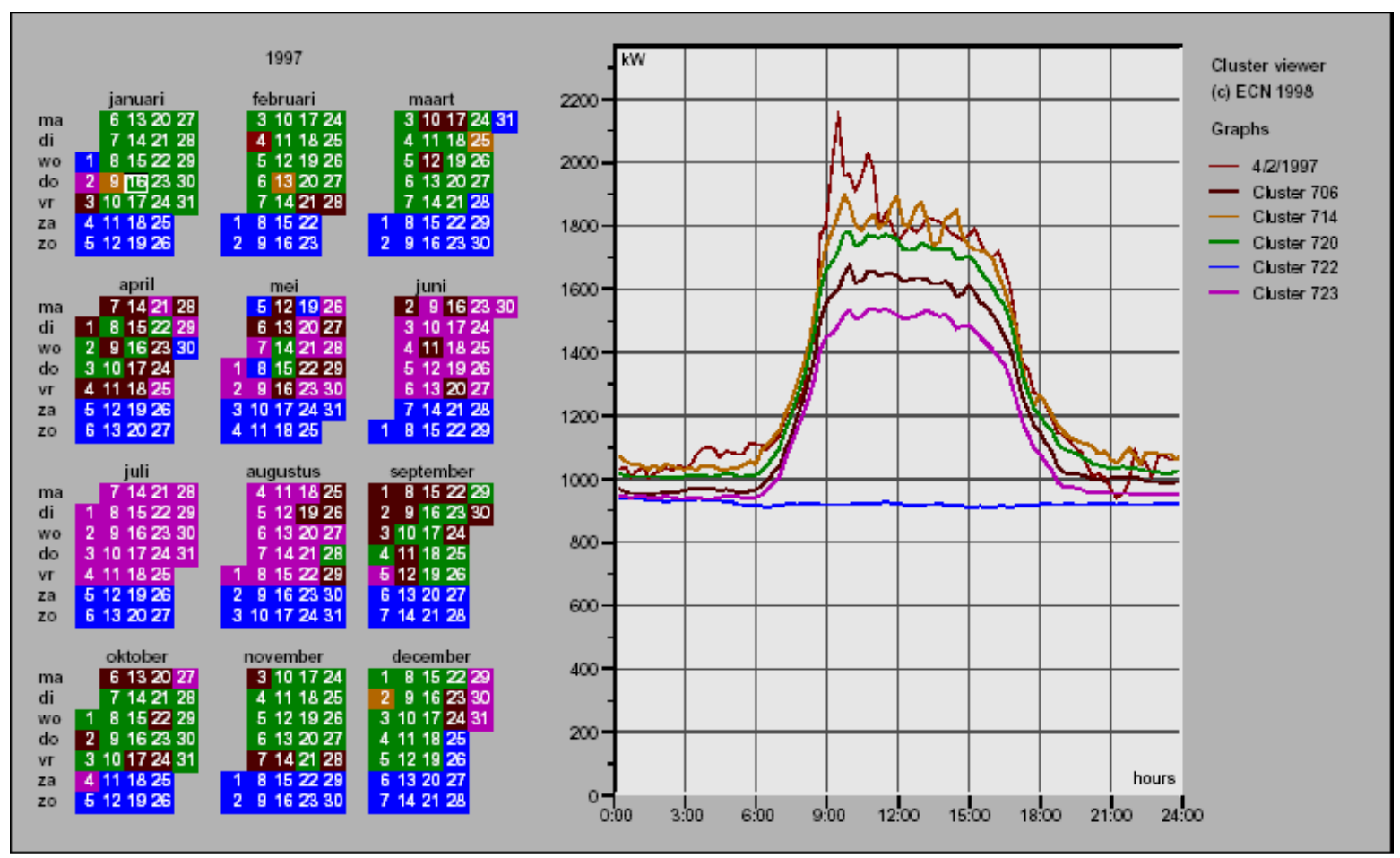

Figura 2.8: Calendar View: Clusters de dados de consumo de energia baseados em observações diárias em Potsdam, durante o ano 1997 (Wijk e Selow, 1999).

As técnicas mencionadas até o momento foram desenvolvidas focalizando a apresentação de dados de séries temporais simples, isto é, contendo apenas uma única variável dependente do tempo. Atualmente, a análise de dados de séries temporais multivariadas tornou-se muito importante. 
Uma técnica bastante difundida na literatura que trata este problema é a ThemeRiver (Havre et al., 2000). Essa técnica foi desenvolvida originalmente para a visualização de documentos: a freqüência de ocorrências de certas palavras em documentos é computada para cada instante de tempo. Estas ocorrências são mapeadas através de gráficos de barras (bar charts) coloridos (com um eixo de tempo linear contínuo). Interpolação entre as barras (bars) é usada para gerar a impressão de uma superfície corrente (river) para cada palavra. O fluxo horizontal do "river" representa o fluxo do tempo e, cada seção vertical corresponde a um instante do tempo ordenado. Assim, cada ocorrência é representada por um "river", de forma que sua largura reflete a freqüência de ocorrência da palavra em função do tempo. A técnica ThemeRiver permite uma interpretação intuitiva sobre as transformações temporais de ocorrências de palavras em documentos, bem como suas relações temporais. A figura 2.9 mostra um exemplo desta técnica utilizada para representar as séries temporais normalizadas para cinco variáveis de um conjunto de dados climáticos.

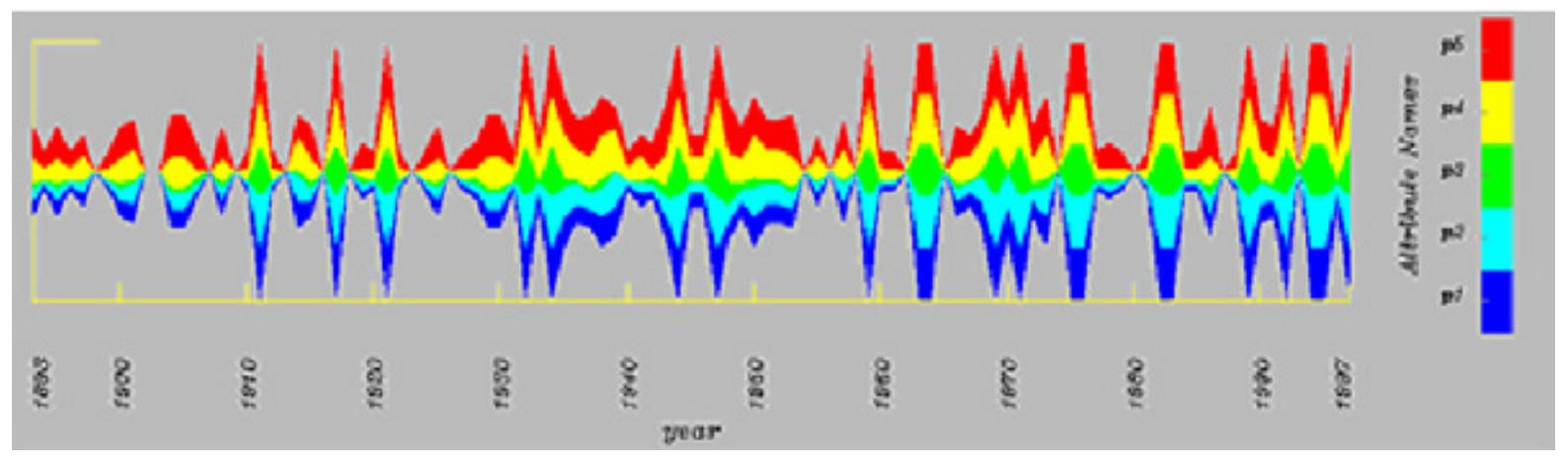

Figura 2.9: ThemeRiver. Visualização para 100 anos de dados climáticos (Havre et al., 2000).

Outros exemplos de técnicas de visualização utilizadas para o tratamento de dados de séries temporais com múltiplos parâmetros são Lexis Pencil (Brian e Pritchard, 1997), Spiral Clock (Dragicevic e Huot, 2002), Spiral Graph (Carlis e Konstan, 1998; Weber et al., 2001), TimeWheel (Tominski et al., 2004) e Space Time Cube (Andrienko et al., 2003b). Adicionalmente, as técnicas Lexis Pencil e Space Time Cube permitem ainda a visualização do aspecto espacial dos dados através de um mapa geográfico. Maiores detalhes sobre a visualização de séries temporais multivariadas podem ser vistos em Carlis e Konstan (1998); Havre et al. (2000); Weber et al. (2001); Muller e Schumann (2003).

\subsubsection{Métricas de Distância}

A mineração de dados de séries temporais atraiu grande atenção na comunidade de mineração de dados nos últimos anos (Yi e Faloutsos, 2000; Roddick et al., 2001; Keogh e Lin, 2005). Agrupamentos em séries temporais e outras seqüências de dados tornou-se um 
importante tópico de pesquisa, motivado por vários desafios em áreas como bioinformática e análise de séries temporais. Segundo Keogh e Lin (2005) existem duas categorias principais em agrupamentos de séries temporais. Whole Clustering é o agrupamento realizado em muitas séries temporais individuais para agrupar séries similares em clusters. Subsequence Clustering é baseada no agrupamento de subseqüências similares para uma mesma série temporal. Neste contexto, as tarefas de mineração em séries temporais consistem em identificar similaridades entre séries temporais e subseqüências. Para identificar seqüências similares é necessário adotar alguma função de similaridade que calcule a distância entre duas séries ou seqüências. Nesta seção são apresentadas duas métricas de distância bastante utilizadas por pesquisadores da área: Distância Euclidiana e Compression-Based Dissimilarity Measure (Keogh et al., 2007). Estas métricas de similaridade foram utilizadas no desenvolvimento deste projeto.

\section{Distância Euclidiana}

A medida de distância mais comum utilizada para séries temporais é a distancia Euclidiana (Keogh et al., 2000; Yi e Faloutsos, 2000; Roddick et al., 2001). Segundo Chakrabarti et al. (2002), cerca de 90\% dos trabalhos em séries temporais utilizam a distância Euclidiana como medida de distância. No entanto, a distância Euclidiana é uma medida que só pode ser usada em séries temporais de mesmo tamanho, consistindo no cálculo da distância entre pares de pontos das duas seqüências. Assim, dadas duas séries temporais $\mathrm{Q}=q_{1}, \ldots, q_{n}$ e $\mathrm{C}=c_{1}, \ldots, c_{n}$ de tamanho $\mathrm{n}$, a distância Euclidiana entre elas é definida como:

$$
D(Q, C)=\sqrt{\sum_{i=1}^{n}\left(q_{i}-c_{i}\right)^{2}}
$$

A figura 2.10 ilustra uma intuição visual da medida.

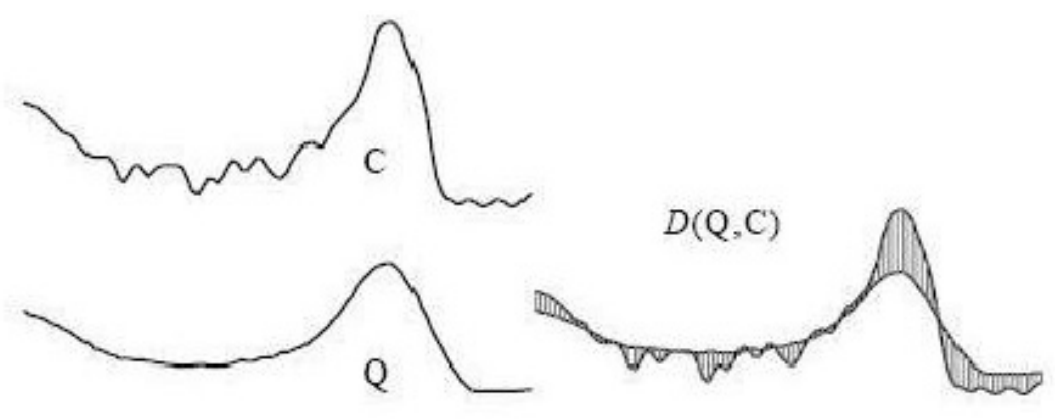

Figura 2.10: Noção intuitiva da distância Euclidiana, que pode ser vista como uma soma das linhas cinzas entre dois pontos (Chakrabarti et al., 2002). 
Uma otimização no cálculo da distância Euclidiana é conhecida como distância Euclidiana quadrada. A distância Euclidiana quadrada é equivalente à distância Euclidiana, no sentido de que ela retorna os resultados equivalentes quando aplicados algoritmos de mineração de dados em séries temporais. No entanto, seu cálculo consome menos tempo de processamento, devido à inexistência da raiz quadrada na equação. Portanto, a distância Euclidiana Quadrada entre duas séries temporais Q e C pode ser definida como:

$$
D_{\text {square }}(Q, C)=\sum_{i=1}^{n}\left(q_{i}-c_{i}\right)^{2}
$$

\section{Compression-Based Dissimilarity Measure}

Em contraste à distância Euclidiana que trabalha somente com séries temporais de mesmo tamanho, a Compreession-Based Dissimilarity Measure ou CDM trabalha com séries temporais de diferentes tamanhos e com valores ausentes.

A Compression-Based Dissimilarity Measure (CDM) é um algoritmo que calcula a distância de similaridade entre duas palavras (strings) baseado na compressão das mesmas. O cálculo da CDM é baseado na complexidade de Kolmogorov, uma medida de correlação de strings baseado no conteúdo de suas informações.

Dadas duas palavras, x e y, define-se a CDM como:

$$
C D M(x, y)=\frac{C(x y)}{(C(x)+C(y))}
$$

Onde, $\mathrm{C}(\mathrm{x})$ e $\mathrm{C}(\mathrm{y})$ definem, respectivamente, os tamanhos das palavras x e y compactadas, e C(xy) define o tamanho da palavra xy concatenada e compactada. Nota-se que os valores para a CDM sempre ficam entre o intervalo de 0 a 1 , isto é, quanto menor a CDM maior a similaridade entre as palavras x e y.

A seguir, na tabela 2.1 é apresentada uma versão da CDM implementada em Matlab:

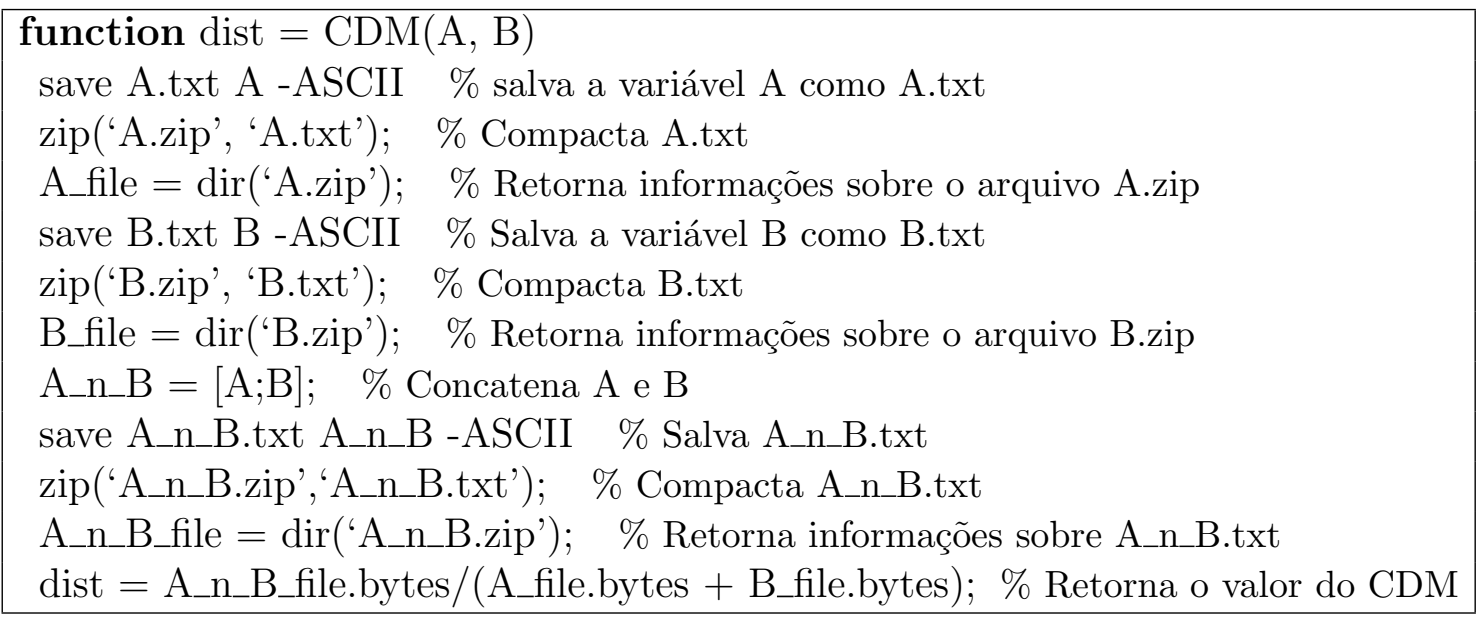

Tabela 2.1: Compression-Based Dissimilarity Measure (CDM)(Keogh et al., 2007). 
As entradas são as duas matrizes a serem comparadas. Estas matrizes podem ser séries temporais, DNA, palavras, imagens, textos, música, etc. O algoritmo começa salvando as duas matrizes em disco, compactando-as e obtendo informações sobre os arquivos compactados. Posteriormente, as duas matrizes são concatenadas ( $\mathrm{A} \_\mathrm{n} \mathrm{B}=[\mathrm{A} ; \mathrm{B}]$ ), e o resultado é armazenado, compactado e a informação sobre o arquivo é recuperada. Finalmente, o resultado final (CDM) é calculado pela divisão do tamanho do arquivo concatenado e compactado pelo tamanho da soma dos dois arquivos compactados.

De acordo com Keogh et al. (2007), o único objetivo na CDM é obter boas compressões. Existem diversas maneiras de alcançar este objetivo. Primeiro, escolher métodos de compressão específicos para cada tipo de dado a ser analisado. Por exemplo, para dados de DNA, utilizar algoritmos de compressão otimizados para a compressão de DNA. Uma outra maneira de melhorar a compressão é garantir que os dados estejam em um formato que possa ser fácil e eficientemente compactado.

No caso específico de séries temporais, os autores recomendam converter os dados em um formato discreto, com um pequeno alfabeto. Neste caso, toda parte da representação contribui com mesma quantidade de informação sobre a forma da série temporal. Isto abre a questão sobre qual representação simbólica de série temporal usar. Neste trabalho de mestrado, a CDM é utilizada em conjunto ao SAX (Symbolic Aggregate ApproXimation)(Lin et al., 2003) para detecção de clusters e padrões em séries temporais. De acordo com Lin et al. (2003), essa representação tem produzido resultados competitivos para classificação e agrupamentos de séries temporais, preservando informações significativas dos dados originais. No apêndice A é explicado em detalhes o funcionamento do SAX.

\subsubsection{Modelos de Previsão de Séries Temporais}

Uma das principais razões para se modelar uma série temporal é tornar possível a realização de previsões de valores futuros. Como em qualquer análise de dados, procura-se obter um modelo matemático que descreva o sistema de maneira parcimoniosa, principalmente no que se refere ao número de parâmetros, que deve ser mínimo para o objetivo desejado. Além disto, o modelo deve, se possível, ser parametrizado de forma que cada parâmetro possa ser interpretado facilmente e identificado com algum aspecto da realidade (Pereira et al., 1986).

Um problema muito freqüente em várias áreas de aplicação de séries temporais surge quando é necessária a análise de uma variável aleatória que é observada ao longo do tempo. Como, por exemplo, o número de chamadas telefônicas que chegam a uma central por dia durante um mês, a temperatura média mensal de uma região observada ao longo de vários anos, o consumo de energia elétrica de uma residência ou as vazões médias que chegam a um reservatório em determinado intervalo de tempo. Nestes casos, a variável aleatória de interesse aparece indexada $X_{t}, \mathrm{t} \geq 0$ e é denominada um processo estocástico. 
Segundo Moretin e Toloi (2004), os modelos utilizados para descrever séries temporais são processos estocásticos, isto é, processos controlados por leis probabilísticas. O principal objetivo ao se analisar um processo estocástico é determinar qual a lei probabilística que rege este processo e se esta lei é invariante no tempo, ou seja, se o processo é estacionário.

\section{Processos Estocásticos Estacionários}

Uma importante classe de modelos estocásticos utilizados para descrever séries temporais é a chamada classe dos modelos estacionários, os quais assumem que os processos permanecem em equilíbrio sobre um nível médio constante (Box et al., 1994), livres de tendência e sazonalidade. Intuitivamente, um processo estocástico X é estacionário se ele se desenvolve no tempo de modo que a escolha de uma origem dos tempos não é importante. Em outras palavras, as características de $X_{t+k}$, para todo k, são as mesmas de $X_{t}$. Formalmente, há dois tipos de estacionariedade: forte (ou estrita) e fraca (ou ampla, ou de segunda ordem) (Moretin e Toloi, 2004).

Definição 1. Um processo estocástico $\mathrm{X}=\left\{X_{t}, \mathrm{t} \geq 0\right\}$ é estacionário no sentido forte se sua distribuição de probabilidade conjunta permanece a mesma sob translações no tempo, ou seja,

$$
F\left(x_{t_{1}}, \ldots, x_{t_{n}}\right)=F\left(x_{t_{1+k}}, \ldots, x_{t_{n+k}}\right)
$$

para quaisquer $t_{1}, \ldots, t_{n}, \mathrm{k}$ de $\mathrm{T}$.

Isto significa, em particular, que todas as distribuições unidimensionais são invariantes sob translações no tempo, logo a média $\mu(t)$ e a variância $V(\mathrm{t})$ são constantes.

Definição 2. Um processo estocástico $\mathrm{X}=\left\{X_{t}, \mathrm{t} \geq 0\right\}$ é estacionário no sentido fraco se:

(i) $E\left\{X_{t}\right\}=\mu$ (média constante independente de t)

(ii) $V\left(X_{t}\right)=\sigma^{2}$ (variância constante independente de t)

(iii) $\operatorname{Cov}\left(X_{t}, X_{t+k}\right)=\gamma(\mathrm{k})$ (covariância de $X_{t}$ e $X_{t+k}$ só depende de k)

A hipótese de estacionariedade implica que a distribuição de probabilidade do processo estocástico é mesma para todo tempo t. Assim, o processo estocástico tem média constante (que define o nível em torno do qual a série oscila) e variância constante (que mede a amplitude dessa oscilação). Como a distribuição de probabilidade é a mesma para todo tempo t, a média $\mu$ e variância $\sigma_{x}^{2}$ do processo estocástico podem ser estimadas pelas equações $(2.5)$ e (2.6), respectivamente: 


$$
\begin{gathered}
\bar{x}=\frac{1}{N} \sum_{t=1}^{N} x_{t} \\
\operatorname{Var}(x)=\frac{1}{N} \sum_{t=1}^{N}\left(x_{t}-\bar{x}\right)^{2}
\end{gathered}
$$

A hipótese de estacionariedade também implica que a função de distribuição conjunta é a mesma para todo tempo $\mathrm{t}, \mathrm{t}+\mathrm{k}$, a qual é separada por um intervalo constante $\mathrm{k}$. Assim, segue que a distribuição conjunta pode ser inferida plotando um diagrama de dispersão usando os valores de $x_{t}, x_{t+k}$ da série temporal, separada por um intervalo constante $\mathrm{k}$.

A covariância entre $x_{t}$ e $x_{t+k}$, separada por $\mathrm{k}$ intervalos de tempo, é chamada de autocovariância de passo $\mathrm{k}$ sendo definida como:

$$
\gamma(k)=\operatorname{Cov}\left(x_{t}, x_{t+k}\right)
$$

Similarmente, o coeficiente de autocorrelação $\rho_{k}$ com passo k é definido como:

$$
r_{k}=\frac{c_{k}}{c_{0}}
$$

onde,

$$
c_{k}=\frac{1}{(N-k)} \sum_{t=1}^{N-k}\left(x_{t}-\bar{x}\right)\left(x_{t+k}-\bar{x}\right), k=0,1, \ldots, K
$$

é a estimativa do coeficiente de autocovariância $\gamma(k)$ e $\bar{x}$ é a média amostral da série temporal.

\section{Modelos de Séries Temporais}

Na análise de métodos paramétricos, os modelos de Box \& Jenkins têm recebido muita atenção nas últimas décadas. Tais métodos consistem em ajustar modelos autoregressivos, médias móveis, modelos mistos auto-regressivos médias móveis e os modelos integrados auto-regressivos médias móveis (Balinni, 2000). Neste trabalho são utilizados modelos lineares, mais especificamente, modelos auto-regressivos.

A estratégia para construção de um modelo de séries temporais é baseada em um ciclo iterativo, no qual a seleção da estrutura do modelo é baseada nos próprios dados. Os estágios do ciclo iterativo são (Moretin e Toloi, 2004):

1. Uma classe geral de modelos é considerada para a análise (especificação);

2. Identificação de um modelo, com base na análise de autocorrelação, autocorrelação parcial e outros critérios; 
3. A seguir vem a fase de estimação, na qual os parâmetros do modelo identificado são estimados;

4. Finalmente, há a verificação do modelo ajustado, através de uma análise de resíduos, para averiguar se este é adequado para os fins em vista, no caso, para a previsão.

$\mathrm{Na}$ fase de estimação, um procedimento muito importante consiste em identificar a ordem (p) de um modelo, ou seja, determinar o número adequado de termos que devem ser considerados na modelagem de uma série temporal. A escolha de um valor pequeno de $\mathrm{p}$, por exemplo, $\mathrm{p}=1$, pode levar a uma representação inadequada da série, por outro lado, a escolha de um valor alto de $\mathrm{p}$, por exemplo, $\mathrm{p}=6$, pode levar a um modelo com um grau de complexidade desnecessário. O critério de escolha do modelo adequado com o menor número de parâmetros possível é denominado como critério de parcimoniosidade (Andrade, 2005).

Caso o modelo não seja adequado, o procedimento acima é repetido, voltando à fase de identificação. Um procedimento, muitas vezes utilizado, é identificar não somente um único modelo, mas alguns modelos que serão estimados e verificados. Assim, a fase crítica do procedimento acima é a identificação do modelo, sendo possível que diferentes modelos sejam identificados para uma mesma série temporal (Moretin e Toloi, 2004).

\section{Modelos Lineares Estacionários}

Os modelos estocásticos empregados neste trabalho são baseados na idéia de que uma série temporal, na qual os valores sucessivos são altamente dependentes, pode ser considerada como sendo gerada através de uma série de independentes "impactos" $a_{t}, \mathrm{t} \in$ T. Estes "impactos" são aleatórios, com distribuição fixa assumindo ser uma distribuição normal, com média zero e variância $\sigma_{a}^{2}$. Esta seqüência de variáveis aleatórias $a_{t}, a_{t-1}, \ldots$ é chamada de ruído branco (Box e Jenkins, 1976).

Estes modelos podem ser interpretados como sendo casos particulares de um modelo de filtro linear, supondo que a saída temporal $x_{t}$ é gerada através de um filtro linear ou sistema linear, cuja entrada é um ruído branco $a_{t}$.

De acordo com Andrade (2005), os três modelos mais usados para modelar séries temporais estacionárias são os processos auto-regressivos (AR), médias móveis (MA) e os mistos auto-regressivos médias móveis (ARMA). Neste trabalho são considerados apenas os modelos auto-regressivos (AR) e periódicos auto-regressivos (PAR).

\section{Modelos Auto-Regressivos (AR)}

Considerando-se uma série temporal estacionária $\left\{x_{t}, \mathrm{t}=0,1, \ldots\right\}$, um processo autoregressivo de ordem $\mathrm{p}$, denotado por $\mathrm{AR}(\mathrm{p})$, é definido como sendo um modelo onde 
o valor corrente do processo $x_{t}$ é expresso como uma combinação linear dos p valores passados $x_{t-1}, x_{t-2}, \ldots, x_{t-p}$ e de um ruído branco $a_{t}$, aqui assume-se que $a_{t}$ é uma seqüência de variáveis aleatórias com distribuição normal de média zero e variância $\sigma_{a}^{2}$, ou seja, $\mathrm{N}\left(0, \sigma_{a}^{2}\right)$. O modelo de $\mathrm{AR}(\mathrm{p})$ pode ser escrito da seguinte forma:

$$
x_{t}=\mu+\phi_{1} x_{t-1}+\phi_{2} x_{t-2}+\ldots+\phi_{p} x_{t-p}+a_{t}
$$

onde o parâmetro $\mu$ está relacionado com a média do processo $x_{t}$ (ver Box et al. (1994)).

As estimativas dos parâmetros $\phi_{1}, \phi_{2}, \ldots, \phi_{p}$ podem ser realizadas através da análise das funções de autocorrelação e autocorrelação parcial e métodos de máxima verossimilhança e a escolha da ordem p mais adequada do modelo é feita a partir dessas funções. Maiores detalhes sobre modelos auto-regressivos podem ser vistos em (Box et al., 1994; Moretin e Toloi, 2004; Andrade, 2005).

\section{Modelos Periódicos Auto-Regressivos (PAR)}

Uma outra classe de modelos para séries temporais a ser considerada são os modelos periódicos auto-regressivos (PAR). Estes modelos foram inicialmente propostos por Thomas e Fiering (1976) e posteriormente estudados por Pagano (1978).

As estimativas dos parâmetros dos modelos periódicos auto-regressivos podem ser realizadas através dos métodos dos momentos como proposto por Pagano (1978), através do método de máxima verossimilhança (Vecchia, 1985) ou, ainda, através do método de inferência Bayesiana para modelos de séries sazonais proposto em Hutter (1998).

Sejam $x_{1,1}, x_{1,2}, \ldots, x_{n, s}$ observações consecutivas de uma série temporal sazonal com períodos s e número de anos n. As séries de vazões consideradas neste trabalho tratam-se de séries mensais de períodos de 12 meses, ou seja, $\mathrm{s}=12$. O índice de tempo t pode ser escrito como uma função do número de anos $\mathrm{r}=1,2, \ldots, \mathrm{n}$ e dos meses $\mathrm{m}=1,2, \ldots, \mathrm{s}$, ou seja, $\mathrm{t}=\mathrm{t}(\mathrm{r}, \mathrm{m})=(\mathrm{r}-1) \mathrm{s}+\mathrm{m}$. Assim, $x_{t(r, m)}$ é a observação da série $x_{t}$ no ano $\mathrm{r}$ e mês $\mathrm{m}$. Nestes casos, costuma-se trabalhar com a série padronizada $z_{t(r, m)}$ dada por:

$$
z_{t(r, m)}=\frac{\left(x_{t(r, m)}-\mu_{m}\right)}{\sigma_{m}}
$$

onde, $\mu_{m}$ e $\sigma_{m}$ são as médias e os desvios-padrão estimados para cada mês m.

Os modelos usuais para descrever séries temporais periodicamente estacionárias são modelos periódicos auto-regressivos de ordem $p_{m}, \mathrm{~m}=1, \ldots, \mathrm{s}$, denotados $\operatorname{por} \operatorname{PAR}\left(p_{m}\right)$, podendo ser representados da seguinte forma:

$$
z_{t(r, m)}=\sum_{i=1}^{p_{m}} \phi_{i, m} z_{t(r, m)-i}+a_{t(r, m)}, t(r, m) \geq p_{m}+1
$$


onde, $\phi_{i, m}$ é uma função periódica com período s, $a_{t(r, m)}$ é um ruído branco com $\mathrm{N}\left(0, \sigma_{m}^{2}\right)$ e $z_{t(r, m)}$ representa a série padronizada.

O fato de muitas séries temporais revelarem um comportamento periódico ou sazonal, as qualifica a serem modeladas por processos periódicos $\operatorname{PAR}\left(p_{m}\right)$. No entanto, além da periodicidade, muitas séries temporais não são gaussianas. Assim, uma abordagem mais geral seria considerar modelos não-gaussianos (Grunwald et al., 2000; Akkaya e Tiker, 2001). Essa abordagem pode torna-se pouco prática devido ao grande número de modelos a serem testados visando a escolha do melhor modelo para uma série temporal. Além do mais, a escolha do melhor modelo para uma dada série pode não ser a mais adequada para outra, o que torna o processo de escolha do melhor modelo ainda mais dispendioso (Andrade, 2005).

Uma abordagem alternativa é transformar a série original em uma série com distribuição aproximadamente normal. Outro objetivo da transformação de uma série temporal é reduzir a correlação temporal dos resíduos do modelo ajustado, pois essa correlação implica em um erro sistemático nas previsões. Uma transformação muito usada é a transformação logarítmica, esta transformação é um caso particular da família de transformações conhecida como transformações de Box-Cox, proposta em (Box e Cox, 1964). Portanto, uma análise mais geral consiste em considerar tanto os modelos AR quanto PAR com a transformação de Box-Cox aplicada às séries temporais.

\subsection{Considerações Finais}

A exploração visual de dados de natureza espacial e temporal requer estratégias que possam ajudar os usuários a encontrar respostas para diferentes tipos de questões que possam ser levantadas em relação a tais dados. Um grande número de técnicas de visualização e mineração especialmente para dados dependentes do tempo foi desenvolvida recentemente e tem adquirido cada vez mais importância. No entanto, não se evidenciaram ferramentas existentes na literatura desenvolvidas especialmente para a visualização e previsão de séries de vazões nas usinas hidrelétricas. É neste contexto que a aplicação de técnicas de visualização em conjunto com modelos de previsão de séries temporais pode certamente contribuir para o planejamento e operação do setor energético.

O próximo capítulo descreve em detalhes o sistema desenvolvido especialmente para a visualização e previsão de dados de vazões nas usinas hidrelétricas. 


\section{Capítulo \\ 3 \\ Descrição do Sistema}

\subsection{Considerações Iniciais}

O grupo de Visualização de Informação do ICMC-USP tem trabalhado em conjunto com o Prof. Marinho Gomes de Andrade Filho, do departamento de Matemática Aplicada e Estatística do ICMC, visando o estudo e o desenvolvimento de estratégias visuais para análise de dados de séries de vazões e previsão de vazões nas usinas hidrelétricas brasileiras. Particularmente, este trabalho de mestrado concentrou-se na realização de duas atividades. A primeira destinou-se ao desenvolvimento de um sistema de previsão de vazões mensais, baseado em modelos lineares auto-regressivos e periódicos auto-regressivos desenvolvidos pelo prof. Marinho Gomes de Andrade Filho (Andrade, 2004). A segunda consistiu em disponibilizar técnicas de visualização de natureza espacial e temporal para apoiar tarefas de exploração de dados, concentrando-se no contexto de dados de vazões nas usinas hidrelétricas.

Como resultado deste trabalho de mestrado foi desenvolvido um sistema gráfico interativo, denominado Power Map Explorer, para visualização e previsão de dados relativos a séries de vazões afluentes nas usinas hidrelétricas brasileiras. O sistema desenvolvido une, em um mesmo ambiente, os módulos de previsão e de visualização exploratória com uma interface que permite ao usuário interagir diretamente com os mesmos. O ambiente resultante é de âmbito mais geral do que unicamente para o tratamento de dados de vazões. Ele pode ser utilizado para visualizar dados gerados em outros domínios de aplicação, desde que descritos pelos atributos espaciais e temporais contemplados pelo sistema.

Neste capítulo são descritos a estrutura geral do sistema e os recursos implementados. A seção 3.2 apresenta a arquitetura simplificada do sistema, as ferramentas adotadas para o desenvolvimento e o módulo de interface do Power Map Explorer. Nas seções 3.3 
e 3.4 são explicados em detalhes os módulos de visualização e de previsão do sistema, respectivamente. Por fim, na seção 3.5, são apresentadas as considerações finais sobre este capítulo.

\subsection{Estrutura de Desenvolvimento do Power Map Explorer}

\subsubsection{Arquitetura do Sistema}

A arquitetura de um sistema de visualização descreve os componentes do sistema e a relação funcional entre eles. O Power Map Explorer pode ser dividido, em linhas gerais, em três módulos principais: Interface, Visualização e Previsão. A figura 3.1 apresenta a arquitetura do sistema, ilustrando como os dados transitam entre seus módulos.

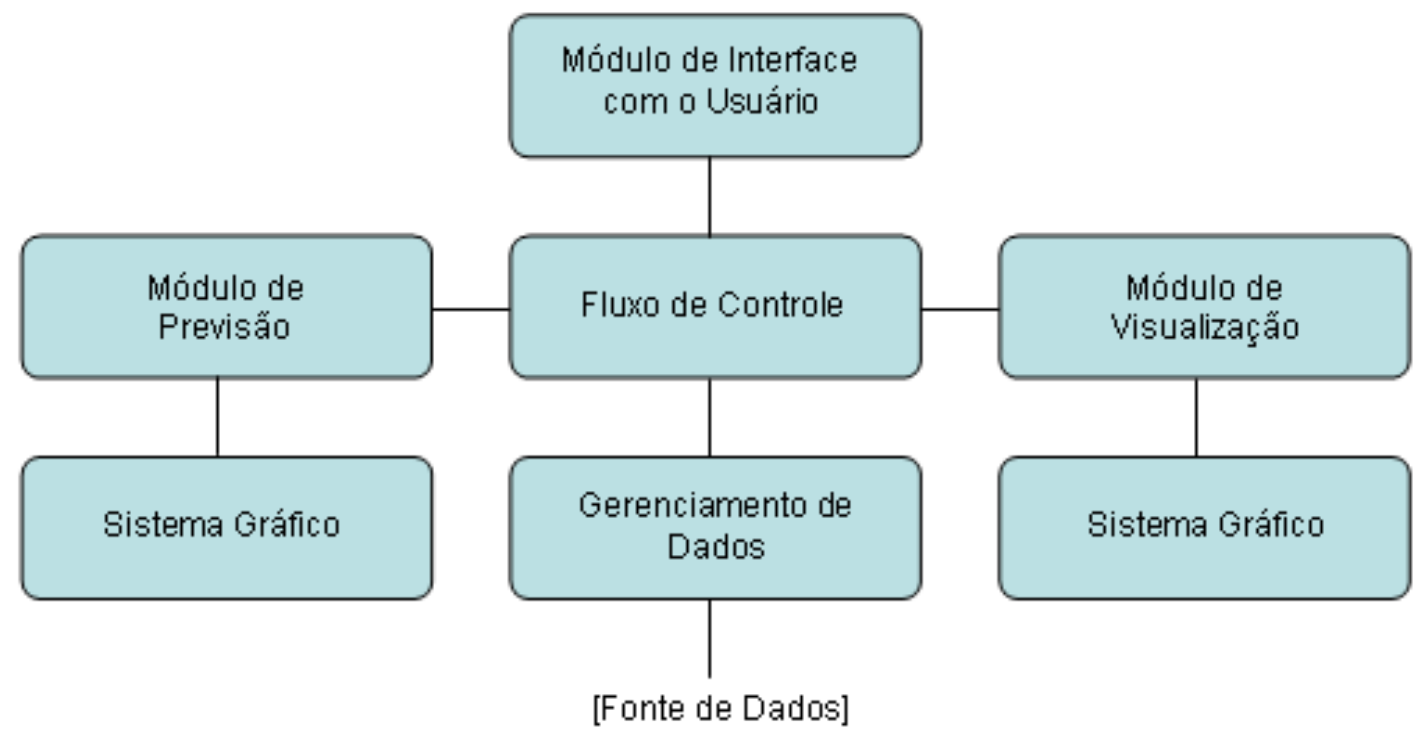

Figura 3.1: Arquitetura do sistema.

O módulo de Interface com o Usuário define o mecanismo pelo qual o usuário se comunica com o sistema. Ele é implementado na classe PowerMapExplorerVisualizer que é constituída por diversos componentes gráficos necessários para manipulação dos dados e possui objetos responsáveis pela comunicação com os módulos de visualização e previsão do sistema. Além disso, tal módulo suporta a interação com usuário, sendo responsável por apoiar a execução das tarefas e pela apresentação dos resultados.

O módulo de Visualização é constituído por um conjunto de classes responsáveis pela implementação das técnicas de visualização e interação extraídas da área de visualização espaço-temporal. Tais classes implementam recursos que permitem a manipulação e interpretação dos atributos temporal e espacial dos dados, possibilitando a análise e extração de informações relevantes embutidas nos dados. A classe Display, por exemplo, permite a 
visualização do aspecto espacial dos dados através da representação dos objetos espaciais (usinas hidrelétricas) como círculos plotados sobre um mapa geográfico.

O módulo de Previsão é um recurso disponível no sistema desenvolvido especialmente para previsão de dados de vazões nas hidrelétricas. O módulo é constituído de modelos de previsão de séries temporais ajustados especialmente para esses dados. A classe principal desse módulo é a IFS, responsável pela comunicação do usuário com os recursos de previsão, isto é, modelos, gráficos e tabela. Além disto, este módulo é constituído de diversas outras classes responsáveis pela implementação dos modelos, pelo processo de previsão e pela apresentação dos resultados na forma gráfica.

O componente de Gerenciamento de Dados abrange os mecanismos de importação e exportação dos dados do sistema, e o seu gerenciamento interno. Ele inclui o acesso às fontes de dados e o gerenciamento da memória interna. Por último, o componente de Controle de Fluxo, que define como os módulos são executados e como os dados fluem entre eles. Tais componentes são implementados na classe PowerMapExplorerVisualizer.

Um diagrama geral das principais classes do Power Map Explorer e da maneira como estão organizadas no sistema é apresentado na figura 3.2.

\subsubsection{Ferramentas de Desenvolvimento}

Para o desenvolvimento do Power Map Explorer foi adotada a plataforma Java ${ }^{1}$ em conjunto com o ambiente matemático Scilab² . A utilização dessas ferramentas associadas possibilitou a criação de um sistema gráfico que integra recursos e operações matemáticas processadas em alta velocidade. Além disso, essa escolha permitiu que toda a interface gráfica e as técnicas de visualizações fossem desenvolvidas em Java, enquanto que os modelos de previsão pudessem ser implementados e executados diretamente no Scilab. Um outro ponto relevante no desenvolvimento desse sistema refere-se à programação de acordo com o paradigma de orientação a objetos, que possibilitou a criação de um sistema robusto e de fácil manutenção. Como resultado final, a ferramenta desenvolvida pode ser utilizada tanto como aplicação local quanto remotamente. Além disto, a característica multiplataforma permite que o Power Map Explorer possa ser executado em múltiplos sistemas operacionais, como Windows e Linux, por exemplo.

Optou-se pelo desenvolvimento de um protótipo evolutivo ao qual as funcionalidades foram acrescentadas gradualmente. Em relação à organização dos dados, definiu-se que seriam estruturados no formato XML (Extensible Markup Language), uma representação hierárquica dos dados (W3C, 1998). A grande vantagem deste tipo de estruturação está relacionada a sua escalabilidade, que provê a capacidade de interoperação das mais variadas aplicações, por ter um padrão de codificação flexível, aberto e independente de dispositivos. No apêndice B é apresentado a estrutura do XML adotado no sistema.

\footnotetext{
${ }^{1}$ http://www.sun.com

${ }^{2}$ http://www.scilab.org
} 


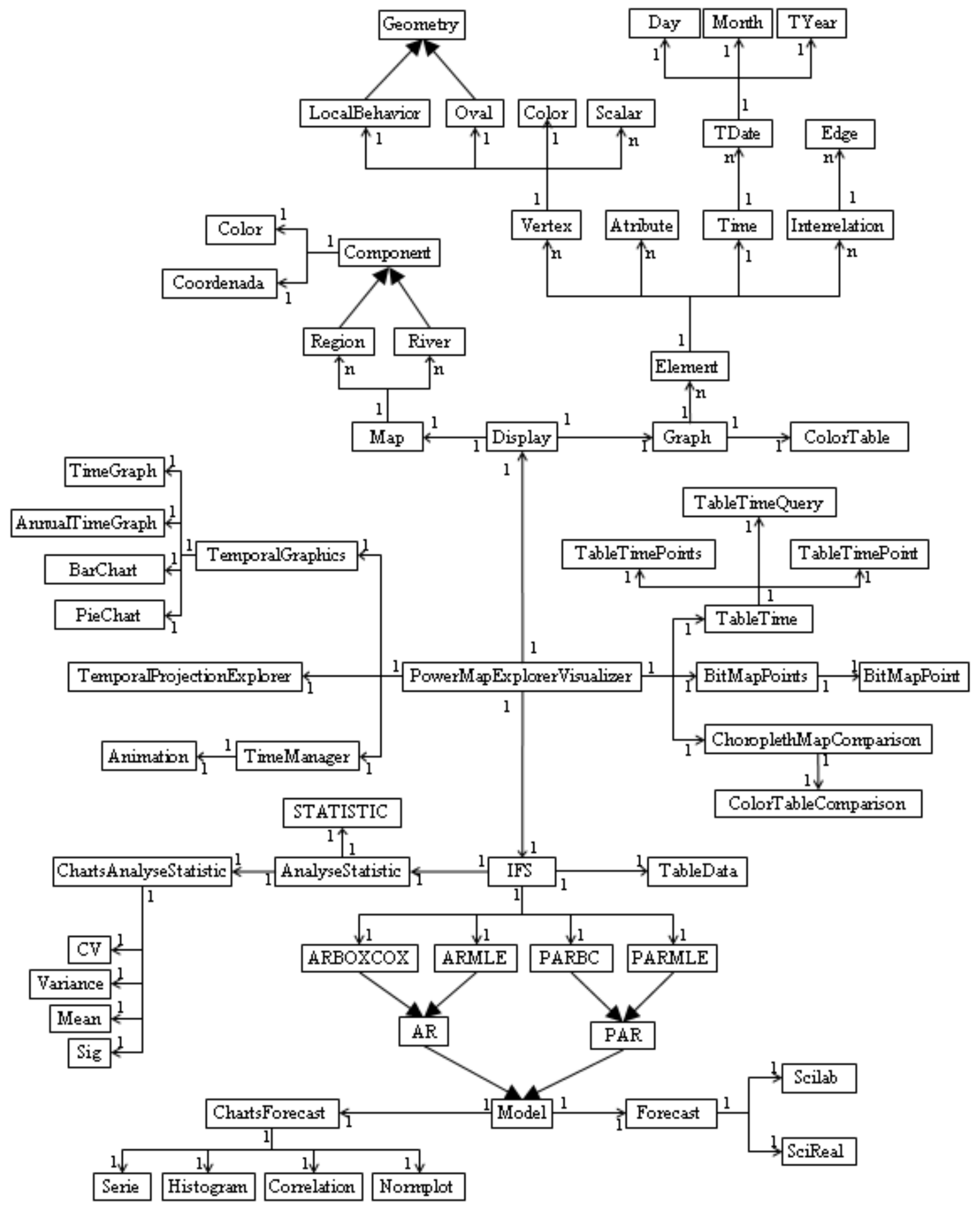

Figura 3.2: Diagrama geral das principais classes do Power Map Explorer. 
O Power Map Explorer está disponibilizado para utilização nas formas de applet e aplicativo local. Este sistema faz parte do projeto InfoVis2 (FAPESP no.04/09888-5), e está disponível para download ou acesso remoto pelo site (http://infoserver.lcad.icmc.usp.br/infovis2/PowerMapExplorer).

\subsubsection{Módulo de Interface}

O Módulo de Interface do Power Map Explorer é responsável pela interação do usuário com outros módulos e componentes do sistema. Basicamente, este módulo é constituído por três funcionalidades principais:

- Entrada de Dados: disponibiliza funções que permitem a inserção de conjuntos de dados no sistema.

- Manipulação dos dados: apóia a manipulação dos dados através recursos gráficos interativos.

- Visualização dos resultados: possibilita a apresentação dos resultados por meio de representações visuais.

A interface principal do Power Map Explorer é composta por diversos componentes e recursos gráficos necessários para entrada, manipulação e apresentação dos dados (ver figura 3.3). Através desta interface o usuário pode carregar, visualizar e explorar o conjunto de dados em estudo, definindo e controlando, de maneira desejada, as diversas opções de visualização dos dados no sistema.

Como mencionado anteriormente, o Power Map Explorer é um sistema de visualização e previsão desenvolvido e ajustado especialmente para análise de dados de séries de vazões mensais. No entanto, o sistema pode ser facilmente utilizado para a exploração visual de dados de séries temporais geo-referenciadas geradas em outros domínios. Além disto, o sistema permite trabalhar com dados constituídos por séries temporais nas escalas diária, mensal e anual.

Detalhes das técnicas de visualização e do módulo de previsão implementados no sistema e os respectivos parâmetros que podem ser definidos e manipulados podem ser encontrados nas seções 3.3 e 3.4 .

\subsection{Módulo de Visualização}

Nesta seção são apresentados os componentes funcionais desenvolvidos visando a visualização e manipulação de dados de vazões mensais, assim como as ações de interação suportadas. Um conjunto mínimo de ações de interação foi disponibilizado a fim de possibilitar um potencial maior de eficiência na interpretação dos dados a partir desses componentes. 


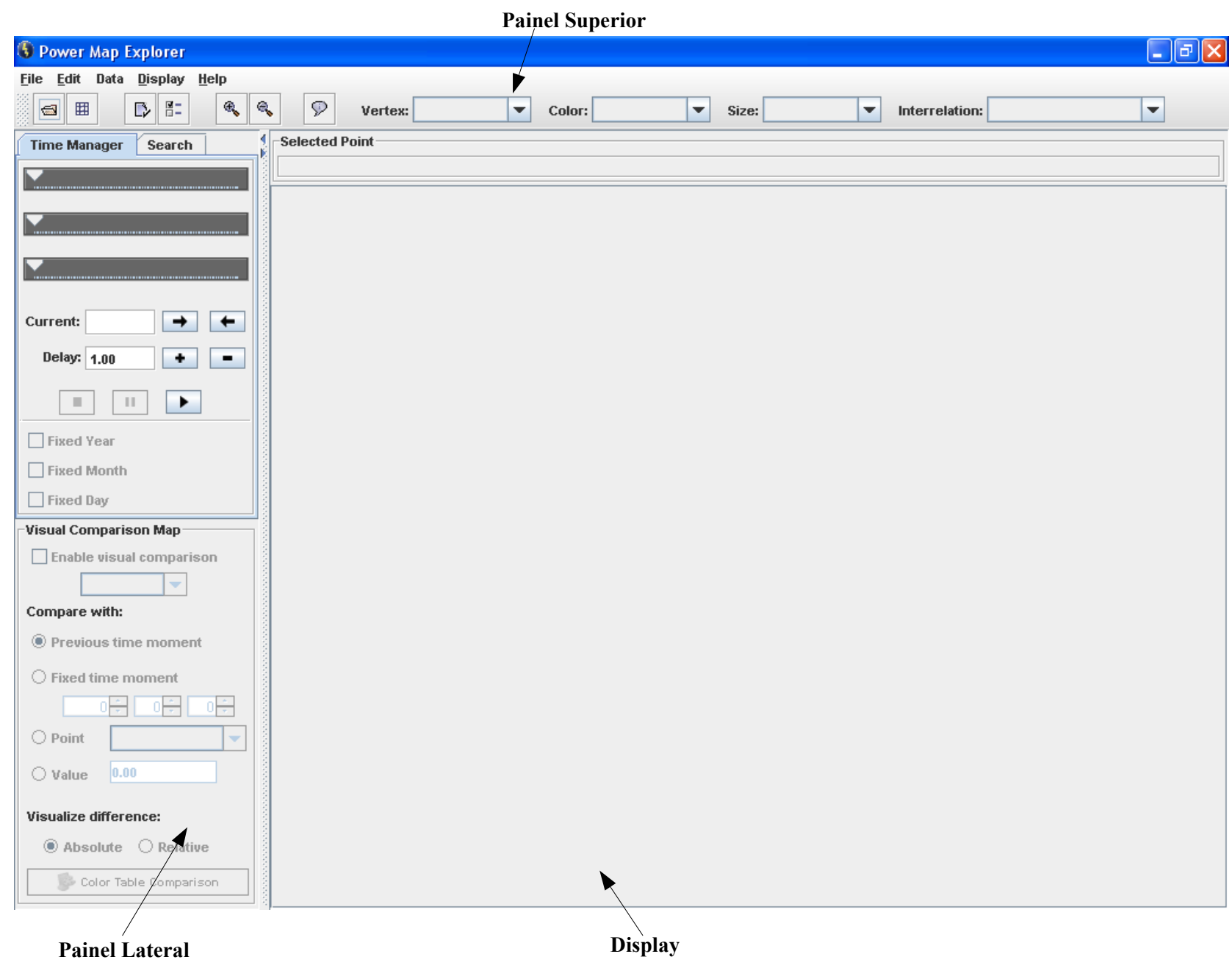

Figura 3.3: Janela principal do Power Map Explorer.

\subsubsection{Distribuição Espacial ou Mapa}

Mapas são de uso comum para dados com natureza espacial e, portanto, poderosas ferramentas no processo de análise e exploração visual. Nesta representação, os elementos do conjunto de dados são representados por círculos coloridos e posicionados sobre um mapa de acordo com os atributos espaciais de latitude e longitude. Os atributos temporais, ou seja, atributos dependentes do tempo, podem ser mapeados na representação com as variáveis visuais cor e diâmetro (ver figura 3.4). Estes recursos possibilitam mapear os valores de dois atributos, simultaneamente, através de uma tabela de mapeamento definida pelo usuário.

Alguns mecanismos de interação são implementados sobre esta representação para auxiliar nos procedimentos de investigação visual. Um deles é o zoom, que possibilita realçar informações pouco legíveis ao usuário através do processo de ampliação da imagem. Outra é o brushing, que permite destacar elementos no mapa selecionados pelo usuário através do mouse. É possível também alterar os parâmetros de configuração de cor e diâmetro dos círculos através das tabelas de mapeamento. 


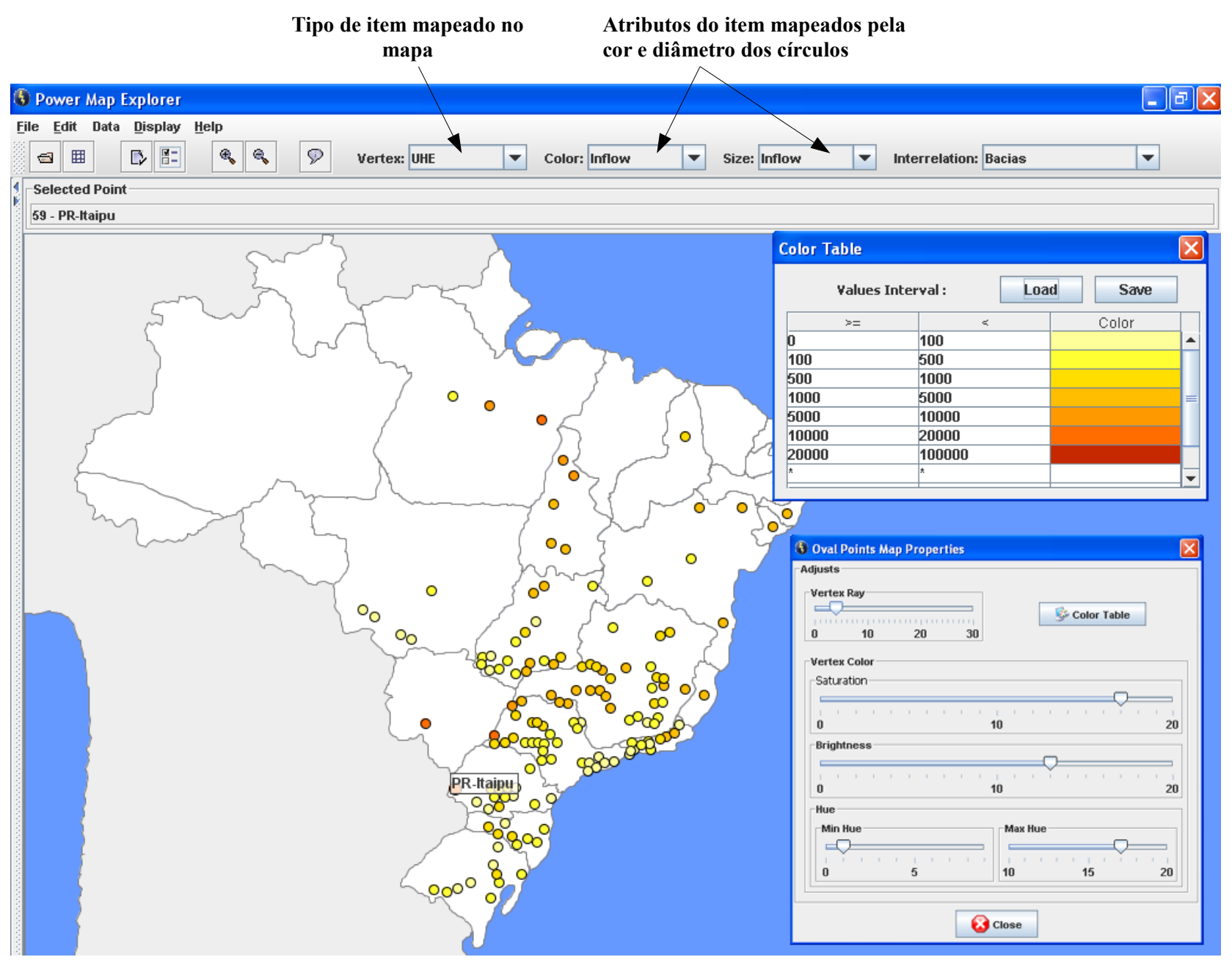

Figura 3.4: Distribuição Espacial ou Mapa.

\subsubsection{Comportamentos Locais}

O termo comportamento, ou comportamento local, denota a variação temporal dos valores de um atributo em um local específico. O comportamento local de cada elemento é representado por um símbolo especial plotado sobre o mapa em sua respectiva posição geográfica. A forma dos símbolos é uma modificação do gráfico de tempo: os eixos das coordenadas são omitidos e as linhas são completamente fechadas e com seu interior preenchido para facilitar a visualização dos elementos sobre o mapa (figura 3.5). Em tais símbolos, a dimensão horizontal corresponde ao intervalo de tempo sob investigação. Neste caso, o intervalo corresponde a um ano. Já a dimensão vertical é usada para representar valores numéricos de um atributo em cada instante do intervalo. Este tipo de representação permite visualizar como diferentes comportamentos anuais estão distribuídos sobre o mapa. Através de uma inspeção visual, o usuário pode descobrir regiões com comportamentos similares, verificando a formação de agrupamentos (clusters) espaciais.

A escolha do período a ser analisado pode ser feita de forma bastante flexível através dos componentes de gerenciamento de tempo disponíveis no painel lateral da interface 


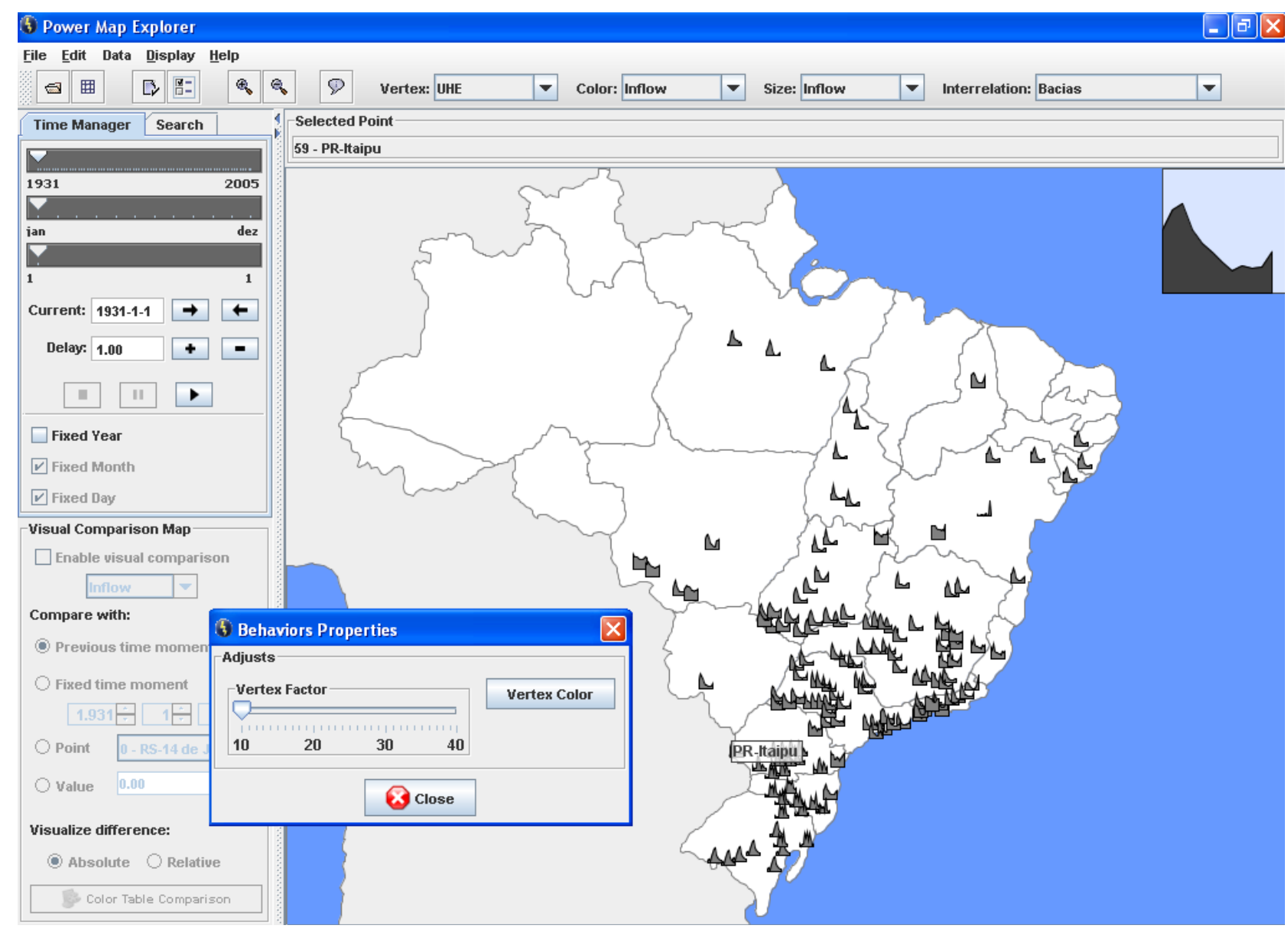

Figura 3.5: Comportamento Anual do atributo vazão sobre o mapa.

principal do sistema. Além das opções de zoom e brushing, é possível modificar o tamanho e as cores dos símbolos plotados no mapa a fim de melhorar o processo visual.

\subsubsection{Time Manager e Animação em Mapa}

Para apoiar a exploração interativa dos dados, foi desenvolvido um conjunto de controles denominado Time Manager (ver figura 3.6). O Time Manager é o componente do sistema responsável pelo gerenciamento do aspecto temporal dos dados. Ele é conectado ao display e permite ao usuário manipular interativamente o tempo de forma que os resultados sejam atualizados dinamicamente no mapa. Um dos controles é o componente time slider que possibilita selecionar momentos específicos no tempo por meio do mouse.

Uma outra forma de manipular o tempo é através dos botões step forth e step back. Suas ações provocam uma nova atualização no tempo corrente e na representação do mapa. Uma outra opção é delegar este poder ao próprio sistema, por meio do processo de animação. Neste caso, a atualização do tempo corrente ocorre em intervalos constantes regulado pelo parâmetro delay. 


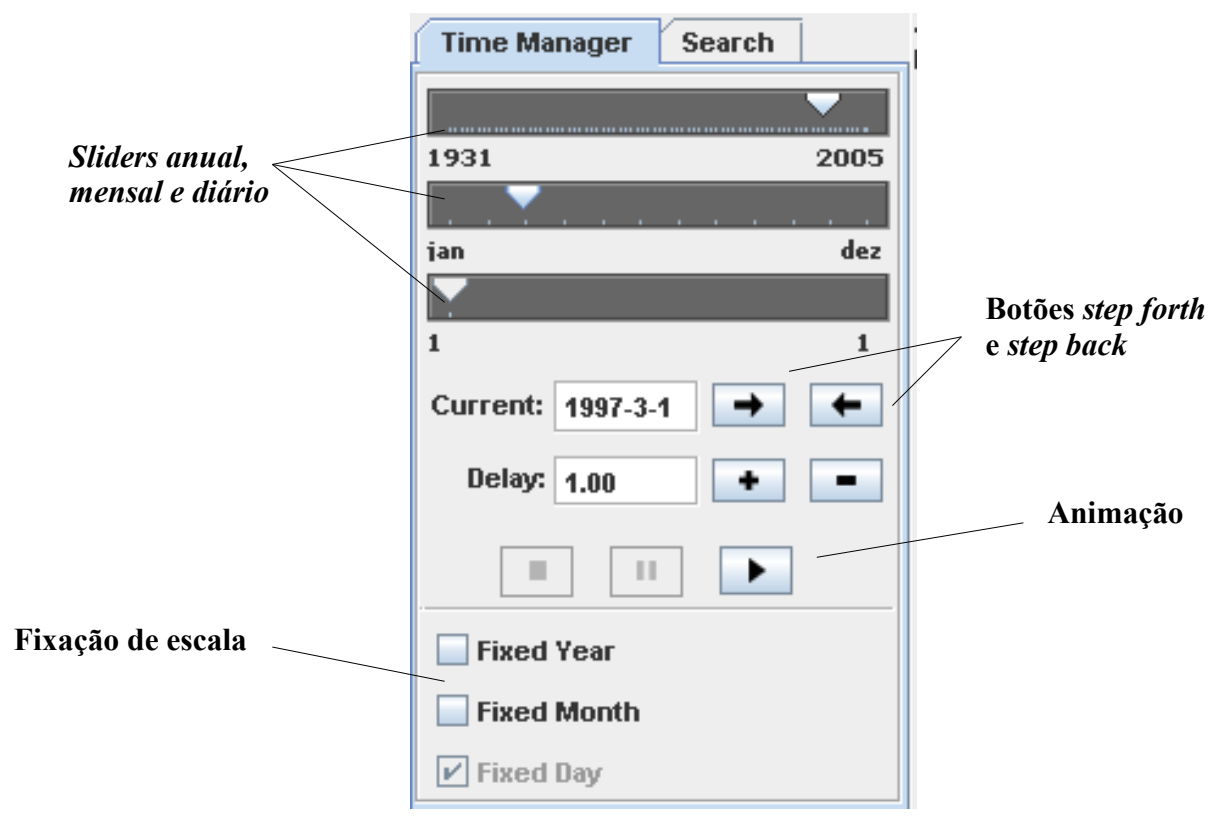

Figura 3.6: Time Manager.

Com o Time Manager, o usuário pode analisar os dados de duas formas: estática e dinâmica. Além disto, é possível visualizar diferentes transformações nos dados através da fixação das escalas anual, mensal e diária.

\subsubsection{Comparação Visual em Mapa}

A Comparação Visual em Mapa é uma técnica de análise de dados extraída da visualização espaço-temporal que combina a essência visual do método choropleth map com estratégias mais sofisticadas de comparação. Segundo esta técnica, cada elemento presente no mapa é preenchido com uma cor cuja tonalidade e intensidade é resultado de um processo de comparação. No Power Map Explorer, esta técnica é combinada com o time manager, de forma que a cada passo no tempo, o mapa represente a diferença entre os elementos ou entre os momentos de tempo através da variação de cores. Em relação ao momento de tempo corrente, a técnica permite a comparação em relação:

- ao momento anterior,

- a um momento fixado pelo usuário,

- a um elemento selecionado,

- a algum valor constante.

Ao habilitar o modo de comparação visual, as cores dos elementos posicionados sobre o mapa passarão a mapear diferenças calculadas e não mais valores de atributos. As diferenças são apresentadas usando um esquema de cor bi-direcional: tonalidades de duas 
cores diferentes são utilizadas para representar diferenças positivas e negativas em relação ao valor de referência corrente. Esta técnica utiliza por padrão tonalidades de azul e amarelo, respectivamente. Entretanto, é possível alterar este esquema de cores através de uma tabela de mapeamento de cores disponibilizada pelo componente. A variação das intensidades destas cores demonstra visualmente as diferenças, isto é, quanto maior a diferença maior é a intensidade. A cor branca é usada por elementos com valores exatamente iguais aos valores de referência. A visualização destas diferenças pode ser combinada com a animação de forma que a cada instante as diferenças são recalculadas e redesenhadas no mapa.

A técnica disponibiliza duas formas diferentes de visualizar as diferenças. O modo Absolute mostra os resultados da subtração dos valores de referência em relação aos valores de origem. Já o modo Relative mostra os resultados da divisão entre a diferença absoluta dos valores de referência e de origem em relação aos valores de referência.

Complementar a esta técnica de visualização, é oferecido o componente Tabela de Dados para a visualização do conjunto de dados na sua forma original, texto ou número. Maiores detalhes sobre estas técnicas podem ser vistos no manual do usuário disponibilizado em (http://infoserver.lcad.icmc.usp.br/infovis2/PowerMapExplorer/).

\subsubsection{Gráficos Temporais}

O Power Map Explorer emprega um conjunto de recursos gráficos com propriedades bastante interativas para auxiliar na interpretação e análise temporal dos dados. Tais recursos dispõem de técnicas clássicas de visualização utilizadas tradicionalmente em diversas áreas de pesquisa para exploração de dados de natureza temporal. Estes gráficos estão ligados dinamicamente aos elementos no mapa, e podem ser acessados pelo clique do mouse.

O primeiro componente gráfico disponibilizado é o tradicional gráfico de tempo, tipicamente utilizado para o estudo de comportamentos temporais. Para cada elemento do conjunto de dados, o comportamento temporal é retratado neste gráfico como uma linha. Esta linha é considerada uma boa representação de um comportamento individual, e possibilita a revelação de padrões, tendências e exceções embutidas nos dados.

Particularmente, esta representação permite realizar comparações de comportamentos entre os diferentes elementos presentes no mapa. Um conjunto de operações disponíveis na interface do componente possibilita ao usuário selecionar interativamente os elementos a serem observados, assim como manipular dinamicamente a janela de deslizamento e o intervalo de tempo que será efetuado a exploração (figura 3.7 (1)).

Para efeito de estudo, foi desenvolvida uma outra representação gráfica, similar ao gráfico de tempo anterior, que permite analisar e comparar os comportamentos anuais de um atributo para um único elemento (figura 3.7 (2)). Nessa opção, cada linha representa 


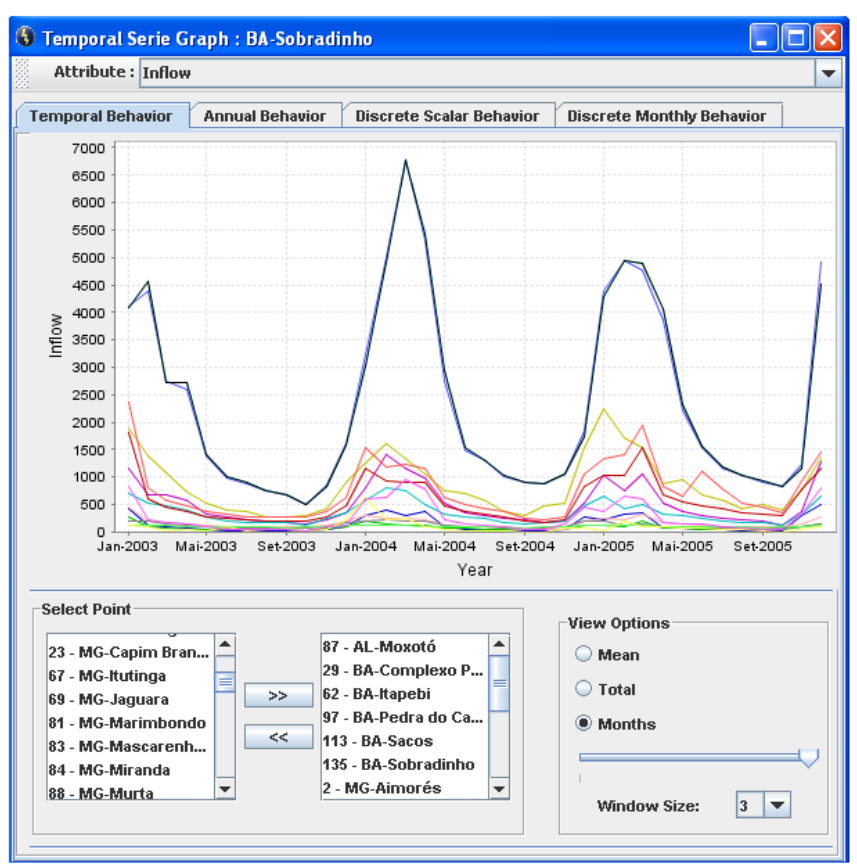

(1)

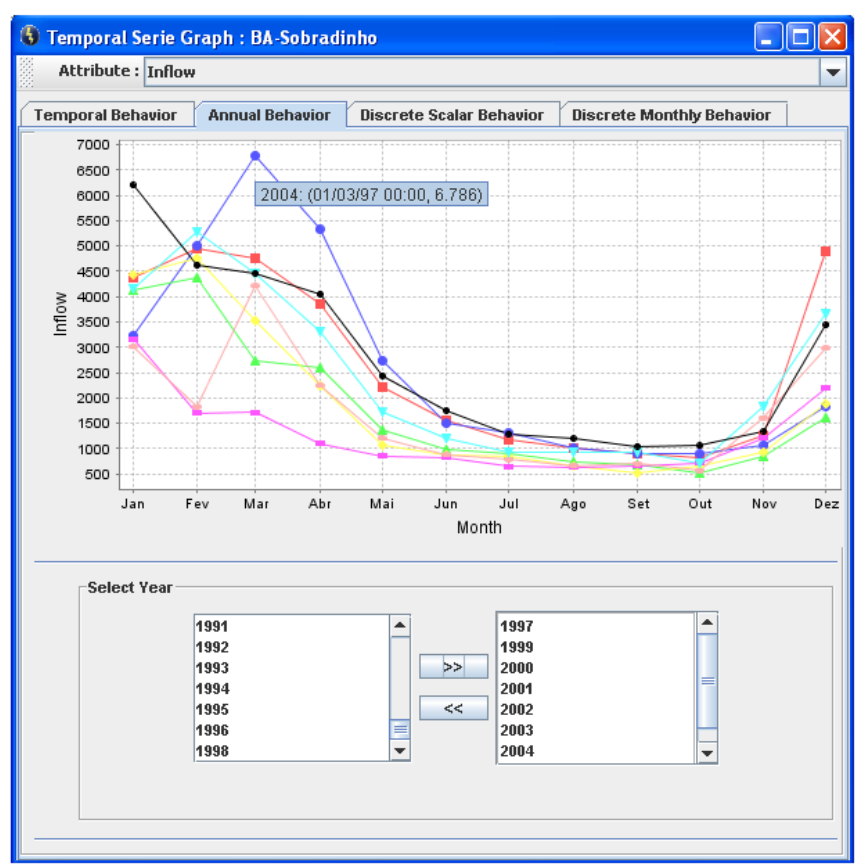

(2)

Figura 3.7: Gráficos de tempo para análise dos comportamentos dos elementos do conjunto de dados.

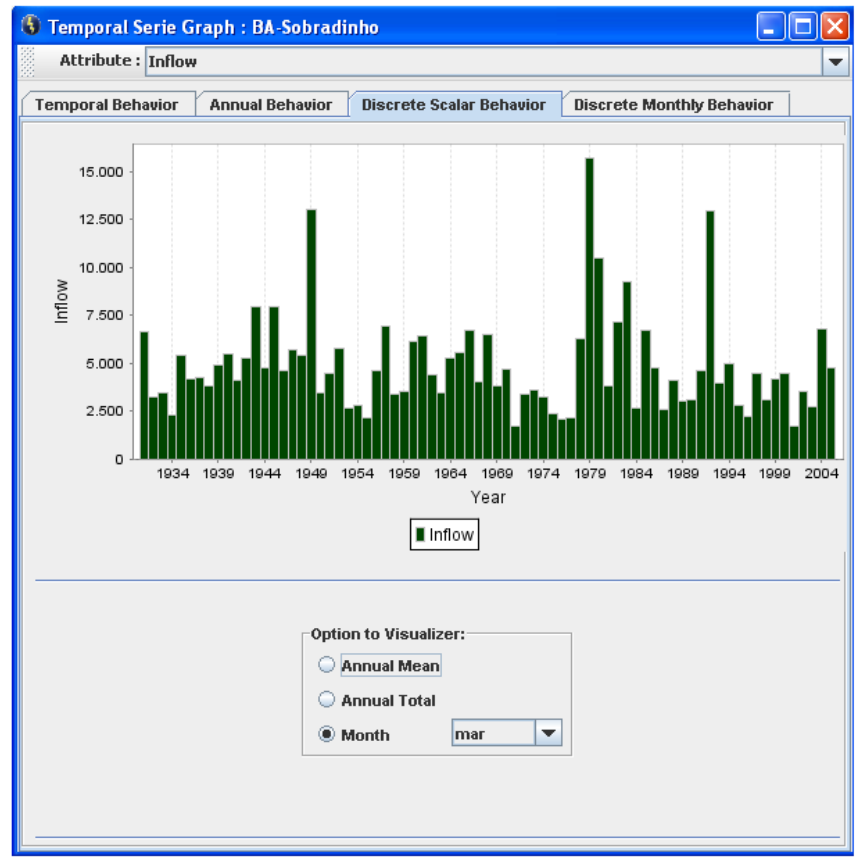

(1)

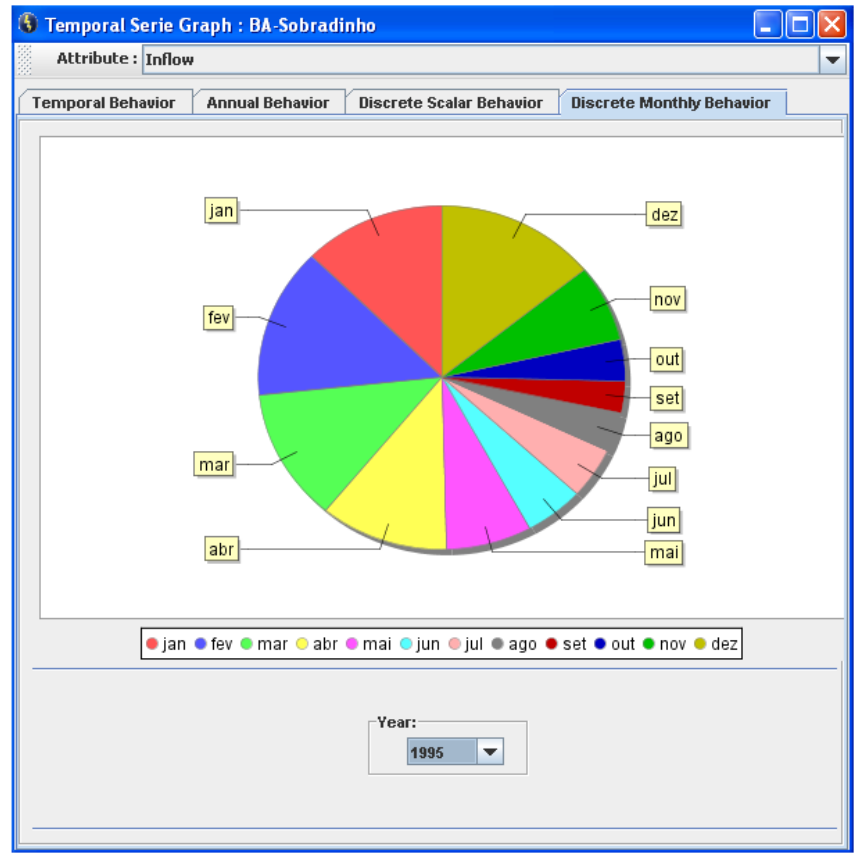

(2)

Figura 3.8: Gráficos de bar charts e pie charts. 
o comportamento do atributo em um ano específico. No entanto, é possível selecionar interativamente na visualização intervalos menores através do mouse.

Além disso, o usuário pode estar interessado em estudar detalhadamente a distribuição discreta mensal (ou diária) dos valores de um atributo em um ano específico, ou mesmo observar o comportamento de um mesmo mês (ou dia) de um atributo para todo o intervalo de tempo. Para atender esses objetivos, foram adaptados e adicionados ao sistema os componentes gráficos de pie charts (2) e bar charts (1), respectivamente (figura 3.8). Ambas representações são bastante simples, mas podem auxiliar e contribuir substancialmente para o processo de interpretação e extração de informações relevantes nos dados.

\subsubsection{Variação Temporal Uni-Escala}

Esta representação é adequada para exibir a variação temporal de um determinado atributo segundo uma escala de tempo (dia, mês, ano), e uma tabela de cores definida pelo usuário que mapeia intervalos de valores de interesse em cores. Os valores de um atributo temporal são representados por uma sequência de pixels, ou pontos, esquematizados como quadrados na figura 3.9(a).

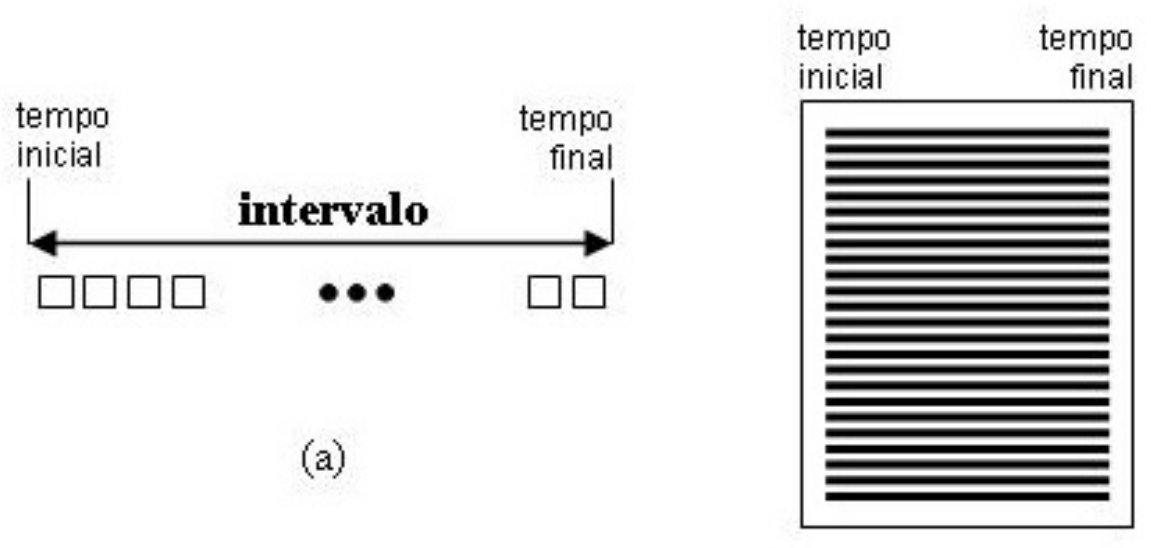

(b)

Figura 3.9: Construção da representação visual Variação Temporal Uni-escala.

Cada sequência de pixels é associada a um objeto espacial, disposta horizontalmente, sobre um eixo temporal de referência, compondo uma linha. A justaposição de várias linhas 3.9(b) cria uma representação visual que permite a observação simultânea de informações relativas a vários objetos espaciais. Considerando que cada ponto da linha é posicionado sobre o eixo temporal definido em uma escala de tempo, informações adicionais (intervalo temporal e ciclos temporais) podem ser percebidas.

A disposição dos dados nesta representação é mostrada na figura 3.10(a). Os valores referentes a um determinado ano são apresentados em uma coluna, distribuídos em elementos retangulares. Cada retângulo consiste de uma grade 4x3 (suficiente para exibir os 
12 meses do ano) cujos elementos são preenchidos da esquerda para a direita, e de cima para baixo.

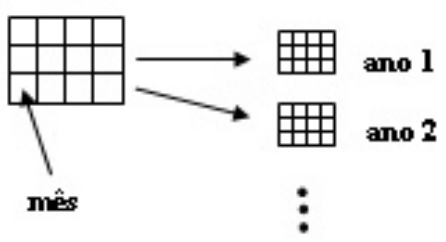

(a)

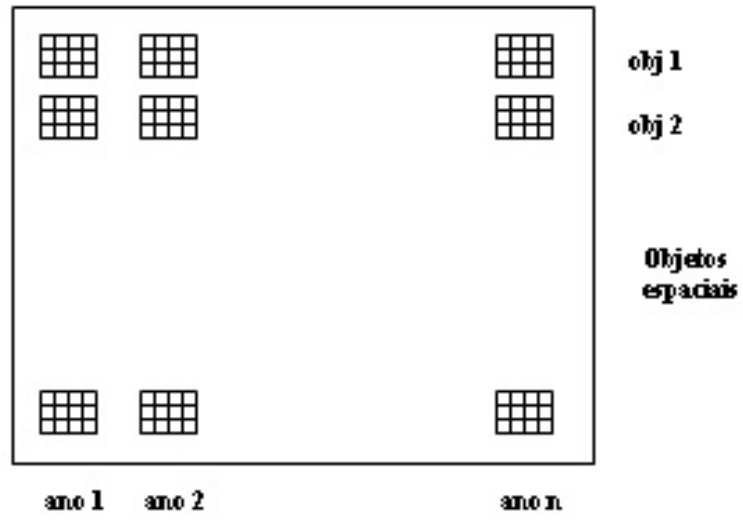

(b)

Figura 3.10: Disposição dos dados na representação uni-escala.

A justaposição das colunas, seguindo uma ordem cronológica, produz uma representação visual esquematizada na figura 3.10(b). A coloração de um retângulo da escala mensal (ver figura 3.11) pode levar, pela disposição das cores, a uma figura que pode ser interpretada como um ícone, o que pode auxiliar tarefas de busca por padrões.

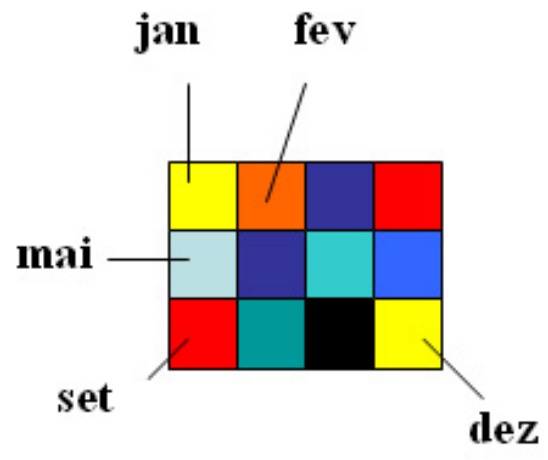

Figura 3.11: Divisão do retângulo para representação da escala mensal.

A técnica de variação temporal uni-escala implementada no sistema foi baseada em estudos conduzidos com dados de vazões mensais nas hidrelétricas, buscando uma forma efetiva de exibir a qualidade de dados de vazões. A figura 3.12 mostra essa representação implementada no Power Map Explorer e utilizada para a visualização de dados de vazões mensais.

Nesta representação é possível alterar o tamanho do ponto (escala de ampliação/redução) para a observação em maiores detalhes. Contornos retangulares e legendas 


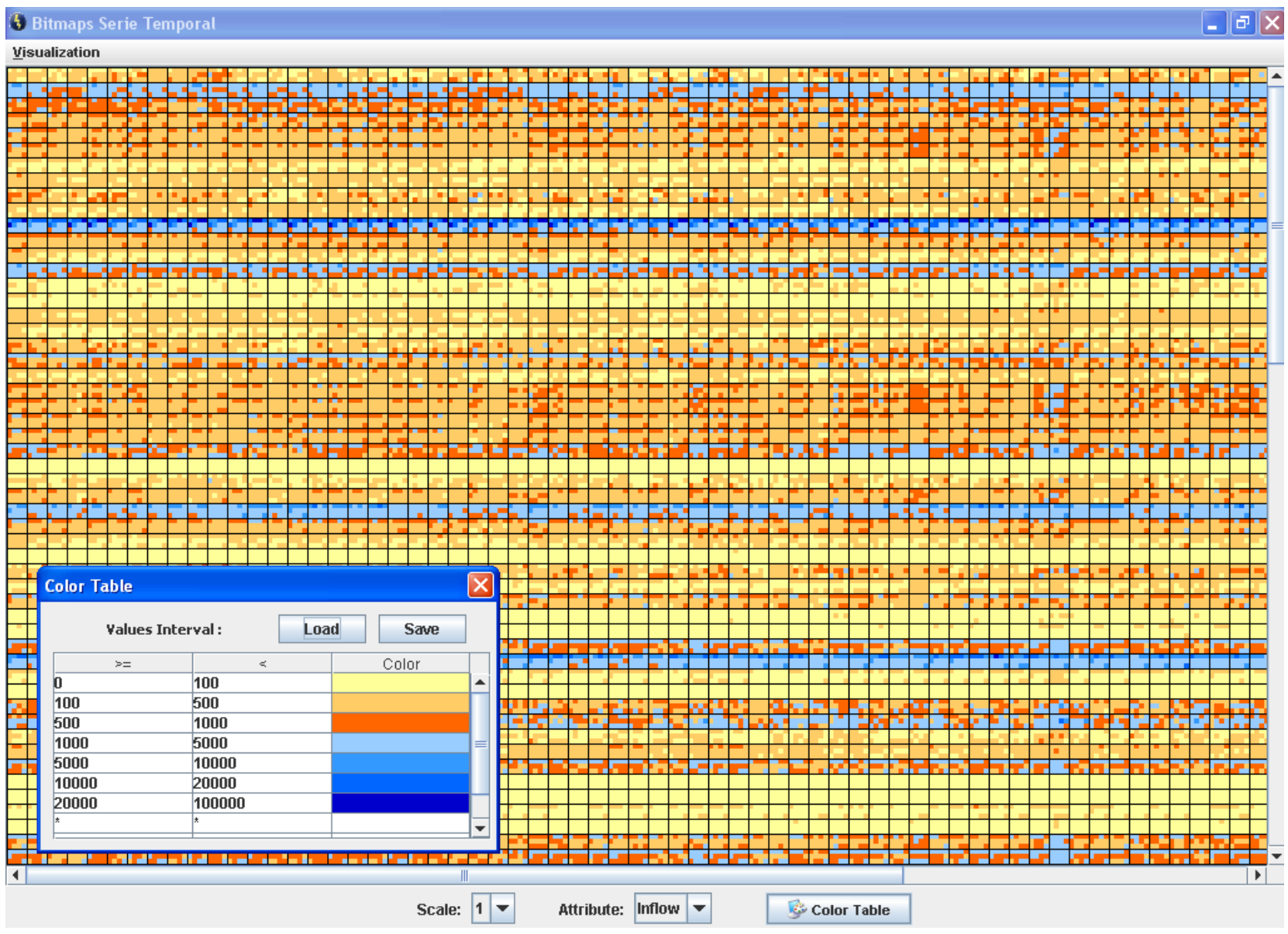

Figura 3.12: Representação uni-escala para os dados de vazões nas hidrelétricas.

são usados como guias para indicar sobre um determinado objeto espacial e momento de tempo.

\subsubsection{Projeção por Similaridades}

Este componente pode ser utilizado para criar e explorar representações visuais de séries temporais, auxiliando os usuários a visualizar similaridades entre seus conteúdos. A idéia é comparar e agrupar objetos espaciais com comportamentos temporais parecidos segundo uma métrica de distância. Nesta representação, cada objeto espacial (representando uma série temporal) é projetado como um círculo em um plano. Assim, se dois círculos estão próximos, o conteúdo de seus dados são similares, porém, se os círculos estão afastados, seus conteúdos não se correlacionam.

O desenvolvimento desse componente tomou por base um arcabouço de dois outros sistemas em andamento no grupo de visualização (Minghim et al., 2006), sendo um deles também focalizado no estudo de séries de vazões mensais (Alencar et al., 2007), e adicionou-se a ele características que permitam a sua integração e utilização de maneira eficaz, auxiliando na análise e extração de possíveis agrupamentos nos dados. 
O primeiro passo para gerar tal projeção consiste em selecionar os objetos espaciais que serão analisados, por exemplo, as usinas hidrelétricas que serão comparadas. O segundo passo consiste em escolher a métrica de distância que será aplicada. O componente oferece duas métricas de distâncias: distância Euclidiana e Compression-Based Dissimilarity Measure (CDM). Ambas são explicadas com detalhes em 2.4.2.

A figura 3.13 mostra um exemplo da visualização gerada para dados de séries de vazões utilizando a distância euclidiana como medida de distância. Nesta representação, as usinas hidrelétricas são representadas por vértices sobre um plano 2D. Quanto mais próximos, maior a similaridade entre elas. A cor pode ser usada para agrupar as usinas segundo alguma pré-classificação dos dados, por exemplo, a bacia hidrográfica a que pertencem. Além disto, o componente oferece algumas opções de interação com a projeção gerada, como por exemplo, selecionar sub-grafos para uma análise mais detalhada, gerar novas projeções a partir de sub-grafos selecionados, calcular e aplicar triangulações nos dados, entre outras. Outros exemplos da aplicação desta técnica no contexto de dados de vazões pode ser visto no capítulo 4.

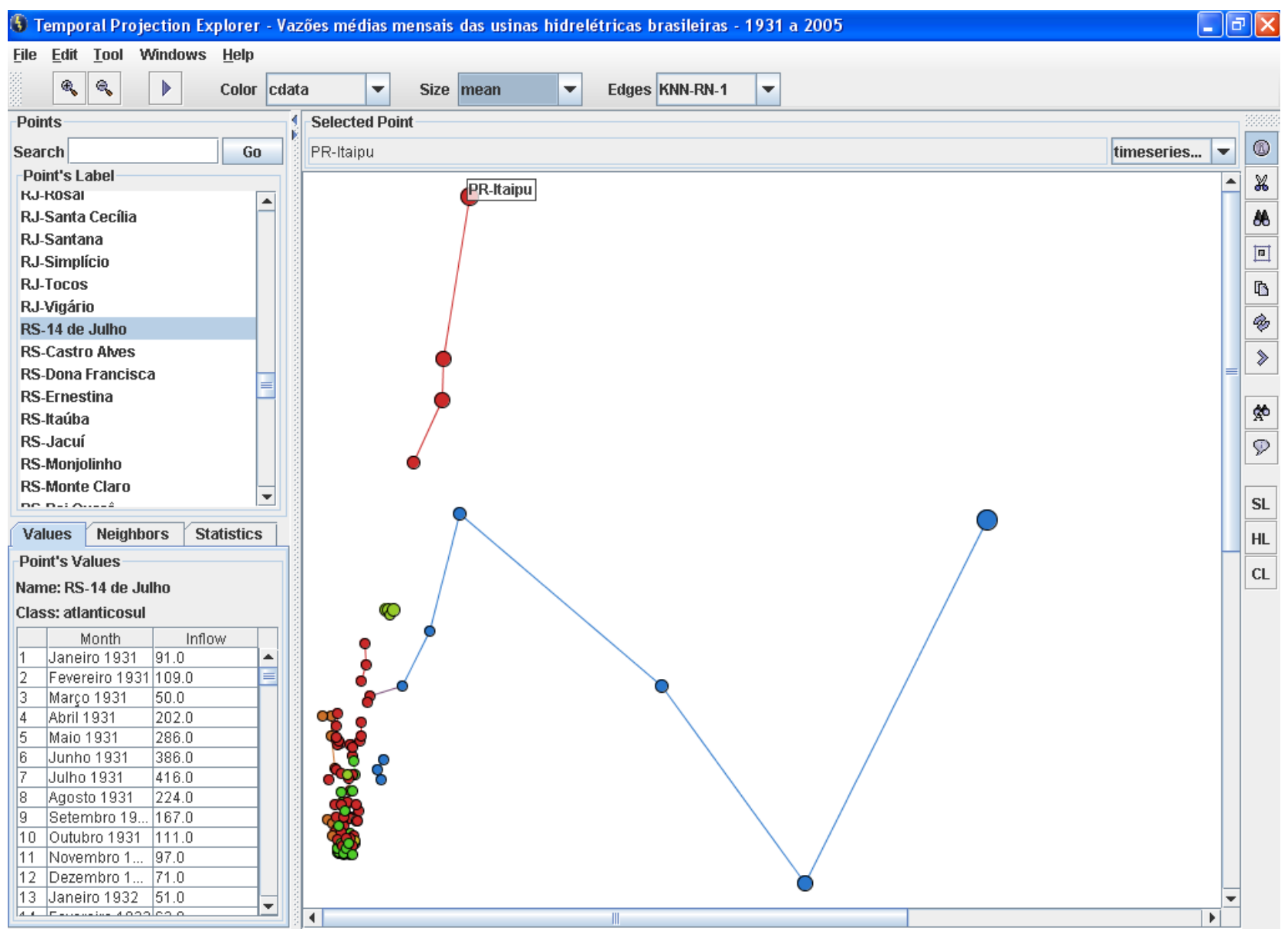

Figura 3.13: Agrupamentos gerados para dados de vazões utilizando a distância euclidiana. 


\subsection{Módulo de Previsão}

O Módulo de Previsão é um recurso unificado ao Power Map Explorer desenvolvido especialmente para a análise e previsão de dados relativos as vazões nas usinas hidrelétricas, motivado pela importância deste tipo de dado no contexto energético. Este módulo, assim como o módulo de visualização, é constituído por uma interface bastante cognitiva e interativa, com diversas opções estatísticas para análise dos dados reais e recursos computacionais gráficos para apoiar o processo de interpretação das informações geradas. Basicamente, o módulo de previsão pode ser dividido em dois sub-módulos distintos: o sub-módulo de interface e o sub-módulo de previsão.

O sub-módulo de interface, implementado puramente em Java, funciona como um instrumento de comunicação entre o sub-módulo de previsão e o usuário. Ele fornece ao utilizador uma interface gráfica direta e interativa para manipulação dos parâmetros de previsão, recursos gráficos para análise dos dados originais e previstos, opções para exportação e importação de dados gerados, entre outros (ver figura 3.14).

O sub-módulo de previsão, desenvolvido em Scilab, é responsável por todo processo de previsão, isto é, todos os inúmeros cálculos e procedimentos necessários para realizar a previsão são efetuados em tempo de execução neste ambiente matemático. Por isto, todos os modelos de previsão podem ser escritos diretamente na linguagem interpretada por Scilab, não exigindo assim do programador dos modelos, conhecimento específico sobre a linguagem de programação Java.

A seguir é apresentado o componente funcional empregado para a análise preliminar dos dados de vazões, bem como os parâmetros de previsão e os recursos gráficos utilizados para a visualização das informações geradas.

\subsubsection{Análise Preliminar}

A análise preliminar das séries de vazões das usinas hidrelétricas tem o objetivo de auxiliar o usuário especialista na obtenção de informações sobre a natureza e o comportamento estatístico destes dados. O sistema fornece um componente que abrange um conjunto de gráficos estatísticos para a análise inicial dos dados, entre eles, os gráficos de média, desvio padrão, coeficiente de variação e variância versus média. Estes gráficos possibilitam ao usuário realizar um estudo estatístico preliminar sobre os comportamentos das séries de vazões e, conseqüentemente, extrair propriedades que contribuam para a definição de parâmetros de previsão mais apropriados. A figura 3.15 mostra, por exemplo, as informações estatísticas geradas sobre os dados de vazões mensais da usina hidrelétrica de Furnas. 


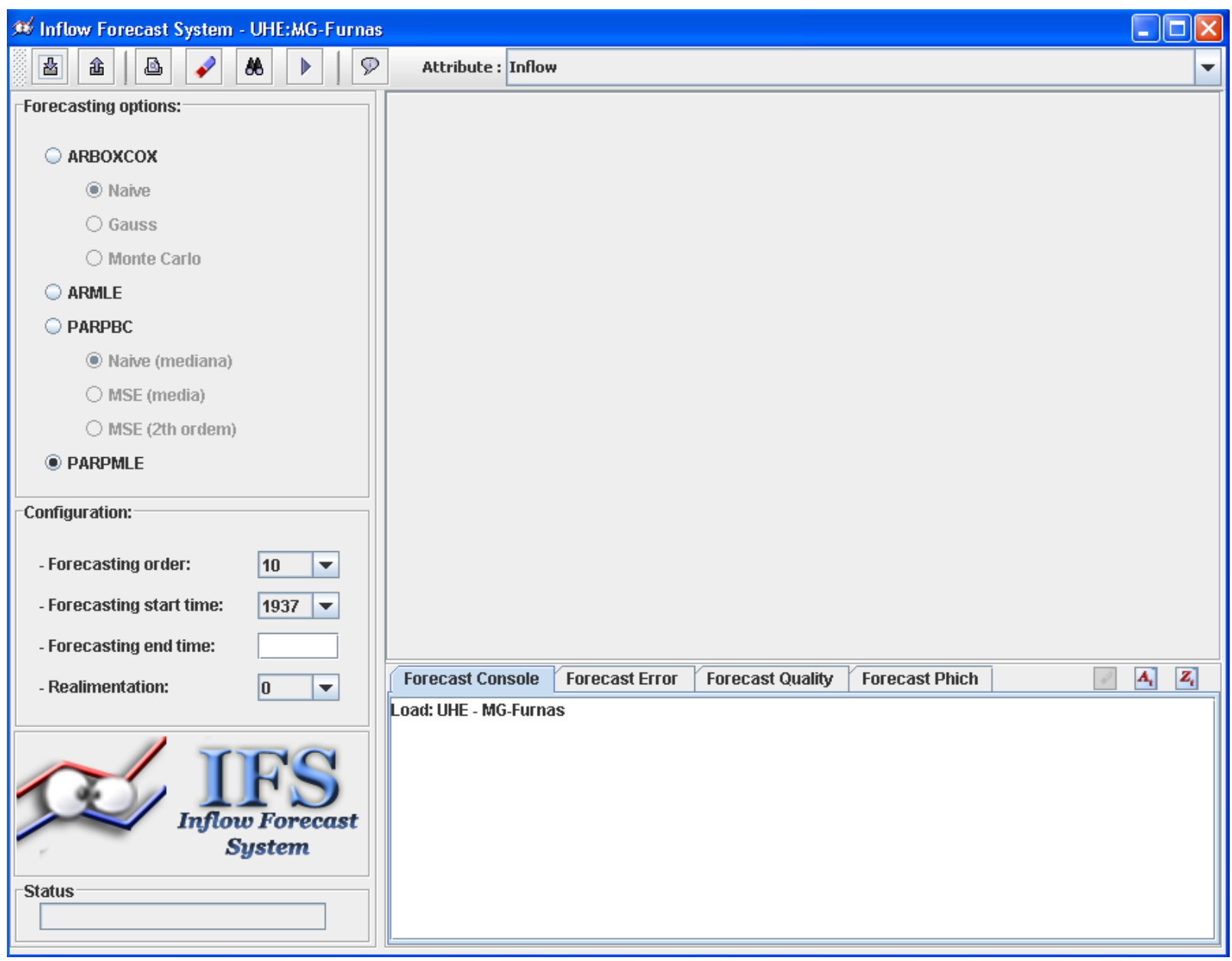

Figura 3.14: Interface gráfica do módulo de previsão.

\subsubsection{Parâmetros de Previsão}

Os parâmetros de previsão são informações específicas utilizadas pelo sistema com o objetivo de direcionar todo o processo de previsão. Estas informações são definidas pelo usuário através da interface do sistema e repassadas ao Scilab durante fase inicial da previsão. A configuração dos parâmetros de previsão pode ser dividida em duas etapas:

- Seleção do modelo de previsão,

- Definição dos parâmetros de entrada do modelo.

A primeira etapa consiste na escolha do modelo que será utilizado no processo de previsão. O Power Map Explorer disponibiliza duas classes de modelos estocásticos para a previsão de séries de vazões mensais: modelos auto-regressivos (AR) e modelos periódicos auto-regressivos (PAR), explicados com mais detalhes em 2.4.3. Enquanto que nos modelos auto-regressivos os parâmetros internos são ajustados igualmente para todos os períodos (meses), no caso dos modelos periódicos auto-regressivos são definidos parâmetros diferentes para cada período em particular. 


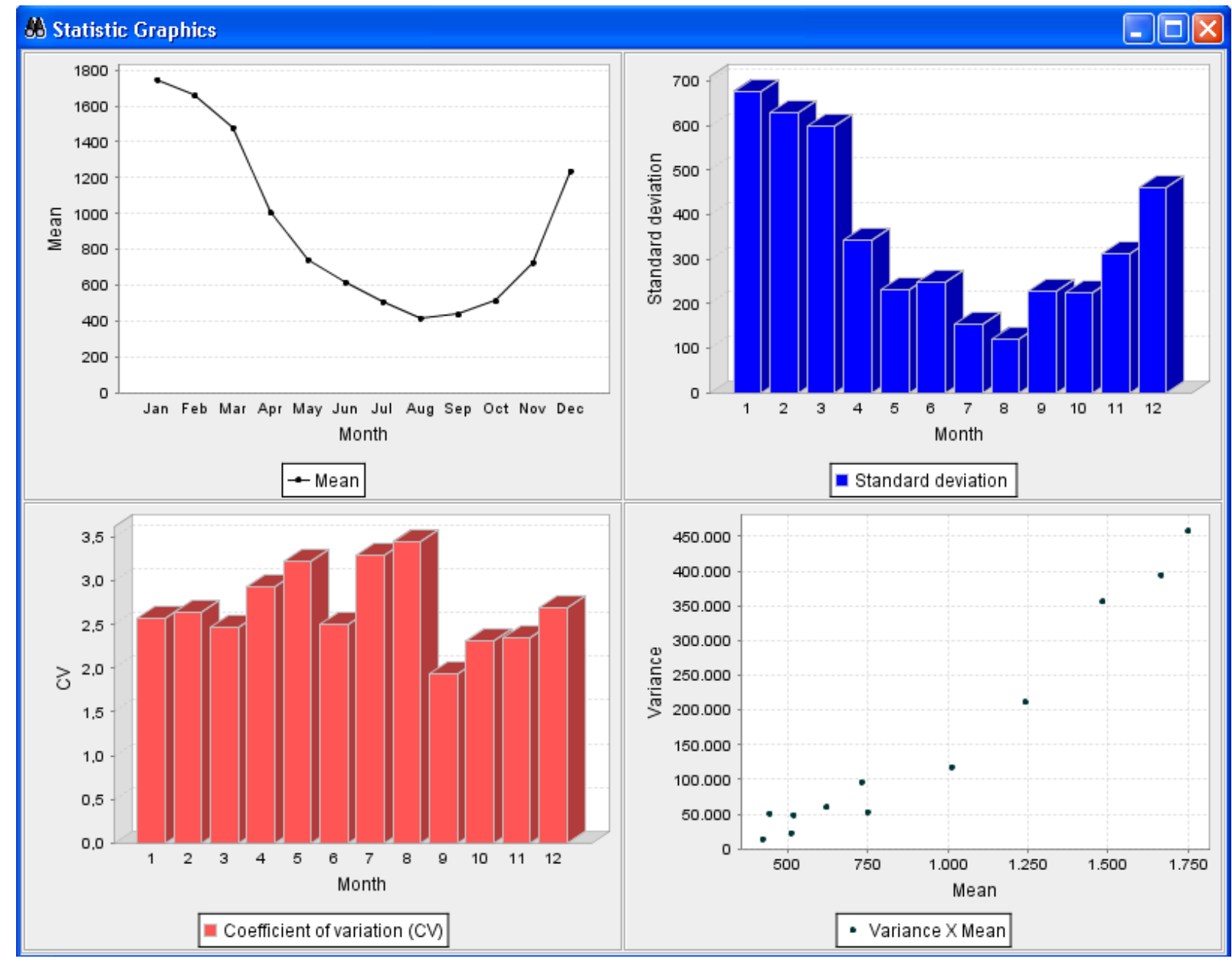

Figura 3.15: Gráficos de média, desvio padrão, coeficiente de variação e de variância versus média para os dados de vazões da usina hidrelétrica de Furnas.

Basicamente, o sistema oferece como opção de previsão dois modelos auto-regressivos, ARBOXCOX e ARMLE, e dois modelos periódicos auto-regressivos, PARPBC e PARPMLE. Diferentemente dos modelos ARMLE e PARPMLE, os modelos ARBOXCOX e PARPBC são ajustados fazendo uso da transformação de Box-Cox para assegurar uma distribuição conjunta aproximadamente normal e estabilizar a variância periódica da série transformada.

No caso em que a transformação de Box-Cox é adotada, técnicas específicas de simulação são usadas para ajustar os parâmetros internos do modelo. Para o modelo ARBOXCOX são empregados os métodos de Naive, Gauss e de Monte Carlo, e para o modelo PARPBC são utilizados os métodos de Naive, Mínimo Erro Quadrático Médio e Mínimo Erro Quadrático Médio de Segunda Ordem.

Todos estes modelos são de autoria do prof. Marinho G. de Andrade Filho e seus associados (Andrade, 2004), e foram convertidos do ambiente estatístico Matlab para o ambiente Scilab, a fim de tornar o resultado final do sistema de previsão e de visualização independente de software proprietário. 
Uma vez definido o modelo que será utilizado, a segunda etapa destina-se a configuração dos parâmetros de entrada do modelo. Os parâmetros de entrada do modelo são:

1. forecasting order: este parâmetro limita a ordem máxima que o modelo poderá ser ajustado durante o processo de previsão. Tal informação é elemento fundamental na configuração dos parâmetros internos do modelo, podendo afetar a qualidade da previsão;

2. forecasting start time: indica o ano inicial da previsão;

3. forecasting end time: indica o ano final da previsão;

4. realimentation: determina o passo de realimentação (em meses) do processo de previsão com dados já previstos, isto é, está informação instrui o modelo a realimentar iterativamente o processo com dados de vazões previstos segundo o intervalo de tempo estipulado.

\subsubsection{Resultados da Previsão}

Uma vez finalizado a previsão, o Scilab repassa ao sistema todas as informações geradas pelo processo. Por sua vez, o sistema retrata estas informações ao usuário por meio de representações visuais a fim de guiá-lo na interpretação e análise dos resultados obtidos. Tais informações são compostas por uma enorme variedade de dados que variam em função do modelo e dos parâmetros de entrada escolhidos. Estas informações podem ser divididas em:

- Dados de séries de vazões previstas,

- Dados de resíduos da previsão,

- Dados sobre a qualidade, erro e phich da previsão.

Para representar as séries de vazões previstas são utilizados os tradicionais gráficos de tempo. Os gráficos de tempo são excelentes ferramentas utilizadas para representar séries temporais, pois permitem interpretar eficientemente os comportamentos dos dados. A figura 3.16 mostra a interface do módulo de previsão com o gráfico de tempo das séries de vazões prevista e observada para a usina de Furnas, compreendendo o período de janeiro de 1999 a dezembro de 2001. A representação das séries prevista e observada no mesmo gráfico é um poderoso meio para comparação visual.

Alguns mecanismos de interação são implementados sobre esta representação com o intuito de auxiliar o usuário nos procedimentos de investigação visual. Um deles é o zoom, que permite realçar intervalos específicos no gráfico através do mouse. Uma outra forma 


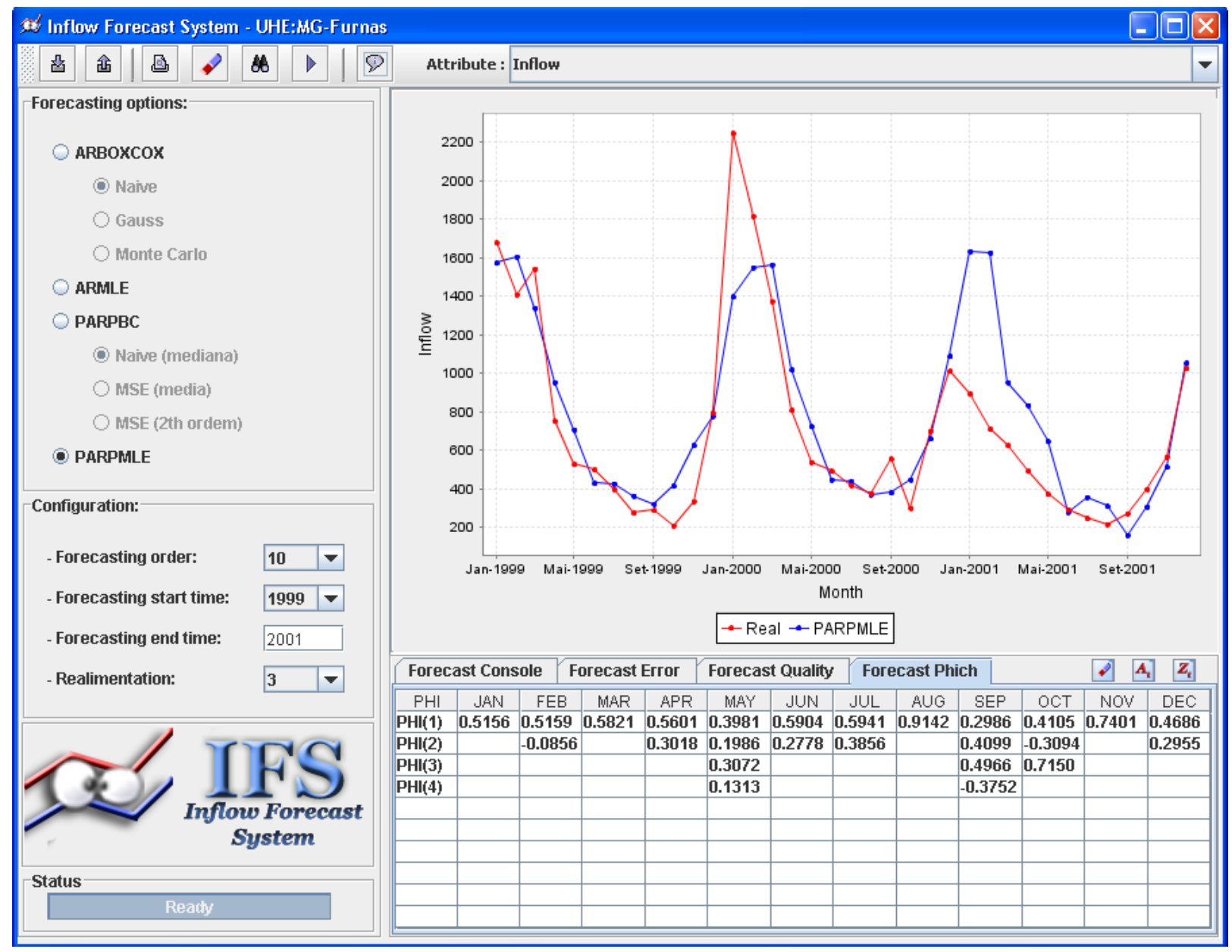

Figura 3.16: Gráfico de tempo das séries de vazões prevista e observada para a usina de Furnas a partir da previsão pelo modelo PARPMLE.

alternativa de interação possibilita visualizar sobre o mesmo gráfico de tempo as séries previstas para os diferentes modelos. Tal estratégia viabiliza a comparação visual entre as diferentes séries geradas, além de permitir determinar a proximidade das séries previstas com a efetivamente observada.

Basicamente, existem dois tipos de dados a serem analisados: a série padronizada $z_{t}$ e os resíduos $a_{t}$. A série padronizada $z_{t}$ é oriunda da padronização dos dados reais com a extração da média e desvio-padrão sazonal. Já os resíduos $a_{t}$ são os erros de ajuste do modelo. Estes resíduos são dados resultantes da fase de ajuste dos modelos que revelam importantes informações sobre a qualidade dos modelos ajustados. A figura 3.17 mostra um exemplo dos gráficos dos resíduos $a_{t}$ resultantes da previsão pelo modelo PARPMLE.

Por fim, os dados sobre a qualidade e erro da previsão são resultados de cálculos comparativos entre os dados previstos e observados (se existir). Eles revelam a precisão da previsão em relação ao originalmente observado. Já os dados referentes ao phich retratam informações sobre os parâmetros de ajuste do modelo. Diferentemente das séries previstas e dos resíduos, esses dados são representados e analisados no seu formato numérico. Para a visualização de tais informações são utilizadas tabelas. Como exemplo, ver a tabela de 


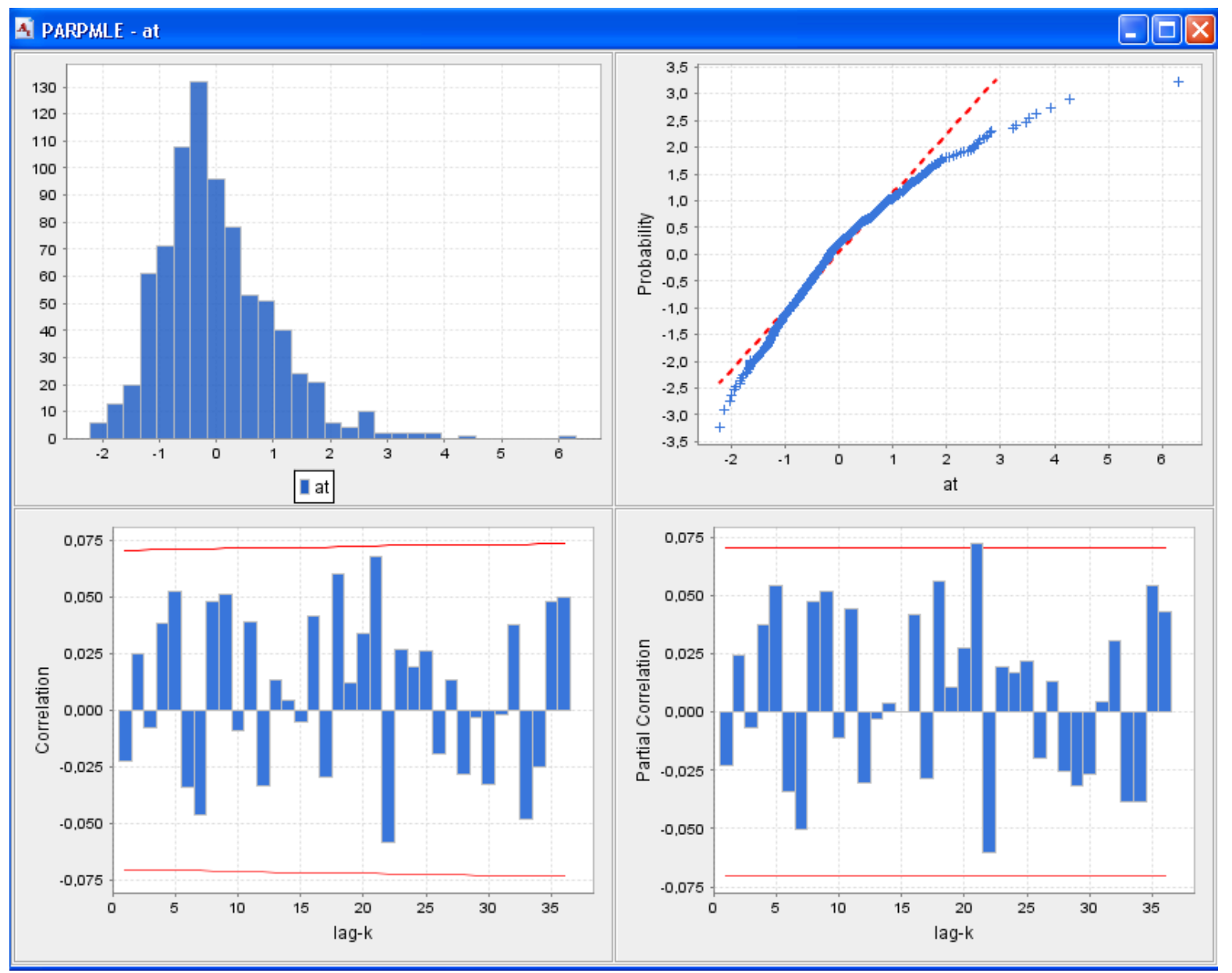

Figura 3.17: Gráficos de resíduos $a_{t}$ gerados pelo modelo PARPMLE.

valores referentes ao phich disponibilizada na parte inferior da interface (ver figura 3.16). Outros exemplos de previsão de dados de vazões podem ser vistos no capítulo 4.

\subsection{Considerações Finais}

Neste capítulo foi detalhado o desenvolvimento do Power Map Explorer, que incorpora alguns conceitos e recursos discutidos no capítulo anterior. Foi apresentanda a estrutura de desenvolvimento do Power Map Explorer, abordando sua arquitetura e plataformas adotadas para o desenvolvimento. Uma divisão conceitual foi aplicada ao sistema, dividindo-o em três módulos principais: interface, visualização e previsão. Cada módulo foi descrito em detalhes, destacando suas funcionalidades e características de implementação. A adoção do desenvolvimento orientado a objetos permitiu criar um sistema robusto e de fácil manutenção, requisitos fundamentais durante a etapa de implementação do Power Map Explorer. 
O próximo capítulo é destinado a verificar a utilidade do ambiente computacional desenvolvido para apoiar a exploração e previsão de dados de séries de vazões nas usinas hidrelétricas. 


\section{Capítulo \\ 4 \\ Aplicação do Sistema}

\subsection{Considerações Iniciais}

Os módulos de Visualização Exploratória e de Previsão, implementados no Power Map Explorer e descritos no capítulo 3, foram avaliados em testes de uso com o objetivo de: (1) verificar a utilidade das técnicas de visualização espaço-temporais adaptadas e implementadas para apoiar a exploração e análise de conjuntos de dados de vazões mensais nas usinas hidrelétricas; (2) validar o módulo de previsão desenvolvido por meio de exemplos de previsões realizadas com dados de vazões.

O objetivo dos casos de uso foi explorar os dados para descobrir novas informações, completando ou detalhando aquelas advindas de processamento numérico tradicionalmente aplicado. Além disso, foram apreciadas as vantagens e desvantagens envolvidas na adoção de uma abordagem com visualização interativa, a fim de verificar se o uso de recursos visuais interativos efetivamente proporciona benefícios do ponto de vista do usuário final.

Este capítulo ilustra exemplos de utilização do sistema desenvolvido para dados de vazões, descrevendo as tarefas realizadas, os resultados obtidos e as conclusões alcançadas, analisando as vantagens e desvantagens no uso das visualizações, e apresentado algumas previsões realizadas e informações extraídas.

\subsection{Visualização de Dados de Vazões Mensais}

O estudo de dados de vazões mensais foi escolhido por se tratar de uma aplicação real cujas tarefas de análise e previsão possuem grande importância para o planejamento e operação do sistema energético brasileiro. Para essa investigação, foi utilizada uma base 
de dados disponibilizada pela ONS (Operador Nacional do Sistema), contendo valores mensais do atributo vazão, medidos em $\mathrm{m}^{3} / \mathrm{s}$, entre os anos de 1931 e 2005 referentes a 145 usinas hidrelétricas do sistema brasileiro. A quantidade de vazão mensal registrada em cada usina ao longo de vários anos, armazenada na base de dados, define um atributo temporal. Segundo o especialista prof. Dr. Marinho Gomes de Andrade Filho, muitos destes dados são baseados em previsões, outros são medidas reais (estimativas) de vazões. Além disso, foi adicionado a essa base de dados a posição geográfica original de cada usina hidrelétrica, facilitando a observação da distribuição espacial dos dados.

Inicialmente, para os testes de uso, foram definidas algumas tarefas principais a fim de verificar a aplicabilidade e potenciais benefícios do uso das técnicas de visualização e dos recursos interativos no contexto de dados de vazões. Essas tarefas foram baseadas em algumas questões propostas por MacEachren (1995) utilizadas para análise e interpretação de dados de natureza espacial e temporal. A partir dessas questões foram identificadas três tarefas básicas para a exploração dos dados de vazões:

\section{- Tarefa 1: Definição da distribuição do atributo vazão sobre o território} Brasileiro. Esta tarefa procura avaliar o comportamento corrente e as taxas de transformações do atributo vazão nas usinas hidrelétricas em intervalos específicos do tempo.

- Tarefa 2: Determinação de padrões, comportamentos e fenômenos embutidos nos dados. Esta tarefa procura verificar a existência de padrões e relacionamentos entre as usinas, a fim de que tais informações possam contribuir para a planejamento e operação do sistema. Além disto, busca-se a análise de comportamentos de longos períodos com o objetivo de facilitar a observação de fenômenos temporais ocorridos nos dados, por exemplo, períodos chuvosos e secos.

- Tarefa 3: Detecção de similaridades entre usinas. O objetivo desta tarefa é destacar usinas com comportamentos temporais parecidos.

A seguir são apresentados os detalhes dos testes de uso, e das respectivas visualizações utilizadas para execução das tarefas propostas.

\subsubsection{Definição da distribuição do atributo vazão sobre o terri- tório Brasileiro}

A visualização das usinas hidrelétricas plotadas sobre o mapa geográfico brasileiro permite observar como elas estão distribuídas sobre todo território. A partir da figura 4.1, que ilustra também os principais rios brasileiros, pode-se notar uma grande densidade de hidrelétricas concentradas na região sudeste e sul do Brasil, razão que pode ser inferida 
por fatores geográficos e principalmente econômicos, por exemplo, quanto maior a produção industrial de uma região, maior a quantidade de energia consumida por ela. Além disso, o acoplamento hidráulico existente entre usinas situadas no mesmo rio torna as condições de operação de cada usina dependente da operação das demais, por isso suas posições espaciais devem ser consideradas para efeito de planejamentos mais eficientes e coordenados.

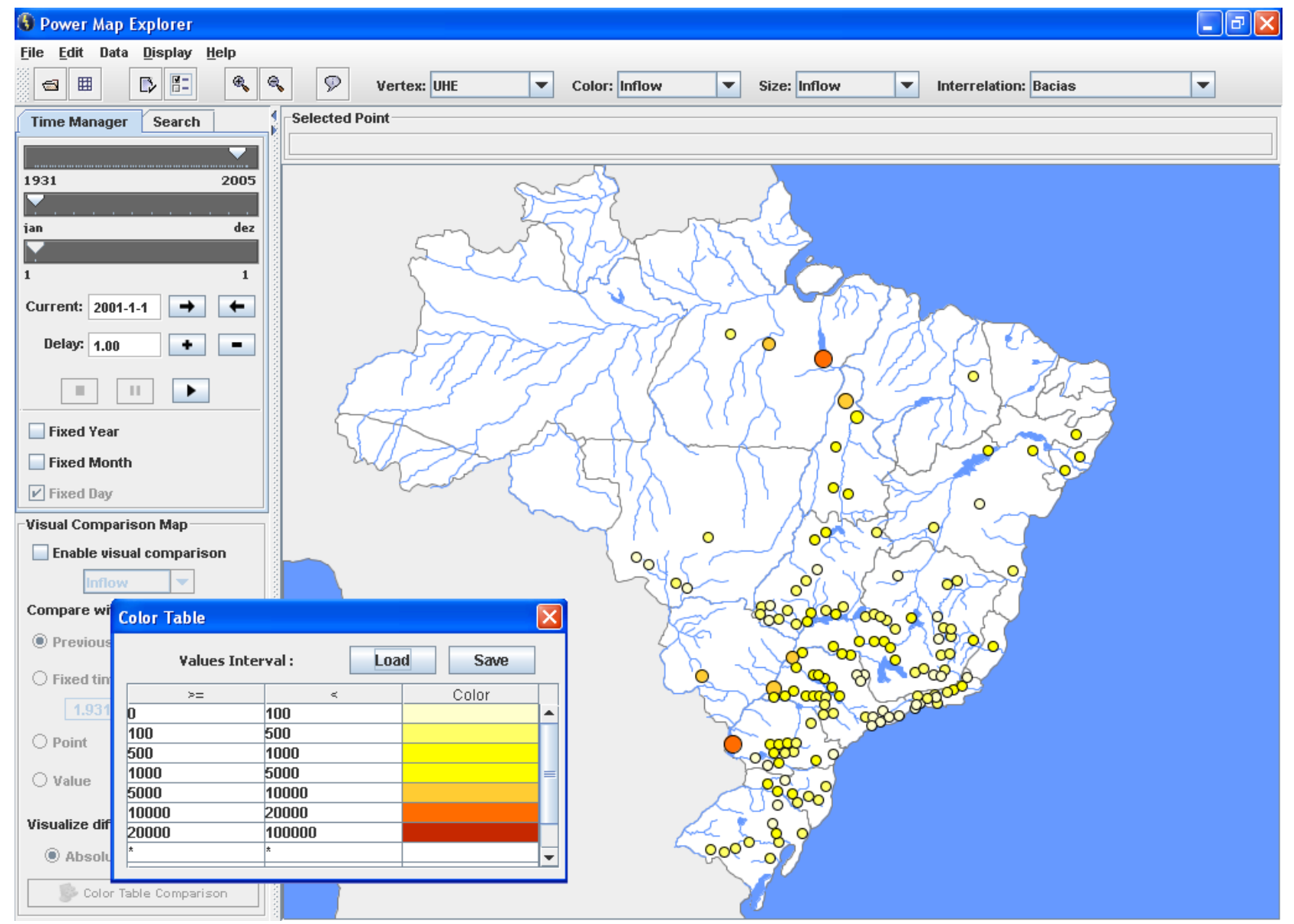

Figura 4.1: Representação das usinas hidrelétricas como círculos coloridos plotados sobre o mapa.

A quantidade de vazão mensal medida (ou estimada) em cada usina ao longo de vários anos define o atributo temporal. A partir das variáveis visuais cor e diâmetro dos círculos (hidrelétricas) plotados sobre o mapa, pode-se perceber visualmente a variação dos valores do atributo vazão em relação às diversas usinas. Uma tabela de cores é disponibilizada pela ferramenta, possibilitando ao usuário mapear intervalos de valores de interesse em cores. A escolha cuidadosa de mapas de cores é uma etapa importante no processo da visualização, pois o tamanho de cada intervalo pode ocultar ou evidenciar detalhes relevantes do atributo mapeado.

Ainda na figura 4.1, a instância representada mostra uma semelhança existente entre a maioria das usinas em relação a taxa mensal de vazão (representada pela cor amarelo) 
para o período analisado. Por outro lado, duas usinas se destacam pela alta taxa de vazão (representada pela cor vermelho): Itaipu e Tucuruí. Durante as várias etapas de testes e exploração dos dados, essa situação foi freqüentemente observada para a maior parte dos períodos, confirmando a superioridade, do ponto de vista da vazão mensal, dessas usinas em relação às demais.

Uma vantagem dessa representação é permitir a visualização tanto estática quanto dinâmica do conjunto de dados através de sua aplicação associada com o Time Manager, componente responsável pelo gerenciamento de tempo, para apoiar a exploração visual de dados com atributos variantes no tempo. A representação dinâmica fornece uma boa visão global sobre a distribuição espacial dos valores do atributo vazão, pois permite visualizar e comparar o comportamento corrente entre as usinas em decorrer do tempo. Entretanto, uma grande desvantagem é não possibilitar a comparação visual das usinas, em relação à vazão, em diferentes momentos do tempo.

Para apoiar a realização de comparações de uma mesma usina em diferentes momentos, ou de diferentes usinas num mesmo momento, e considerando ainda o aspecto espacial dos dados, o componente 'Comparação Visual em Mapa' foi utilizado. Esse componente permite ao usuário analisar visualmente as transformações das taxas de vazões nas diversas usinas do conjunto de dados.

Nessa nova representação, as cores das usinas desenhadas no mapa, que antes representavam valores do atributo vazão, passaram a mapear diferenças calculadas, absolutas ou relativas, entre a taxa de vazão no momento atual e um determinado valor referencial. O tipo de referencial e o modo de comparação podem ser definidos pelo usuário através da interface do componente, explicados com detalhes em 3.3.4.

As figuras 4.2 e 4.3 mostram exemplos da comparação visual utilizando o modo Absoluto e Relativo, respectivamente. Ambos mapas retratam transformações da taxa de vazão nas usinas hidrelétricas, de junho de 1987 em relação a junho do ano anterior (1986). Pode-se observar que em 1987 a vazão cresceu em praticamente todas as usinas da região sul e na maioria do sudeste, crescimento representado pelo tom de azul. Diferentemente das usinas do norte e nordeste que diminuiram, fato indicado pelo tom de amarelo. O primeiro mapa (fig. 4.2) mostra que a transformação máxima absoluta, isto é, o crescimento máximo absoluto da taxa de vazão ocorreu principalmente nas usinas do rio Paraná: Itaipu e Porto Primavera. Já no segundo mapa (fig. 4.3), a distribuição das transformações relativas é um pouco diferente. O crescimento máximo relativo é observado nas usinas situadas nos rios Tiête e Paranapanema: Bariri, Barra Bonita, Ibitinga, Três Irmãos e Foz do Areia. Nos dois mapas, a transformação máxima é indicada por tom de azul mais escuro. Os valores exatos dessas usinas podem ser vistos na tabela 4.1. 


\begin{tabular}{|c|c|c|c|c|}
\hline $\begin{array}{c}\text { Usina } \\
\text { Hidrelétrica }\end{array}$ & $\begin{array}{c}\text { Vazão } \\
\text { Jun/1986 }\end{array}$ & $\begin{array}{c}\text { Vazão } \\
\text { Jun/1987 }\end{array}$ & $\begin{array}{c}\text { Diferença } \\
\text { Absoluta }\end{array}$ & $\begin{array}{c}\text { Diferença } \\
\text { Relativa }\end{array}$ \\
\hline Itaipu & 8281 & 13398 & 5117 & $61.7 \%$ \\
\hline Porto Primavera & 5188 & 7136 & 1948 & $37.5 \%$ \\
\hline Bariri & 218 & 918 & 700 & $252 \%$ \\
\hline Barra Bonita & 214 & 902 & 688 & $321.4 \%$ \\
\hline Capivara & 786 & 2706 & 1920 & $244 \%$ \\
\hline Foz do Areia & 346 & 1386 & 1040 & $300 \%$ \\
\hline Três Irmãos & 406 & 1242 & 836 & $205.9 \%$ \\
\hline
\end{tabular}

Tabela 4.1: Tabela com valores exatos das diferenças absoluta e relativa.

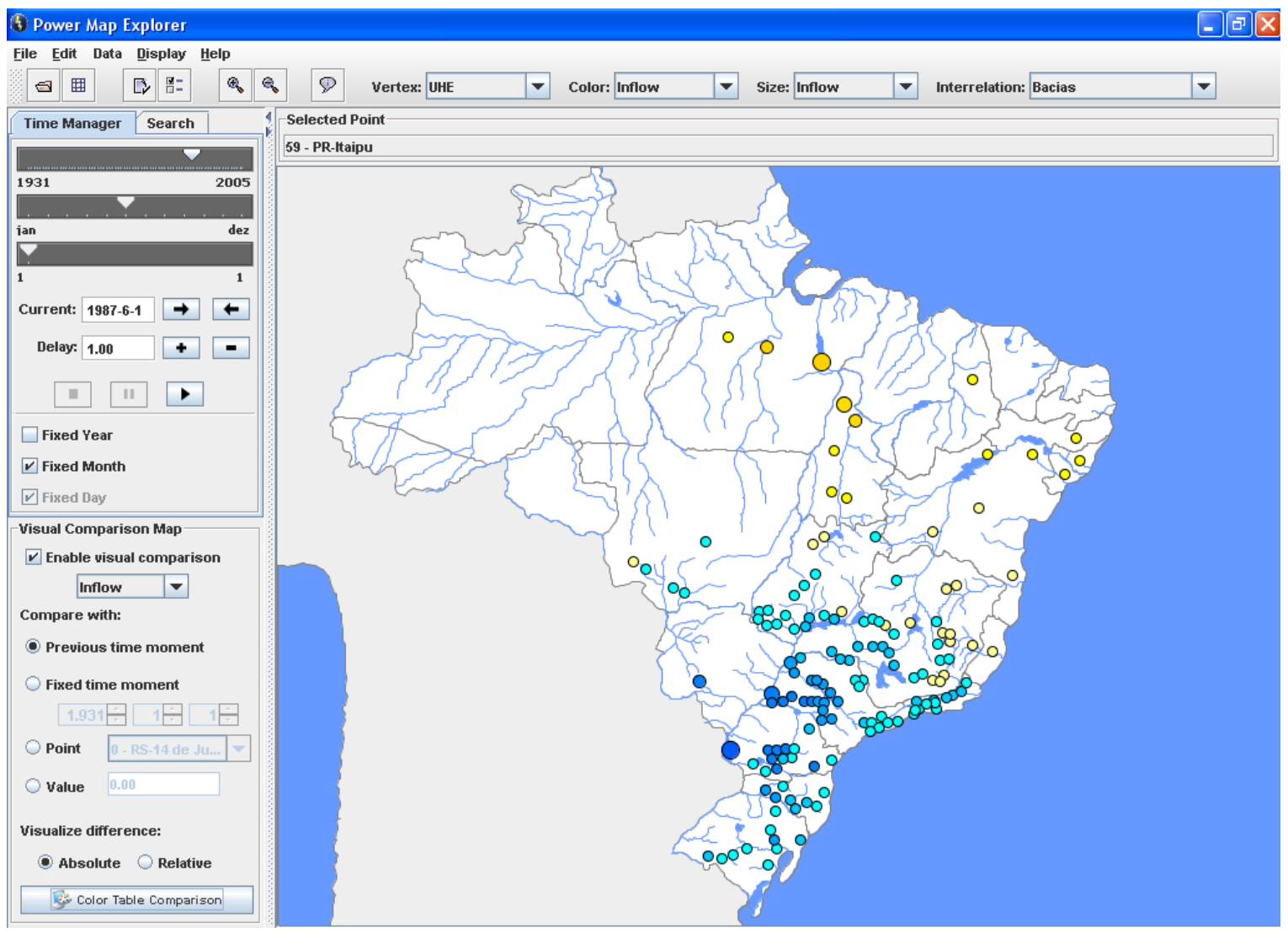

Figura 4.2: Análise das transformações nas taxas de vazão das usinas hidrelétricas do sistema: diferenças absolutas entre os meses de junho de 1987 e junho de 1986.

No decorrer dos testes percebeu-se que o componente 'Tabela de Dados' (figura 4.4) poderia atuar de forma complementar às representações anteriores, permitindo ao usuário analisar as transformações temporais do atributo vazão, também, em seu formato numérico. Assim, além das visualizações baseadas nos comportamentos e nas transformações correntes das usinas, uma verificação numérica desses valores poderia ser efetuada. 


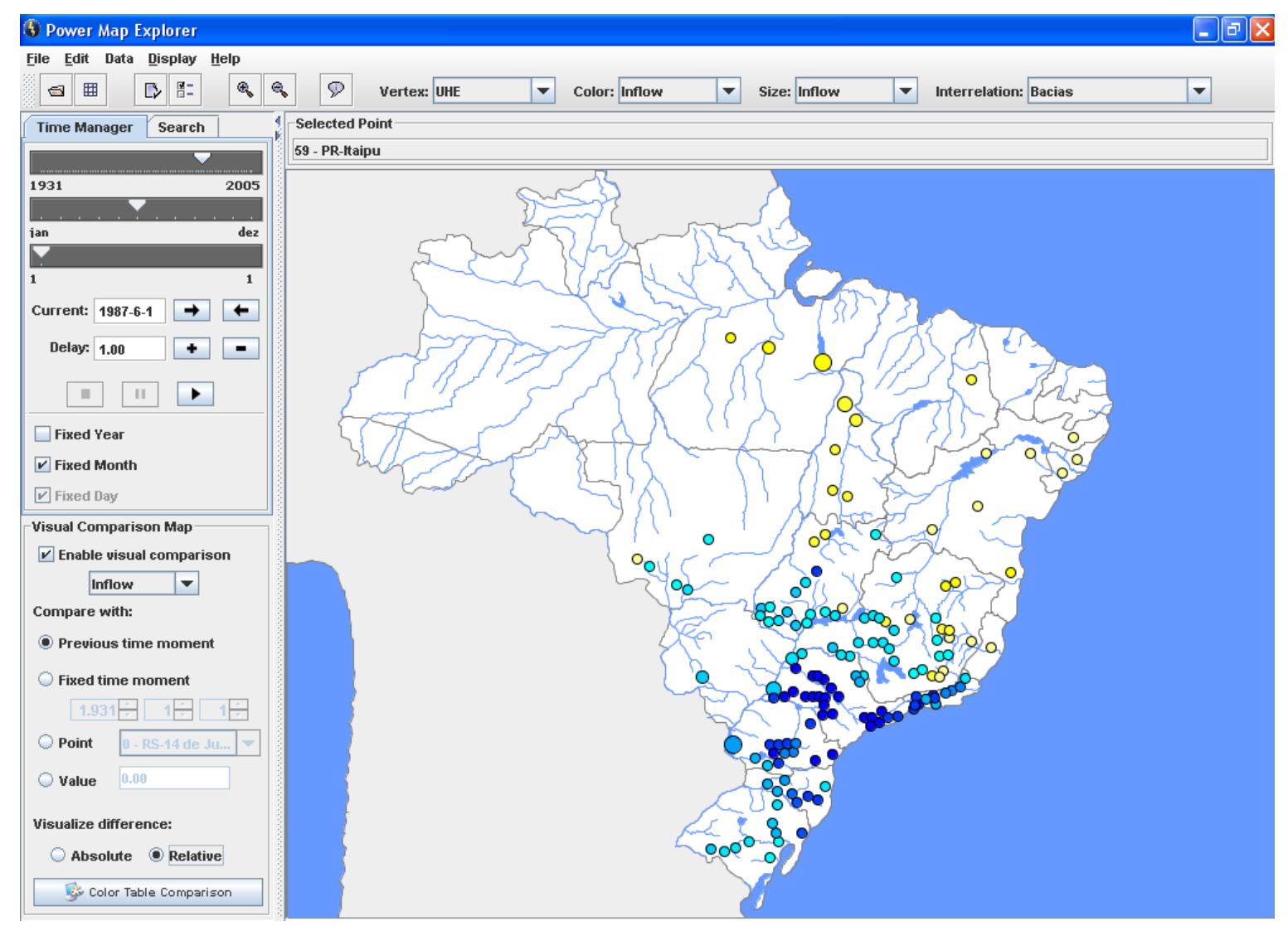

Figura 4.3: Análise das transformações nas taxas de vazão das usinas hidrelétricas do sistema: diferenças relativas entre os meses de junho de 1987 e junho de 1986.

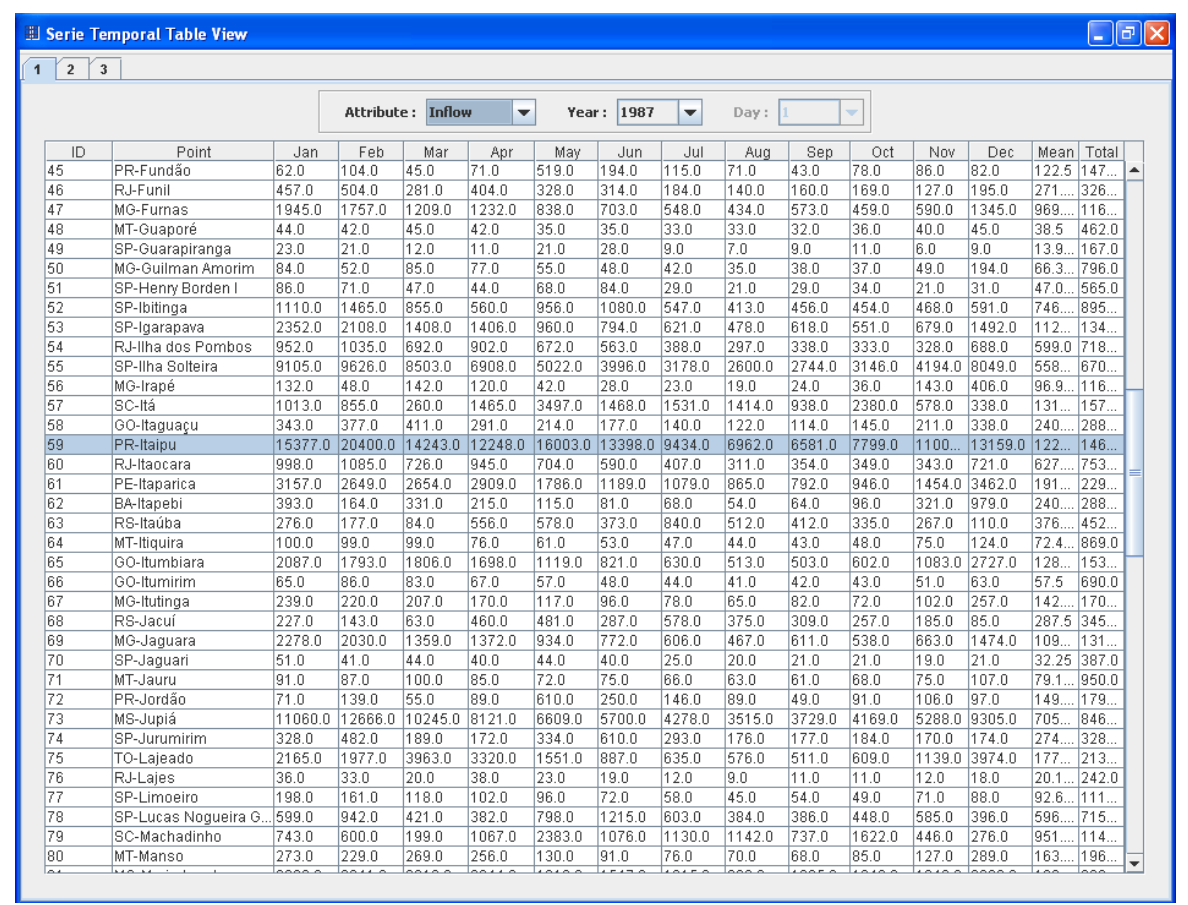

Figura 4.4: Verificação numérica dos comportamentos e das transformações correntes nas usinas. 


\subsubsection{Determinação de padrões, comportamentos e fenômenos embutidos nos dados}

As técnicas visuais utilizadas para execução da tarefa anterior são pouco apropriadas quando se deseja analisar o comportamento geral e os padrões existentes em cada usina em particular, e menos apropriadas para a comparação de comportamentos entre diferentes usinas.

Para efetuar o estudo do comportamento geral das vazões nas diversas usinas hidrelétricas do sistema de energia, a visualização dos dados em um gráfico de tempo foi apropriadamente usada. O comportamento de um atributo numérico aparece freqüentemente em tais gráficos na forma de uma linha, resultado da conexão da posição dos valores em sucessivos momentos de tempo. A figura 4.5 mostra o gráfico de tempo correspondente aos comportamentos do atributo 'vazão média' ocorrido na maioria das usinas hidrelétricas nos últimos 75 anos. Esta representação permite extrair duas informações sobre fases de cheias e de secas ocorridas durante esse período: (1) no princípio dos anos 80, aproximadamente entre os anos de 1983 e 1985, ocorreu um crescimento acentuado das taxas de vazões na maioria das usinas das regiões sul, sudeste e centro-oeste, resultado, provável, de um aumento das taxas de chuvas nesse intervalo; (2) em meados da década de 50, pode-se verificar a existência de um intervalo de estiagem que acarretou em quedas das taxas de vazões nas usinas.

Alternativamente, por meio da manipulação dos diversos recursos interativos do componente 'Gráficos Temporais', pode-se selecionar usinas, intervalos e escalas de tempo de interesse que possibilitassem investigar outras perspectivas nos dados. A figura 4.6 (a) mostra, por exemplo, o comportamento mensal da vazão nas usinas da bacia do rio Paraná durante os últimos 10 anos. Nota-se a existência de um comportamento padrão nesses anos, com altas taxas de vazão no inicio e final de cada ano e pequenas taxas no meio tempo. Uma outra informação, decorrente desse fato, refere-se a grande amplitude de variação da taxa de vazão entre os períodos do ano para as grandes usinas. Essa última informação é retratada melhor na figura 4.6 (b), que apresenta o comportamento das usinas de Itaipu, representada pela linha de cor verde, e Furnas, representada pela cor preta. Verifica-se que a variância para a usina de Itaipu é muito maior que a de Furnas.

Um outro recurso gráfico presente no componente 'Gráficos Temporais' permitiu analisar e comparar os comportamentos anuais de cada usina hidrelétrica individualmente. A figura 4.7 mostra o gráfico de tempo para a usina hidrelétrica de Tucuruí. Diferentemente da representação gráfica anterior, cada linha nesse gráfico corresponde ao comportamento de um ano específico. Essa representação torna claro e confirma o padrão existente durante os anos, ou seja, altas taxas de vazão no início e no final de cada ano, justificado pelo período mais intenso de chuvas, e baixas taxas no meio do ano, devido ao período 


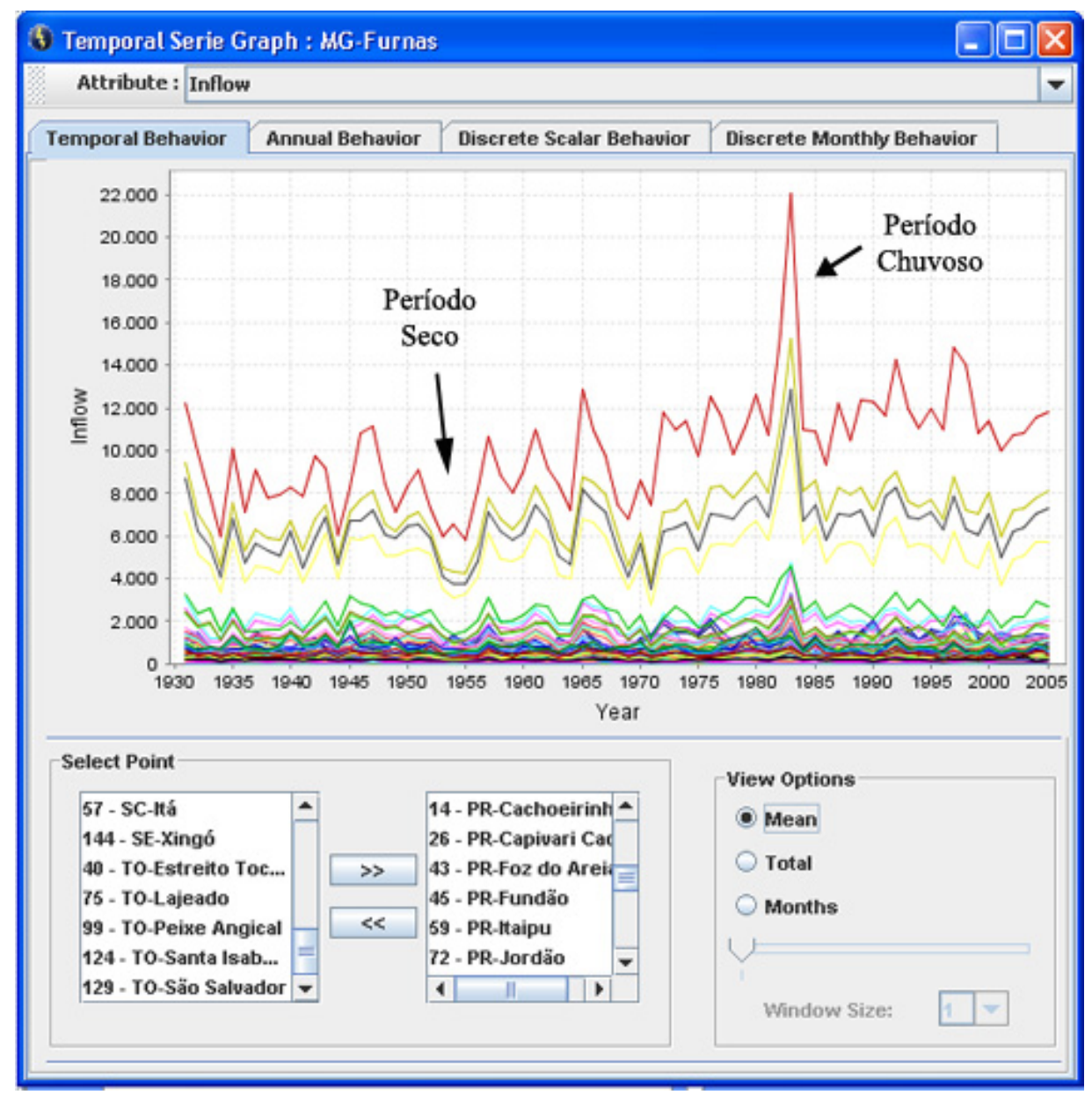

Figura 4.5: Vazão média nas usinas hidrelétricas para os últimos 75 anos.

menos intenso. Essa informação pode também ser confirmada pela visualização de comportamentos de outras usinas hidrelétricas utilizando essa mesma representação.

Uma adaptação dos gráficos de bar charts e pie charts permitiu analisar a distribuição discreta mensal dos valores do atributo vazão. A figura 4.8 mostra, por exemplo, duas perspectivas diferentes de visualização para a usina de Sobradinho. A representação (a) ilustra o comportamento discreto da taxa de vazão no mês de janeiro para os 75 anos em análise. No caso específico de vazões, esse tipo de representação pode ser considerado bastante apropriado para o processo de exploração, pois permite comparar meses com características climáticas semelhantes. Já através da representação (b), pode-se observar a distribuição discreta da vazão nos diferentes meses do ano de 2003. Nela, os meses iniciais (janeiro, fevereiro e março) contabilizam mais da metade da vazão ocorrida durante o ano. Além disso, tal estratégia de representação pode ajudar a confirmar o padrão existente durante os anos, mencionado anteriormente. 


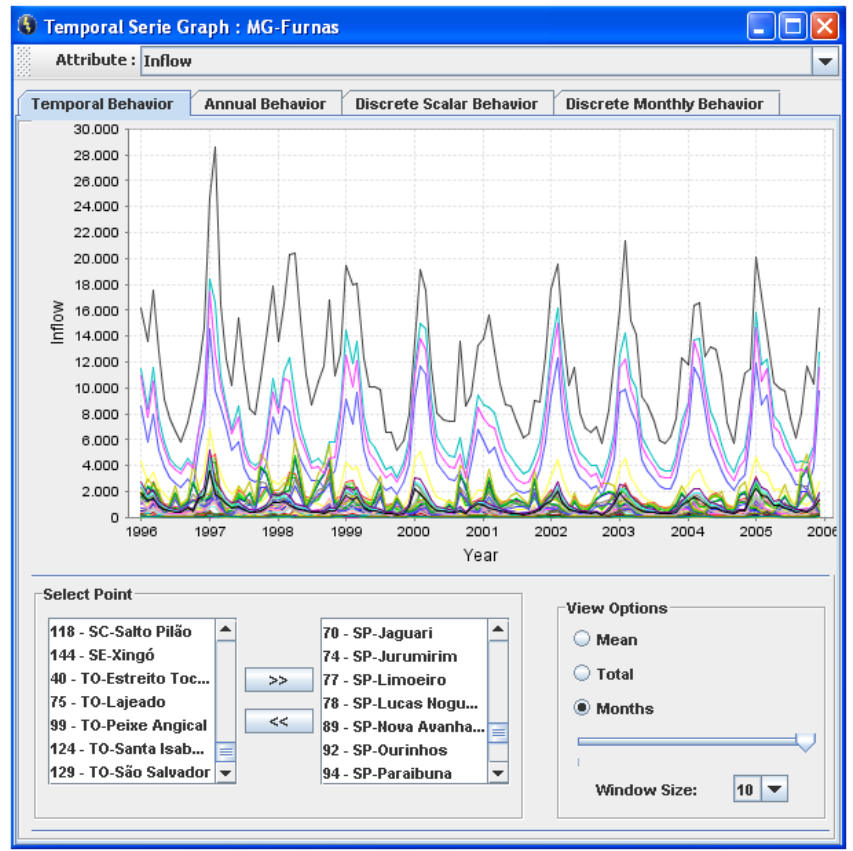

(a)

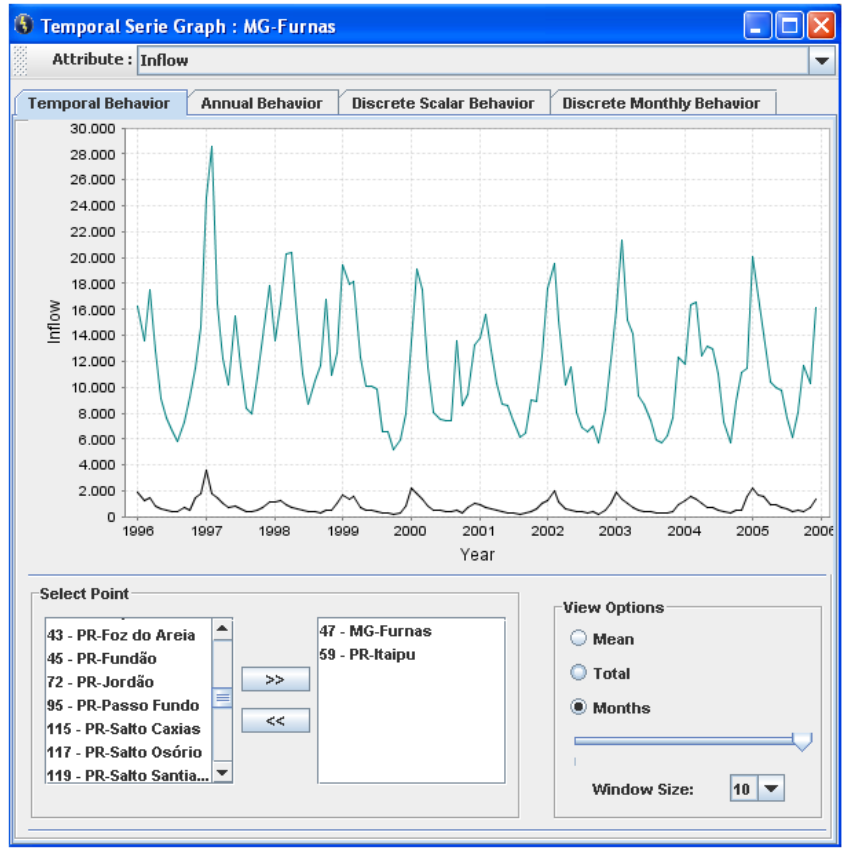

(b)

Figura 4.6: Vazão mensal nas usinas hidrelétricas da Bacia Hidrográfica do rio Paraná durante os últimos 10 anos.

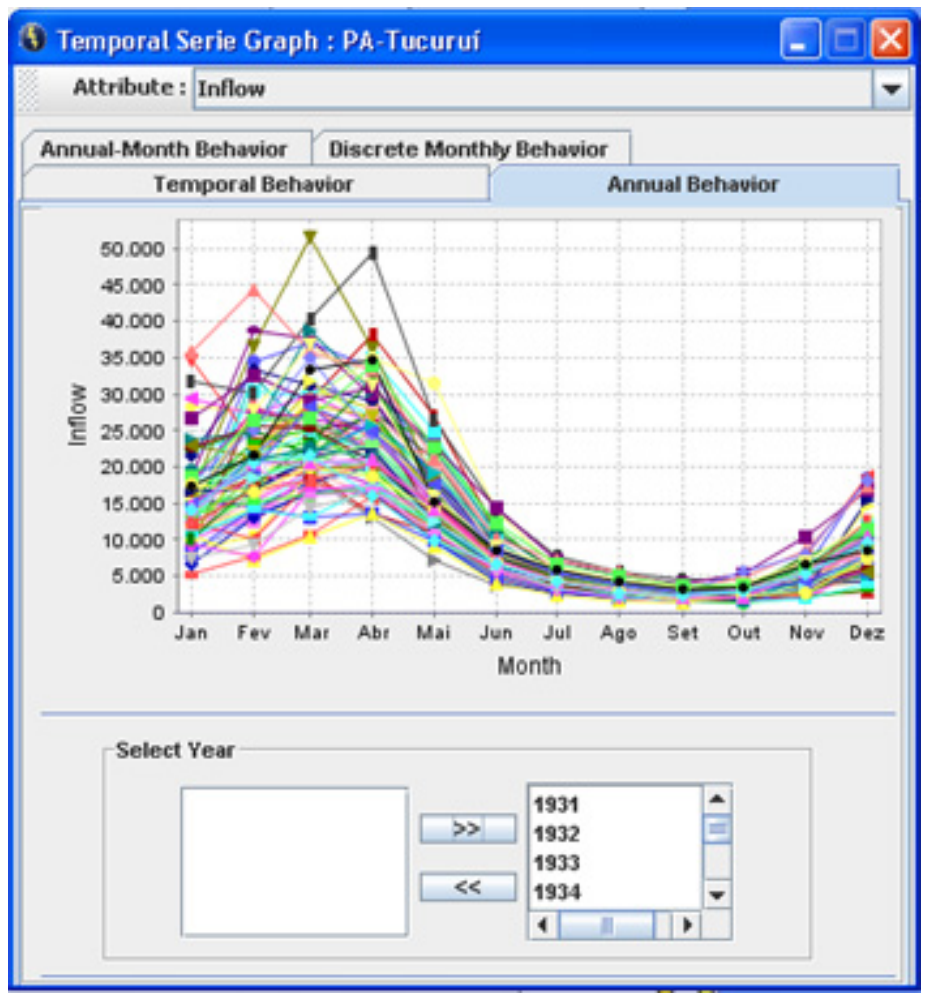

Figura 4.7: Comportamentos anuais da usina de Tucurui. 


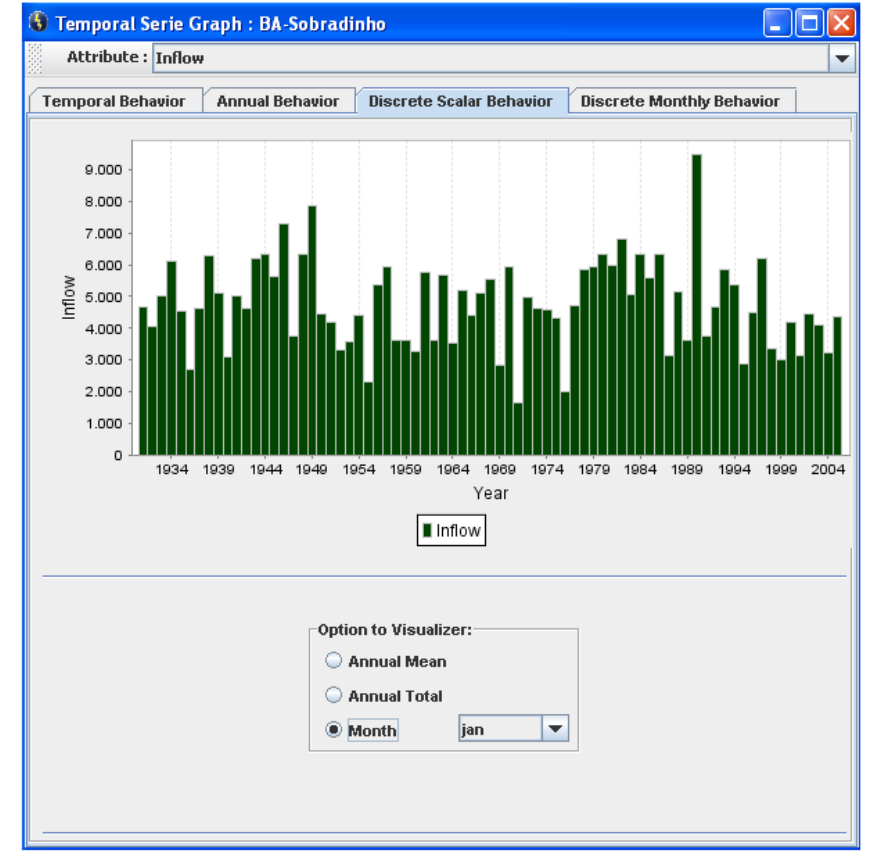

(a)

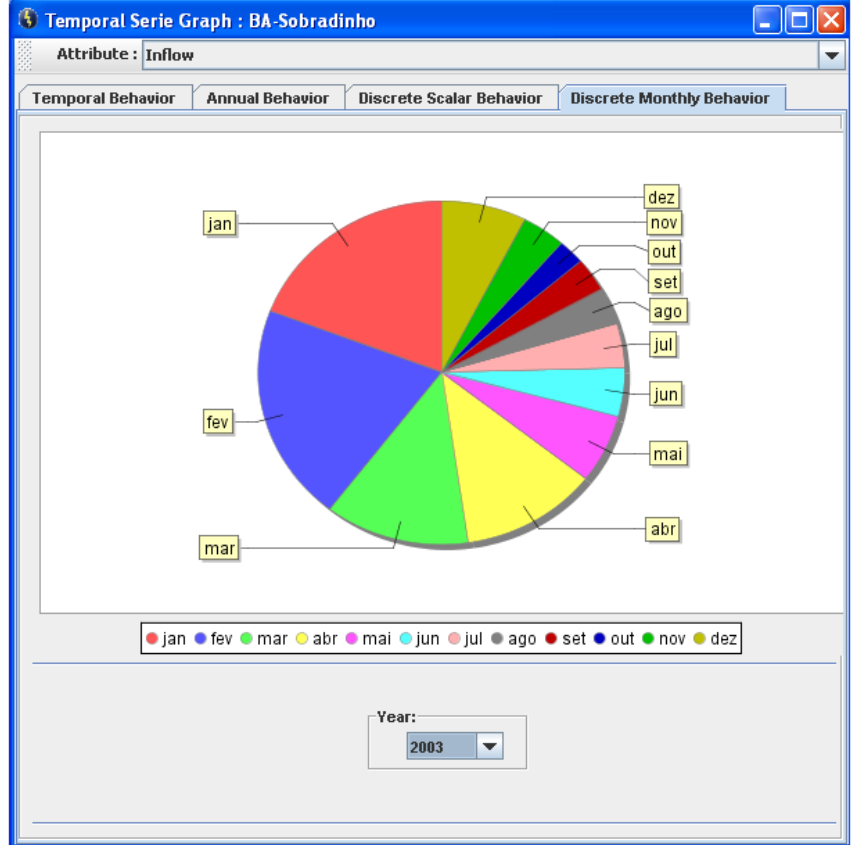

(b)

Figura 4.8: Distribuição discreta mensal do atributo vazão para a usina de Sobradinho. (a) Variação do mês de janeiro para os 75 anos em análise. (b) Discretização da vazão nos 12 meses do ano de 2003.

\subsubsection{Detecção de similaridades entre usinas}

Para a execução desta tarefa, foram avaliadas quais estratégias de visualização poderiam ser úteis para sua conclusão. Assim, três diferentes componentes funcionais desenvolvidos no Power Map Explorer foram selecionados: 'Comportamento Local', 'Variação Uni-Escala' e 'Projeção por Similaridades'.

O componente 'Comportamento Local' possibilitou a verificação de similaridades entre as diversas usinas hidrelétricas do conjunto de dados através da comparação visual de seus comportamentos por meio de gráficos de tempo especiais plotados sobre o mapa. A figura 4.9 mostra, por exemplo, o comportamento anual do atributo vazão em cada usina hidrelétrica. A representação permite visualizar como diferentes comportamentos anuais estão distribuídos sobre o mapa. Através de uma inspeção visual mais apurada, pode-se detectar usinas com comportamentos anuais parecidos, verificando a formação de agrupamentos regionais nos dados.

Pode-se especular que esses agrupamentos observados podem ter sido influenciados por dois possíveis fatores: (1) mesma variação pluviométrica anual em diferentes regiões; (2) influência da vazão de uma usina nas demais usinas localizadas sobre o mesmo rio. No entanto, acredita-se que o comportamento de uma usina ou de várias usinas deva sofrer várias outras influências não analisadas aqui. Entretanto, essas observações podem sugerir hipóteses sobre o funcionamento do sistema. 


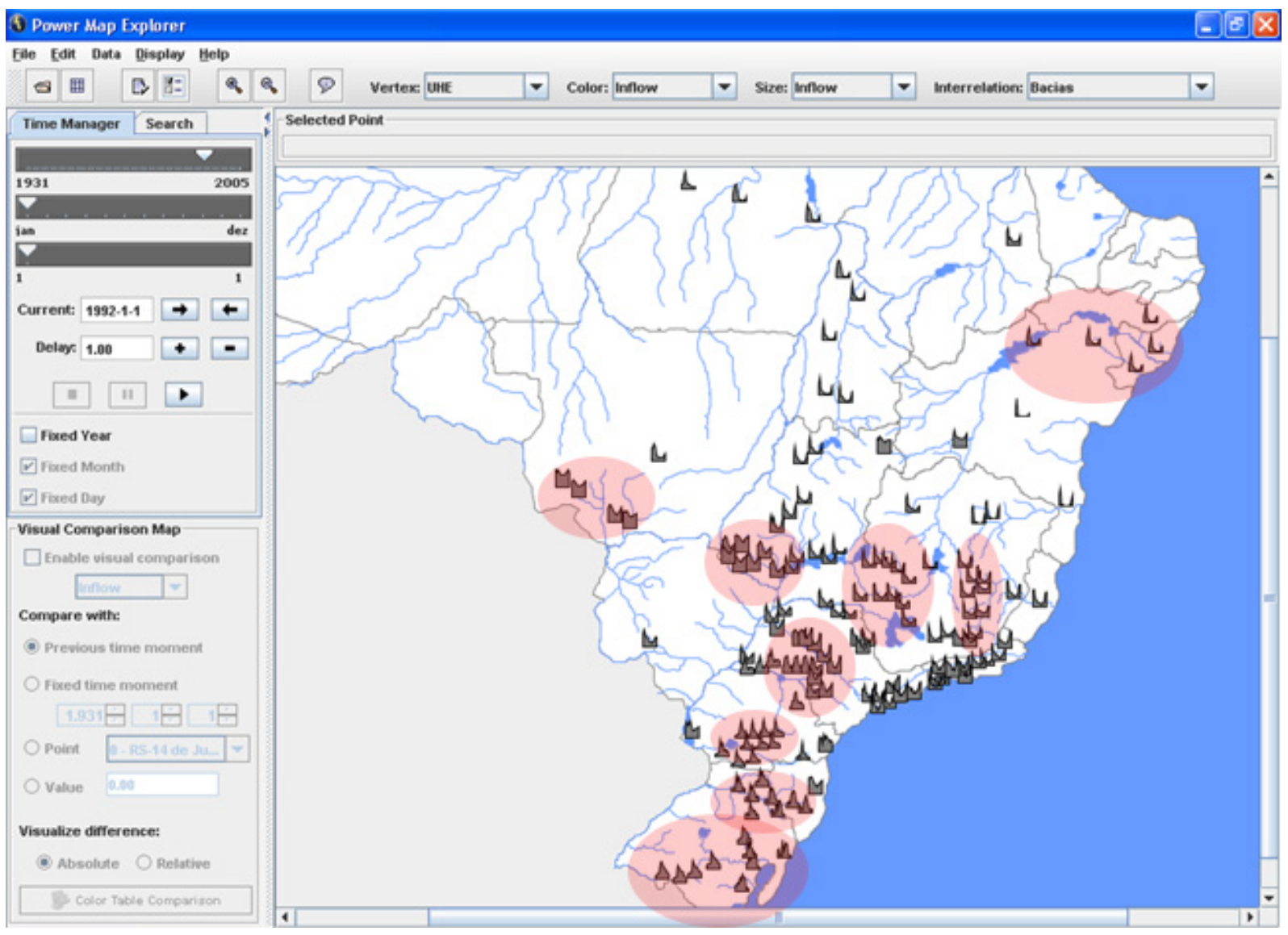

Figura 4.9: Comportamento anual das usinas hidrelétricas para o atributo vazão no ano de 1992.

Ainda com relação ao componente 'Comportamento Local', sua utilização associado ao Time Manager possibilita a visualização dinâmica dos comportamentos anuais distribuídos sobre o território. Entretanto, um ponto crítico é a baixa legibilidade para conjunto de dados com objetos espaciais muito próximos e séries temporais relativamente grandes, que é o caso dos dados de vazões.

Alternativamente, o componente 'Variação Temporal Uni-Escala' é bastante apropriado para a visualização e comparação de séries temporais relativamente longas. Esse recurso permite comparar, simultaneamente, comportamentos entre diferentes usinas em diferentes momentos do tempo. A figura 4.10 exibe os comportamentos mensais dos últimos 30 anos para as usinas da bacia do rio São Francisco. Nesta representação, cada linha corresponde a uma usina hidrelétrica e cada coluna a um ano. Os valores mensais referentes a cada ano são representados por pontos coloridos dispostos na forma de elementos retangulares (ordenados de cima para baixo e da esquerda para direita). A tabela de cor que mapeia os valores mensais de vazão é exibida na parte inferior da figura. Analisando as oito usinas mapeadas na representação e comparando-as entre si, pode-se verificar a formação de três grupos distintos de comportamentos similares: (1) Paulo Afonso, Itaparica, Moxotó, Sobradinho e Xingó (representados pelas linhas com 
predominância das cores azul e vermelho); (2) Três Marias (representado pela linha com a presença da cor laranja); (3) Queimado e Sacos (representados pelas linhas com abundância de amarelo). Essa constatação pode ser ainda confirmada pela visualização desses mesmos comportamentos através dos gráficos de tempo.

Uma percepção decorrente dos testes de uso até este momento é que a tabela de cores utilizada para o mapeamento da taxa de vazão deve apresentar uma variação de cores capaz de facilitar a percepção das diferenças ou semelhanças entre as usinas, contribuindo para realçar comportamentos similares e padrões, por exemplo.

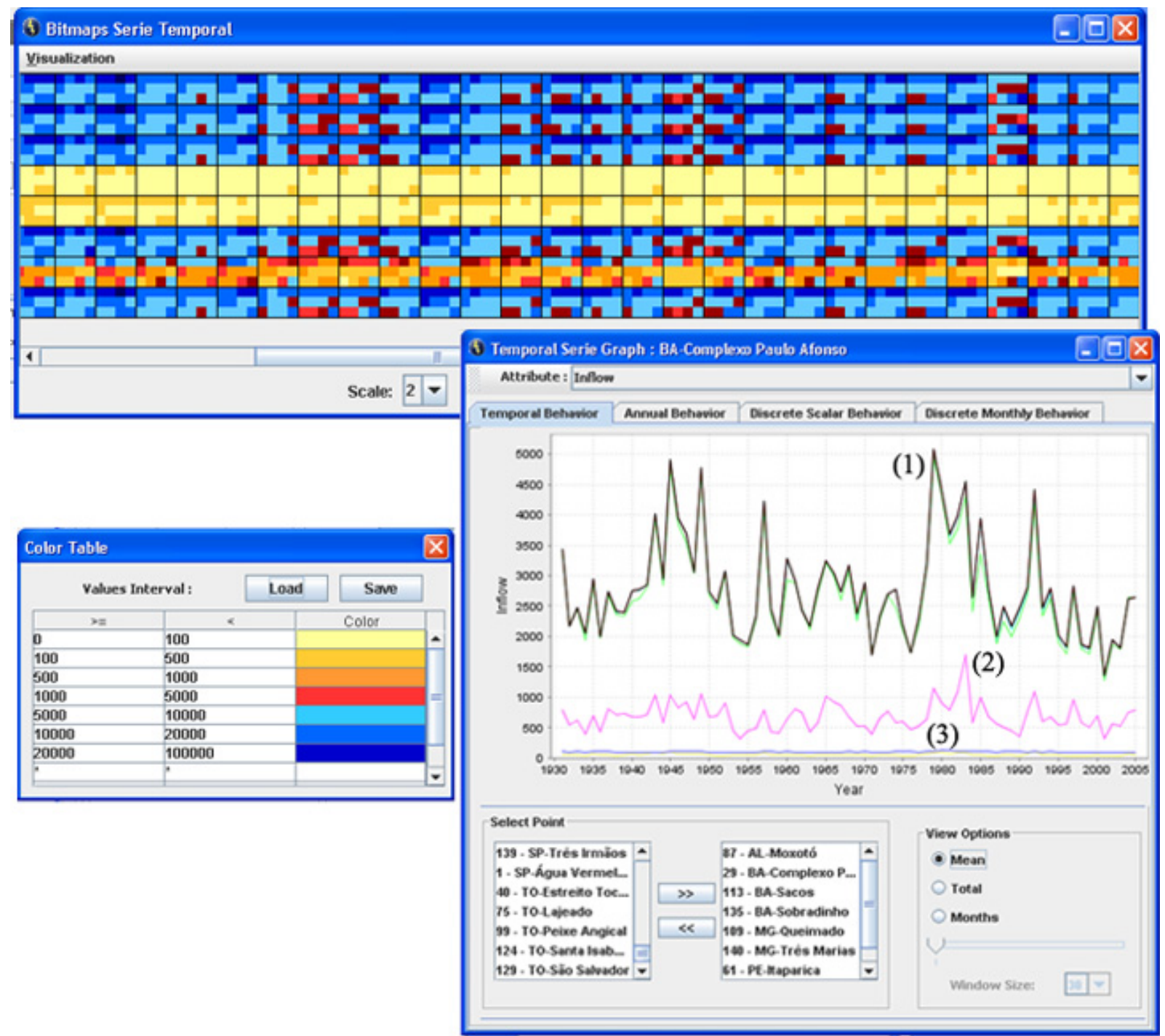

Figura 4.10: Comportamento anual das usinas hidrelétricas para o atributo vazão no ano de 1992.

Por último, e diferentemente dos anteriores, o componente 'Projeção por Similaridades' compara e agrupa automaticamente usinas com comportamentos temporais parecidos segundo uma métrica de similaridade pré-estabelecida. Como resultado, uma representa- 
ção planar é gerada, projetando cada usina como um círculo, de forma que, quanto maior a proximidade dos círculos, maior o grau de similaridades entre eles.

As figuras 4.11 e 4.12 mostram duas projeções geradas para dados de vazões utilizando as métricas CDM e distância euclidiana, respectivamente. A primeira exibe os agrupamentos resultantes da comparação dos comportamentos das usinas da bacia do rio São Francisco. Percebe-se claramente a formação dos mesmos três grupos distintos também observados na representação anterior. A segunda ilustra os agrupamentos formados a partir da projeção das usinas da bacia do rio Paraná. Pode-se observar a formação de três grupos de usinas com comportamentos parecidos: (1) Itaipu (representado pelo tom de azul); (2) Porto Primavera, Jupiá e Ilha Solteira (representados pelo tom de verde); (3) demais usinas (representados pelo tom de vermelho). Essa representação retrata a notável distinção das usinas dos grupos (1) e (2) em relação às do grupo (3). Para a geração das projeções, todo o intervalo de tempo foi considerado, diferentemente das estratégias anteriores que apenas tratavam parte representativa dele.

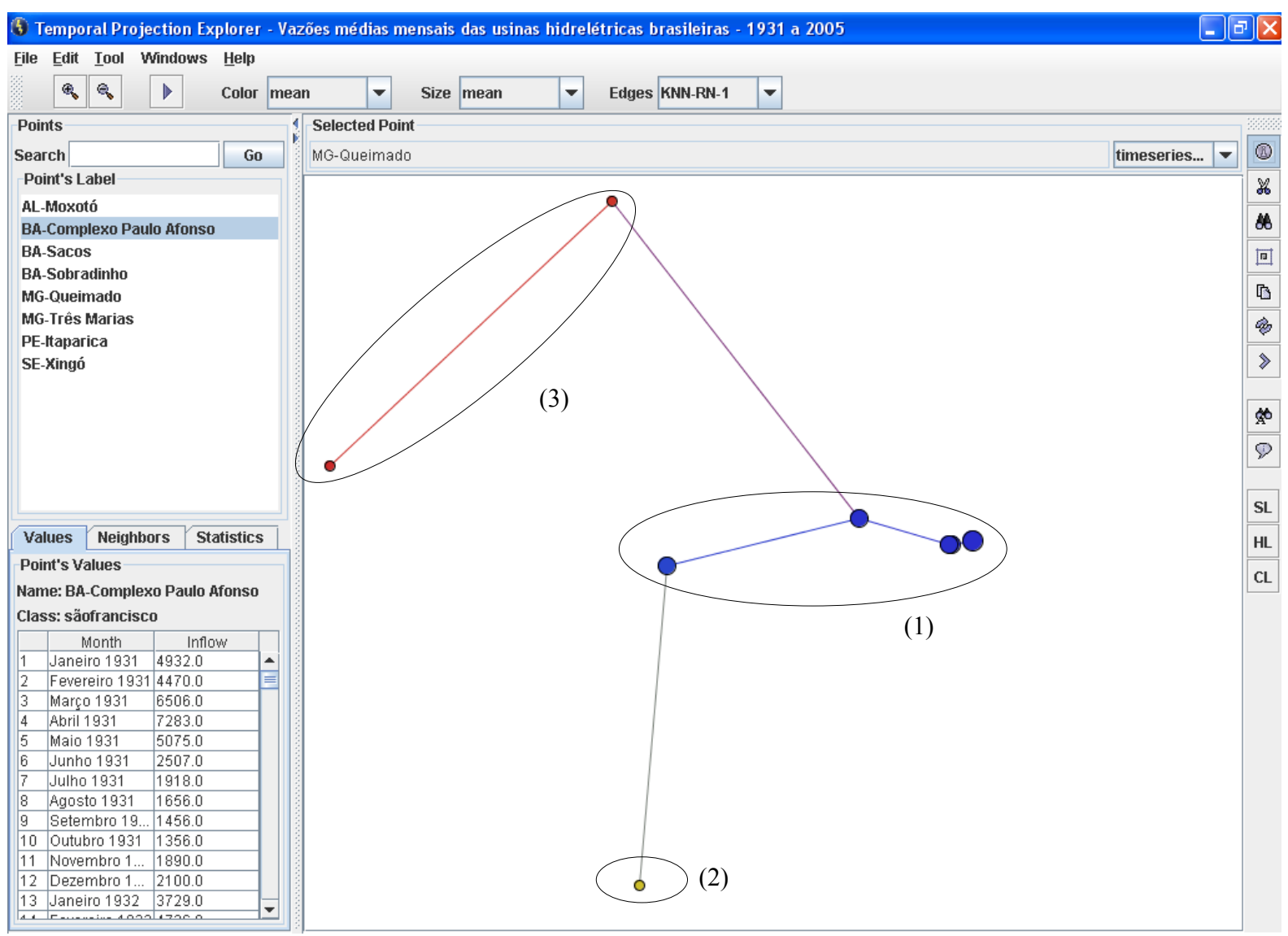

Figura 4.11: Agrupamentos das usinas da bacia do rio São Francisco segundo a CDM. 


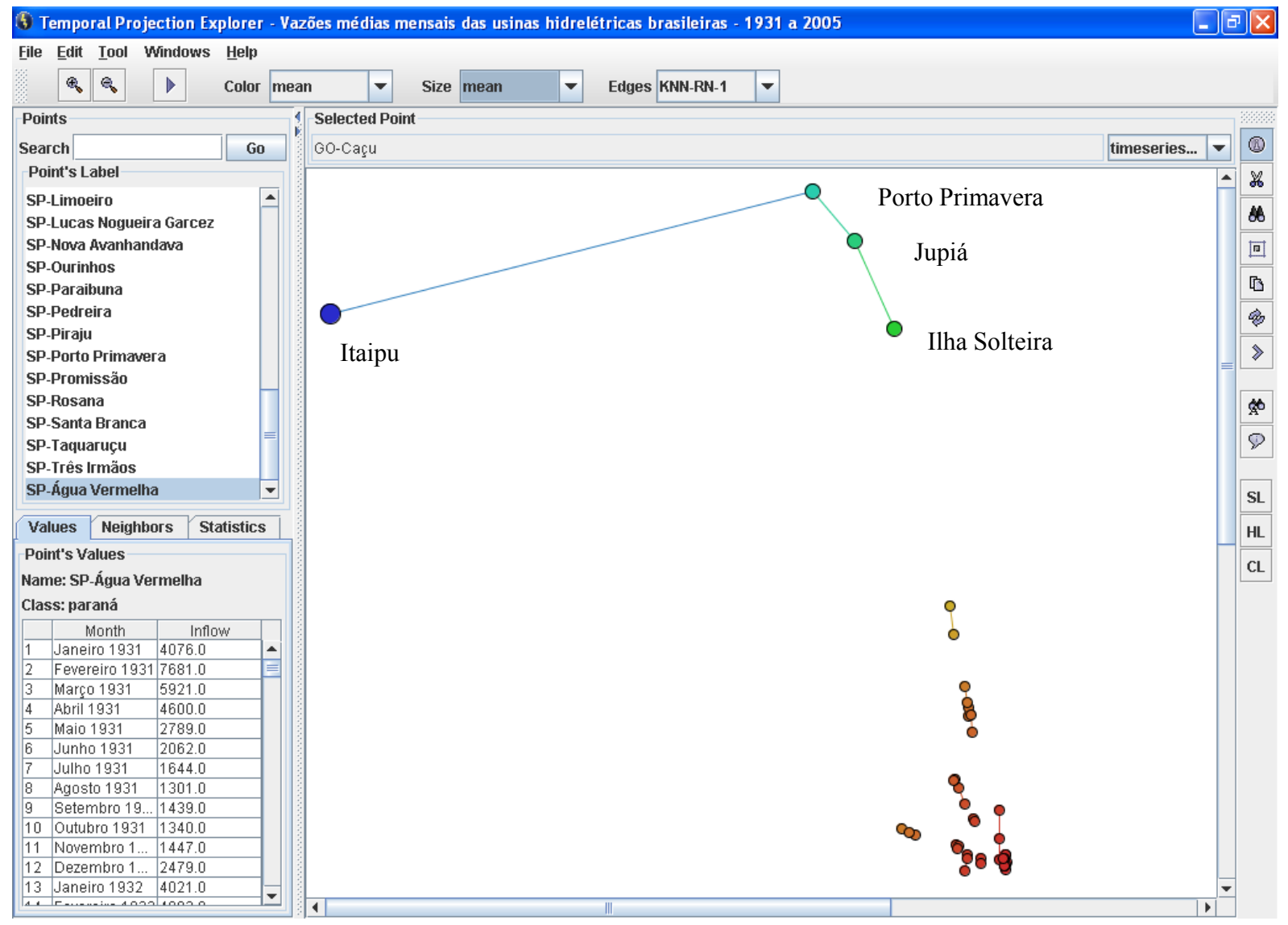

Figura 4.12: Agrupamentos das usinas da bacia do rio Paraná segundo a medida Euclidiana.

\subsection{Previsão de Vazões Mensais}

Nesta seção são apresentadas algumas previsões realizadas utilizando os modelos autoregressivos e periódicos auto-regressivos implementados no sistema, a fim de validar o ambiente computacional utilizado para o processamento dos modelos, bem como os componentes gráficos e os recursos interativos desenvolvidos para apoiar o processo de visualização e manipulação dos dados previstos.

Para efeito de testes de uso, utilizou-se, como exemplo, os dados de vazões mensais da usina hidrelétrica de Sobradinho, localizada no rio São Francisco. A seguir é apresentado um exemplo completo de previsões utilizando os quatro modelos disponíveis, e alguns recursos interativos que podem ser utilizados pelo usuário no processo de interpretação das informações geradas.

\subsubsection{Análise e Previsão dos Dados de Vazão para Sobradinho}

Para a análise inicial desses dados, utilizou-se um componente gráfico desenvolvido especialmente para a visualização de algumas propriedades estatísticas importantes da 
série de vazões. A figura 4.13 mostra o componente constituído pelos gráficos de média, desvio padrão, coeficiente de variação e variância versus média. Estes gráficos possibilitam realizar um estudo estatístico preliminar sobre a natureza da série hidrológica, caracterizando seu comportamento e sugerindo informações sobre os modelos de séries temporais que podem ser ajustados aos dados. Por exemplo, no caso dos gráficos de média e desvio padrão da figura, pode-se notar o comportamento periódico dos dados de vazões de Sobradinho, isto é, a característica sazonal existente na série. Esse tipo de comportamento representa um caso particular de não estacionariedade da série, e requer modelos adequados para tratar tal característica, como por exemplo, formulações auto-regressivas cujos parâmetros apresentam comportamento periódico.

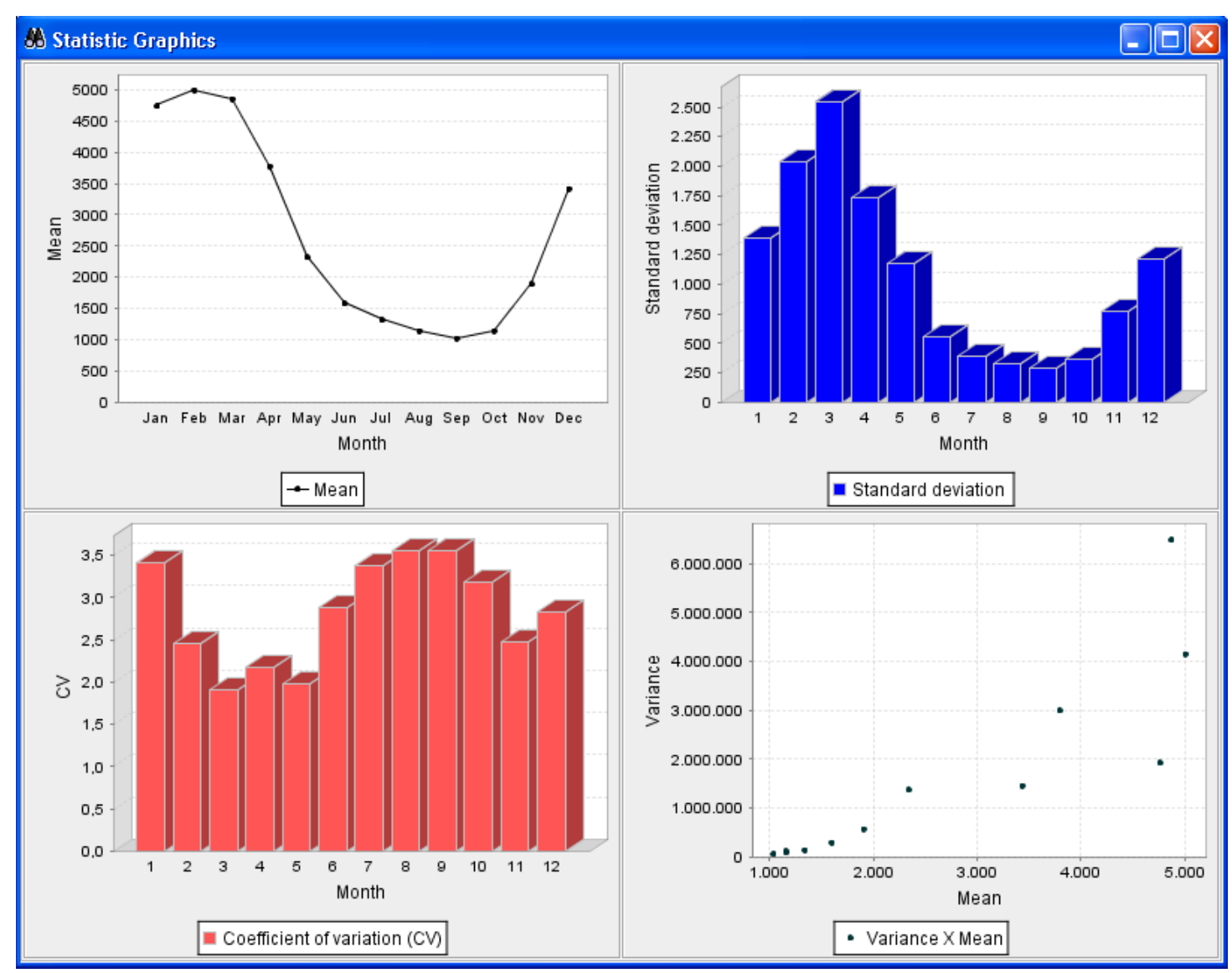

Figura 4.13: Gráficos de média, desvio padrão, coeficiente de variação e de variância versus média para os dados de vazões da usina hidrelétrica de Sobradinho.

Tendo em vista informações sobre o comportamento estatístico da série, o próximo passo no processo de previsão consiste em definir os parâmetros que são utilizados para a execução do processo, isto é, o modelo utilizado e os parâmetros de entrada do modelo. Para efeito de exemplos, foram realizadas previsões com os quatro modelos, adotando os seguintes parâmetros de entrada: intervalo de 1990 a 1995, ordem máxima do modelo igual a 10 e passo de realimentação igual a 3. As figuras 4.14 e 4.15 ilustram os resultados 


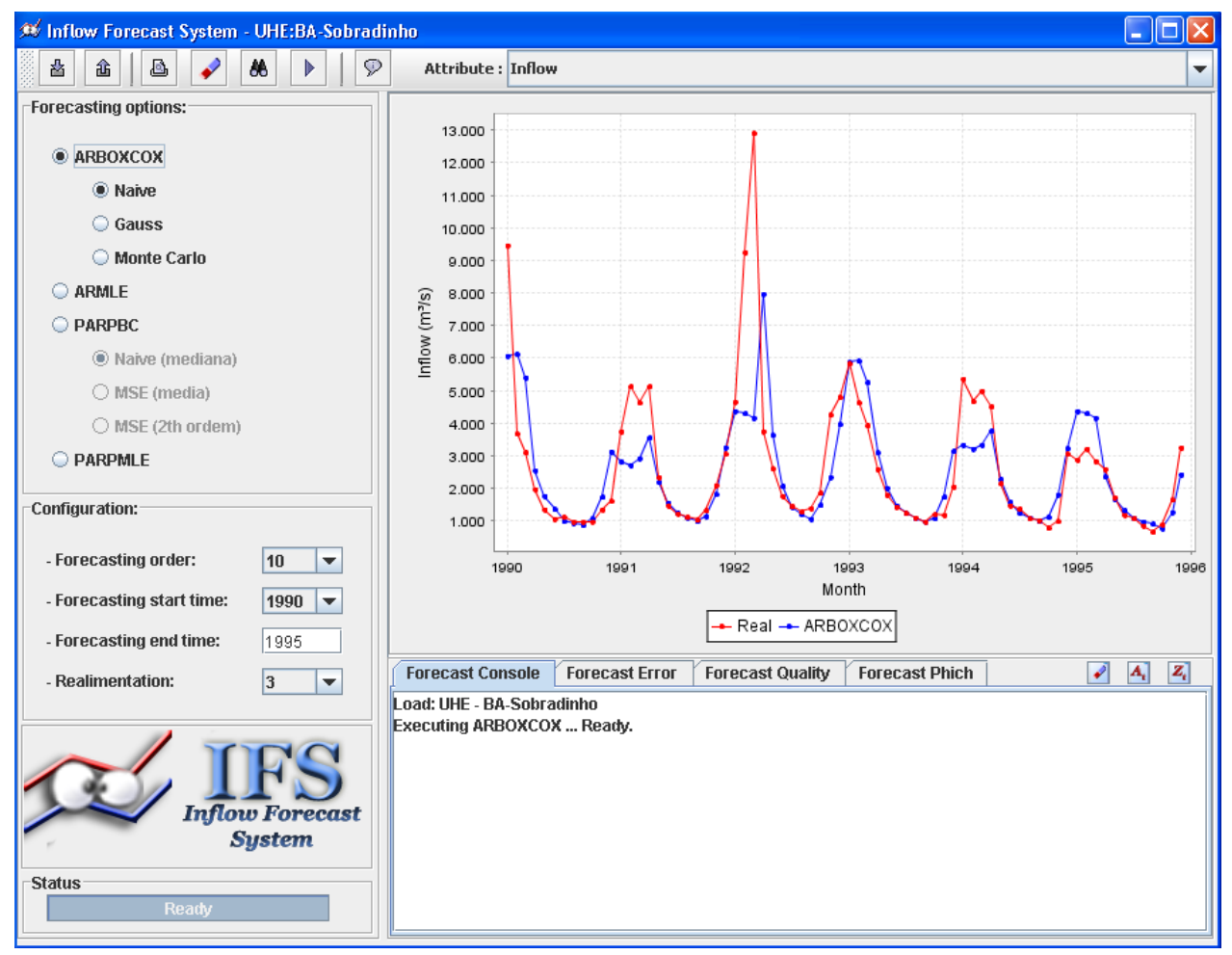

Figura 4.14: Séries prevista (em azul) e observada (em vermelho) a partir da previsão pelo modelo ARBOXCOX.

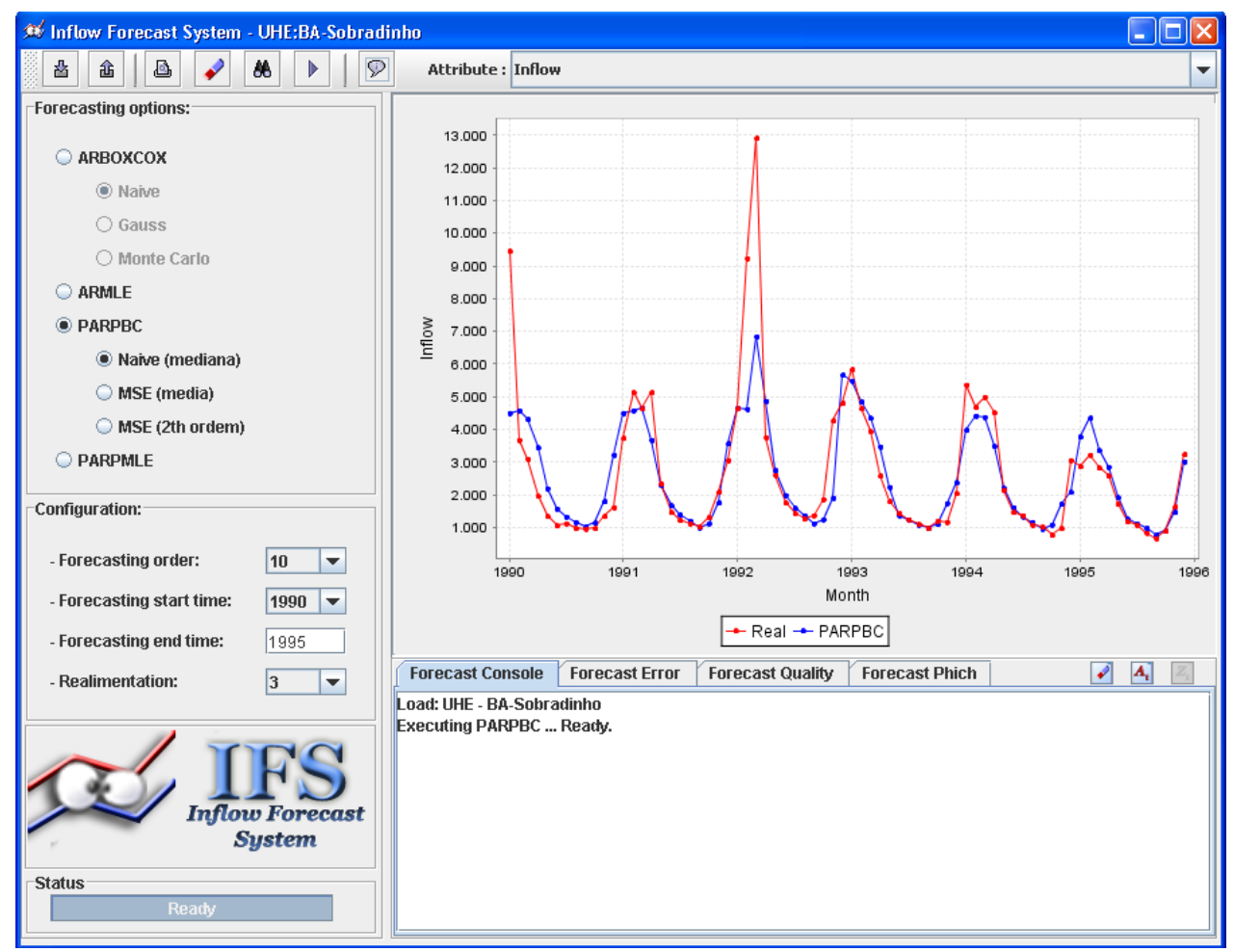

Figura 4.15: Séries prevista (em azul) e observada (em vermelho) a partir da previsão pelo modelo PARPBC. 
gerados a partir das previsões pelos modelos ARBOXCOX e PARPBC, respectivamente. As séries prevista e observada são apresentadas através dos tradicionais gráficos de tempo, tipicamente utilizados para observação de séries temporais. Nos dois gráficos, as séries previstas são representadas pelas linhas de cor azul, enquanto que as séries originais são representadas pelas linhas de cor vermelha. Essa estratégia de representação aumenta a percepção do usuário especialista sobre a qualidade inicial da previsão, pois permite a comparação visual do previsto em relação ao originalmente observado.

Alguns mecanismos de interação são implementados sobre essa representação gráfica a fim de auxiliar o especialista nos procedimentos de investigação visual. Um deles é o zoom, que permite selecionar intervalos específicos diretamente no gráfico através do mouse. Uma outra forma alternativa de interação possibilita visualizar sobre o mesmo gráfico de tempo as séries previstas para os diferentes modelos. Por exemplo, a figura 4.16 mostra o gráfico de tempo com as séries previstas para os modelos ARBOXCOX, ARMLE, PARPBC e PARPMLE, em conjunto a série original.

Além dessas informações, outros dados que podem ser visualizados são: a série padronizada $z_{t}$ e os resíduos $a_{t}$. A série padronizada $z_{t}$ é oriunda da padronização dos dados reais, já os resíduos $a_{t}$ são informações resultantes do processo de ajuste do modelo durante a etapa de previsão. Para os modelos da classe PAR são disponibilizados para a visualização apenas os resíduos $a_{t}$, enquanto que para os modelos da classe AR ambos são disponibilizados. A figura 4.17 mostra os componentes gráficos utilizados para a visualização desses dados gerados pela previsão com o modelo ARBOXCOX. Essas representações revelam ao especialista informações técnicas sobre o processo de ajuste do modelo durante a etapa de previsão, contribuindo, desta forma, para a escolha mais adequada da ordem do modelo de previsão. Resumidamente, os gráficos de autocorrelação e autocorrelação parcial auxiliam o usuário a definir a ordem mais adequada para modelo. Já o histograma e o gráfico de normal plot indicam quanto esses dados se aproximaram da distribuição gaussiana.

Por último, os dados sobre a qualidade, erro e o phich da previsão são apresentados em tabelas. A figura 4.18 mostra, por exemplo, as tabelas extraídas da interface principal do módulo, compostas por valores referentes a esses dados gerados pelo modelo ARBOXCOX. Os dados sobre a qualidade e erro denotam numericamente a precisão da previsão através da comparação entre os dados previstos e originais. Já os valores referentes ao phich revelam informações a respeito dos parâmetros de ajuste do modelo. 


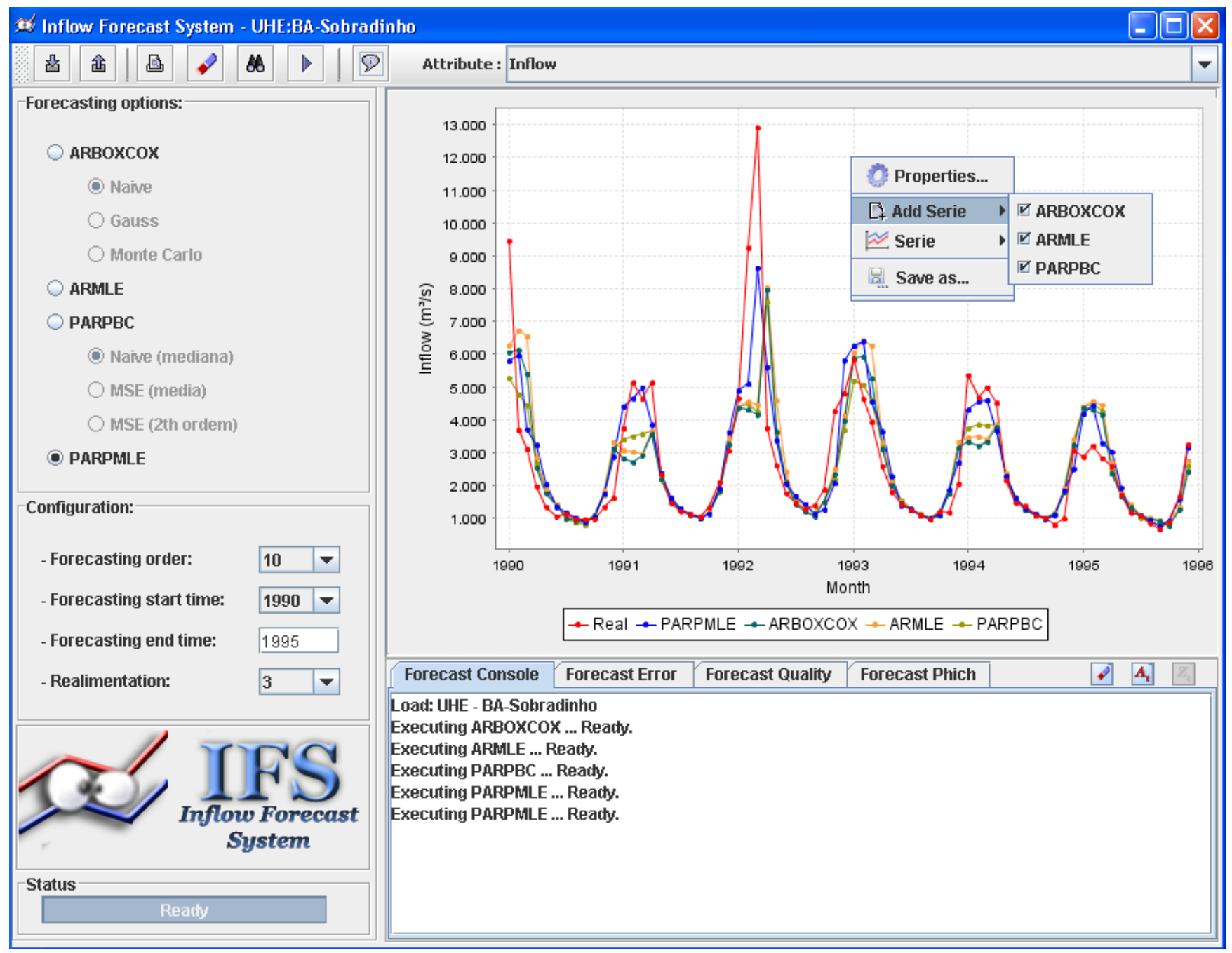

Figura 4.16: Gráfico de tempo com as séries previstas pelos modelos PARPMLE, PARPBC, ARMLE e ARBOXCOX, mais a série original. 

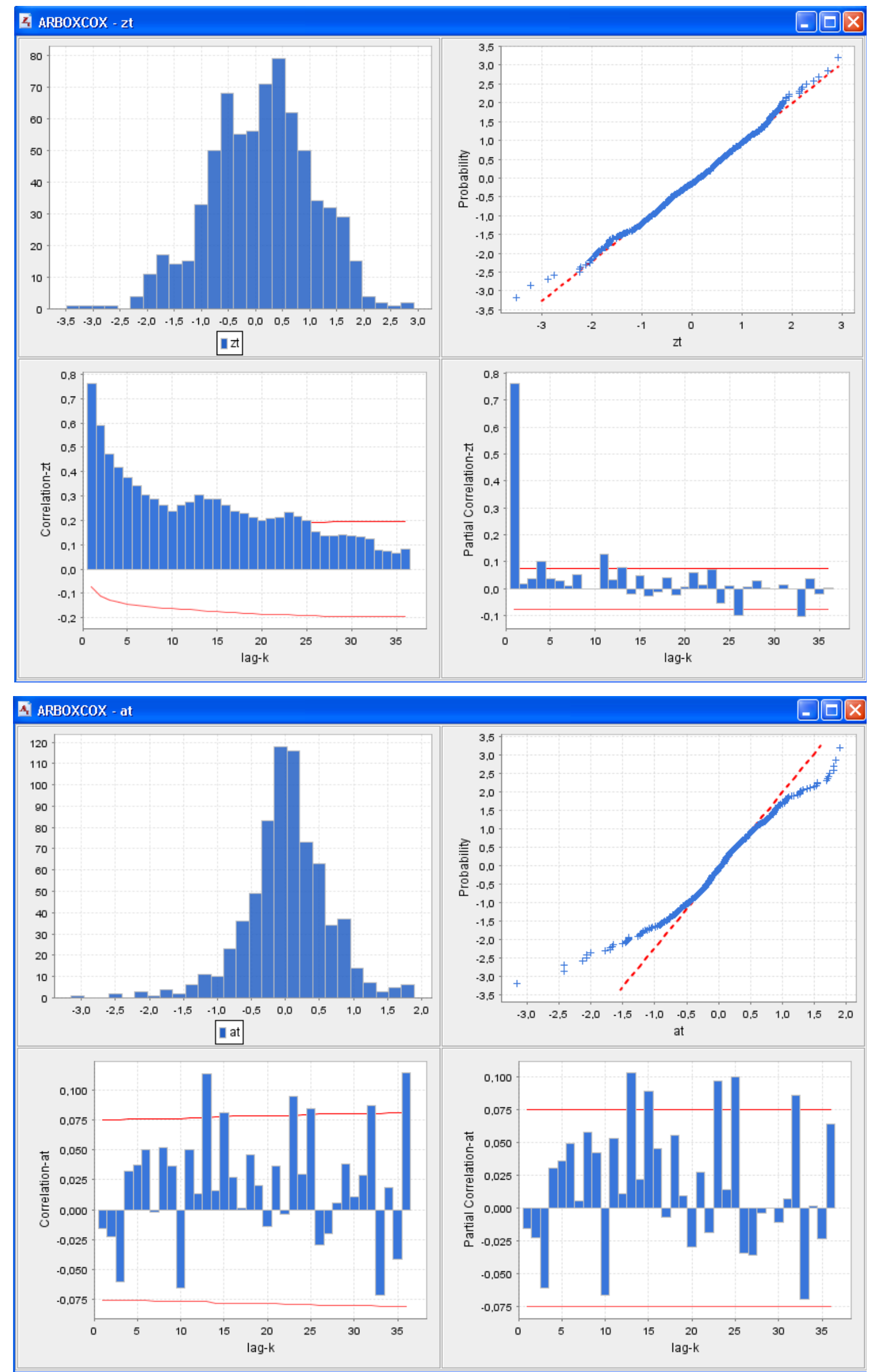

Figura 4.17: Gráficos da série padronizada $z_{t}$ e dos resíduos $a_{t}$ gerados pelo modelo ARBOXCOX. 


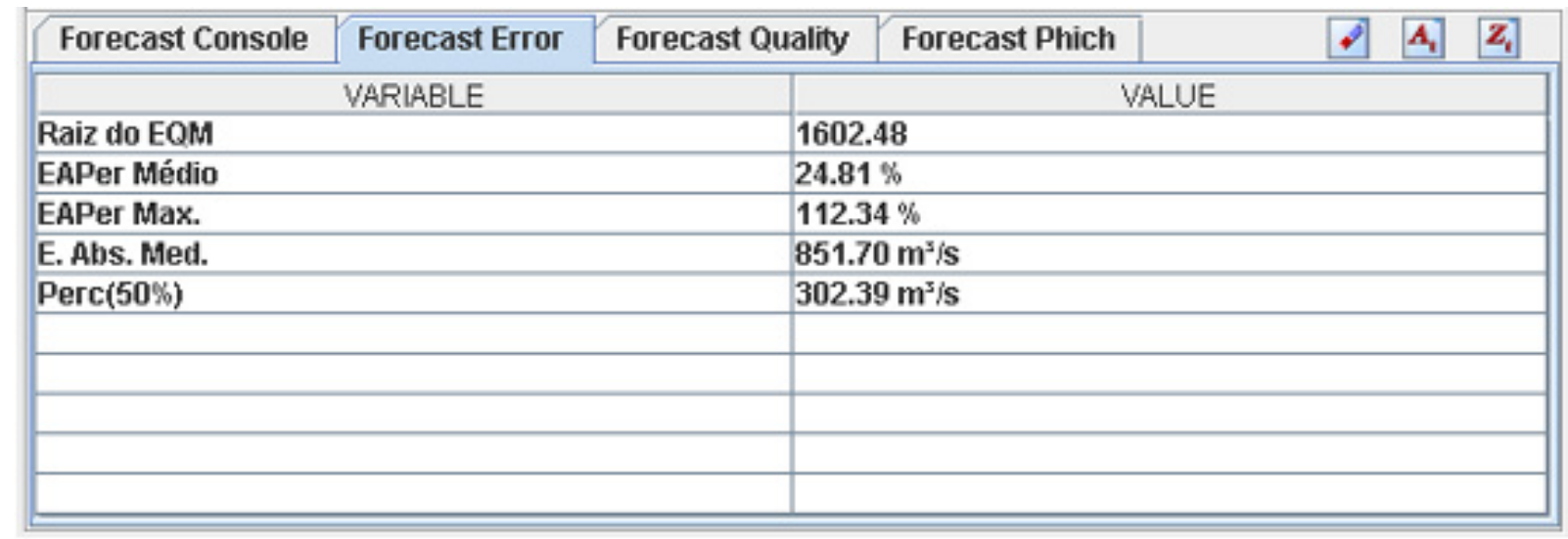

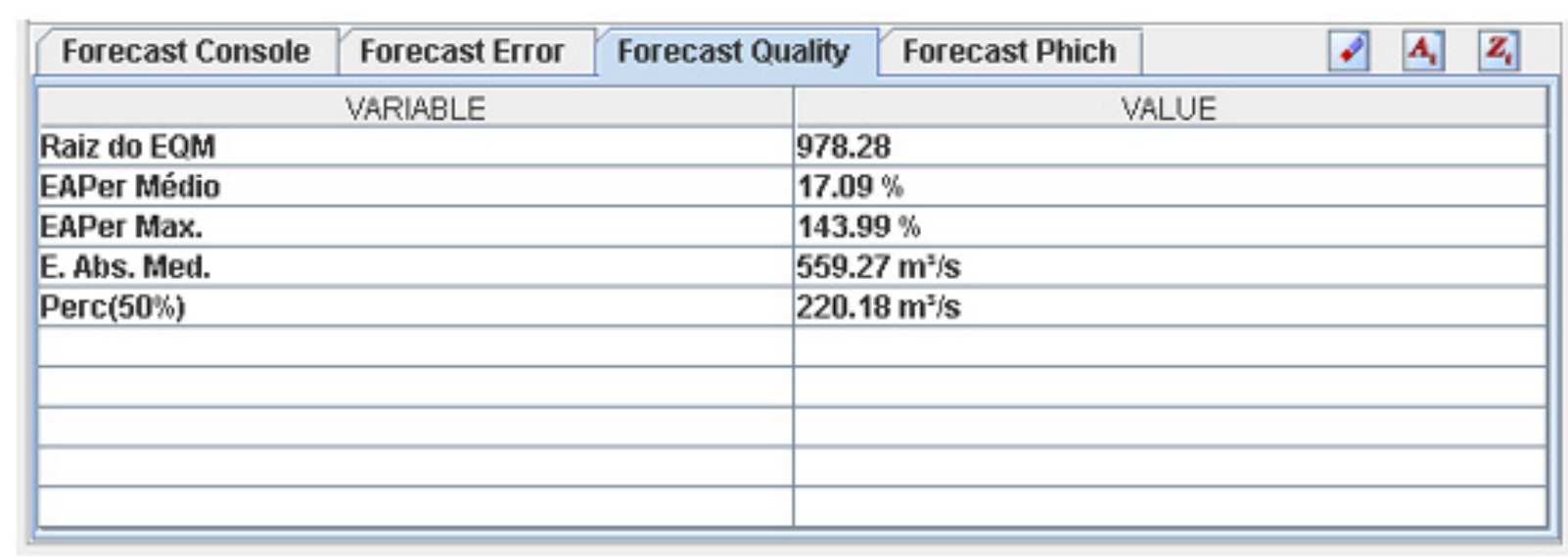

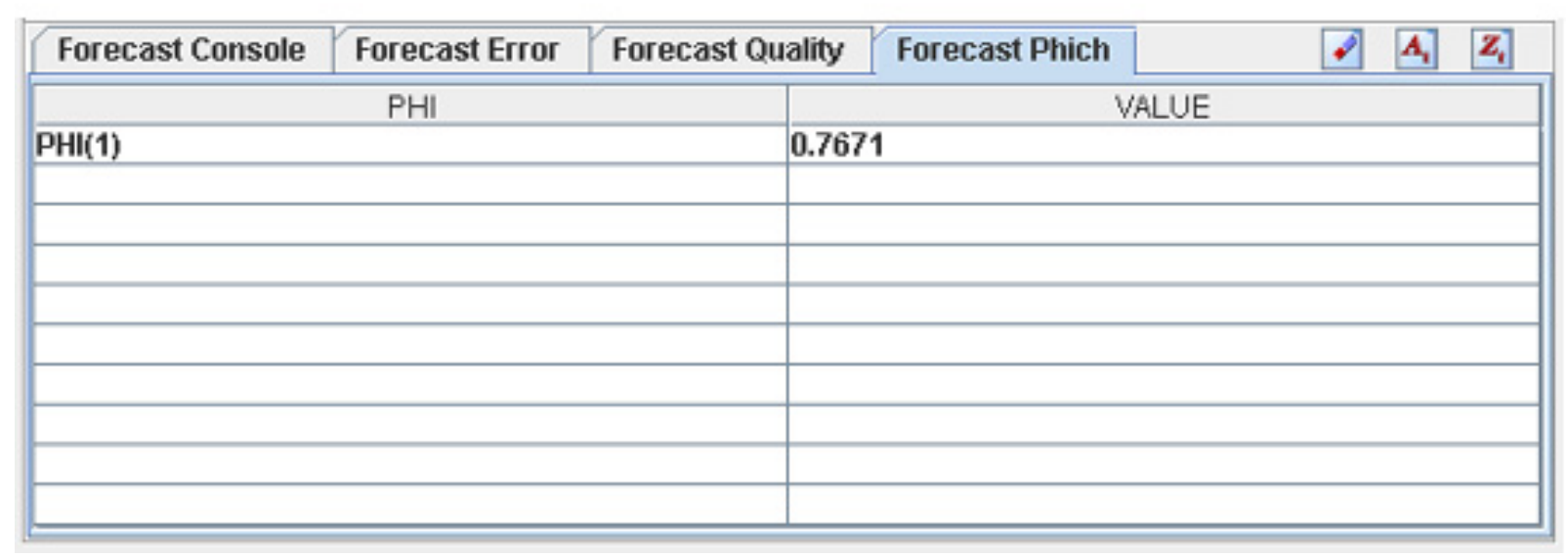

Figura 4.18: Tabelas com valores referentes a qualidade, erro e phich da previsão pelo modelo ARBOXCOX. 


\subsection{Considerações Finais}

Os testes de uso apresentados neste capítulo, com a execução de tarefas e exemplos ilustrativos envolvendo dados de vazões mensais nas usinas hidrelétricas, permitiram validar o ambiente computacional desenvolvido para a visualização e previsão desses dados. Para o módulo de previsão, as funcionalidades foram verificadas por um especialista que apoiou o desenvolvimento do sistema (prof. Marinho Gomes de Andrade Filho, ICMC-USP).

O módulo de visualização é exploratório e baseado em sugestões de técnicas para dados espaço-temporais encontradas na literatura científica. Acredita-se que as representações visuais espaço-temporais adaptadas e implementadas na ferramenta foram aplicadas com sucesso, e a integração complementar das múltiplas visualizações interativas apoiou efetivamente as tarefas de exploração propostas para análise dos dados de vazões.

Os exemplos de previsões realizados permitiram validar o módulo de previsão desenvolvido especialmente para dados de vazões. Tanto o ambiente matemático quanto os recursos visuais interativos utilizados para apoiar o processo de previsão e análise dos resultados corresponderam as expectativas do especialista.

Por fim, o sistema resultante pode ser considerado uma ferramenta valiosa para a exploração e análise de dados de vazões e previsão de vazões, além de poder ser utilizado para dados temporais em outros domínios. Além disso, ele incorpora diversos conceitos na tentativa de facilitar seu acesso e utilização por um maior número de usuários. Isso é consideravelmente importante, pelo fato de possibilitar a familiarização de mais usuários com os processos de visualização, incomuns a esta área de aplicação.

O próximo capítulo é destinado à apresentação das conclusões finais deste projeto e de sugestões para trabalhos futuros. 


\section{Capítulo \\ 5}

\section{Conclusões}

A inexistência de um software específico para análise de séries de vazões nas usinas hidrelétricas brasileiras, associada à importância estratégica desse tipo de dado no contexto energético, motivou a concepção de uma ferramenta gráfica para visualização e previsão desses dados, denominada Power Map Explorer. Como mencionado nos capítulos anteriores, o sistema desenvolvido une, em um mesmo ambiente, um módulo de visualização exploratória e um módulo de previsão. Para a implementação do módulo de visualização, foram reunidas técnicas de visualização e interação extraídas das áreas de visualização espaço-temporal e visualização de séries temporais utilizadas com sucesso na exploração e interpretação de dados com atributos temporais e espaciais. Com relação ao módulo de previsão, foram avaliados quais recursos computacionais matemáticos poderiam ser utilizados para a implementação e processamento dos modelos de previsão. Além disso, um estudo inicial relacionado a conceitos de estatística e de modelos de previsões de séries temporais foi necessário para a mínima compreensão e reprogramação dos modelos.

Como visto no capítulo 2, o uso de técnicas para a visualização de dados espaçotemporais tem ganhado cada vez mais importância, quer pelo crescente volume de dados dessa natureza, quer pela sua aplicabilidade no suporte a tomadas de decisão em diversos domínios. Além desses fatores, a complexidade inerente ao setor energético associado à incerteza das vazões futuras e a dificuldade de analisar um grande volume de dados, eram indicativos de que a integração, em um mesmo ambiente, de recursos de visualização e previsão seria um bom caminho para a exploração de tais dados. Acredita-se que a visualização, associada a dispositivos interativos, pode sugerir novas interpretações e gerar novas hipóteses sobre os dados analisados.

Para o desenvolvimento do Power Map Explorer foi necessária a utilização de vários recursos nas diversas áreas que se enquadra o sistema, como visualização, interação, en- 
genharia de software e estatística. A união de uma quantidade relativamente grande de diferentes conceitos de áreas diversas foi a maior dificuldade encontrada durante o desenvolvimento deste trabalho. Embora boa parte deste projeto a ênfase tenha sido na exploração e análise de dados de vazões, o ambiente resultante é, na verdade, genérico, e pode ser utilizado para a visualização de dados espaço-temporais gerados em outros domínios.

Para implementação do Power Map Explorer foi escolhida a plataforma Java em conjunto com o ambiente matemático Scilab. Essa escolha permitiu que toda a interface gráfica e as visualizações fossem desenvolvidas em Java, enquanto que os modelos de previsão pudessem ser implementados e executados diretamente no Scilab, que possui funcionalidades apropriadas para esse propósito. Um outro ponto relevante no desenvolvimento desse sistema refere-se à programação de acordo com o paradigma de orientação a objetos, que possibilitou a criação de um sistema robusto e de fácil manutenção. Como resultado final, a ferramenta desenvolvida pode ser utilizada tanto como aplicação local ou remotamente pela $W e b$. Além disso, a característica multiplataforma permite que o Power Map Explorer possa ser executado nos mais variados sistemas operacionais, como Windows e Linux, por exemplo.

Através da disponibilização do sistema Power Map Explorer na Web, busca-se um maior nível de utilização dos recursos e técnicas implementados neste projeto, pela facilidade que a $W e b$ proporciona para a comunicação de pesquisadores localizados remotamente. Isso permite que mais usuários tenham acesso e compartilhem os resultados obtidos através do ambiente desenvolvido.

Os testes de uso com o Power Map Explorer permitiram verificar a aplicabilidade das técnicas de visualização e interação no tratamento de dados de vazões medidos nas usinas hidrelétricas, bem como validar o ambiente matemático e os recursos visuais utilizados para apoiar o processo de previsão e interpretação dos resultados previstos. Algumas considerações a respeito dos testes realizados com o Power Map Explorer podem ser destacadas:

- A clareza e objetividade da interface gráfica pode facilitar a manipulação dos diversos componentes do sistema para os diferentes tipos de usuários;

- A simplicidade das visualizações conferida por fatores tais como ordem natural dos dados, imagem bidimensional e mapeamento por cor, mapas e gráficos, pode facilitar a explicação da visualização e sua interpretação visual, e assim diminuir o esforço cognitivo dos usuários;

- A simplicidade também afeta positivamente o desempenho do sistema, exigindo menor esforço computacional para a geração da imagem; 
- A alta velocidade de processamento dos modelos de previsão evita enormes intervalos ociosos entre previsões consecutivas;

- A visualização de um mesmo conjunto de dados por meio de múltiplas visualizações interativas pode apoiar a formulação de novas hipóteses ou confirmar hipóteses existentes sobre os dados analisados.

Com base nos resultados alcançados, pode-se delinear alguns trabalhos futuros relacionados à continuidade e aperfeiçoamento do Power Map Explorer, entre eles:

- Inclusão de novas técnicas de visualização;

- Inclusão de novas técnicas de interação;

- Inclusão do mapeamento sonoro para exploração e interpretação dos atributos temporais e espaciais dos dados;

- Maior coordenação entre as múltiplas visualizações para apoiar a exploração e análise dos dados;

- Representação de maiores detalhes espaciais através da geração de mapas geográficos tridimensionais;

- Ampliação ou adaptação dos modelos para a previsão de séries temporais geradas em qualquer domínio de aplicação, uma vez que tais modelos são, até o momento, ajustados especialmente para dados de vazões mensais.

Além disso, um outro aspecto a ser abordado seria o estudo do uso do sistema por usuários alvo para uma avaliação mais consistente, a fim de que eles possam estabelecer os pontos fortes e fracos do sistema.

Finalmente, espera-se que a ferramenta desenvolvida proporcione uma opção a mais aos especialistas do setor energético na exploração de dados de energia, em especial, dados de vazões. Além do mais, espera-se que o desenvolvimento deste projeto possa revelar novos desafios e inspirar, quer seja na área de pesquisa, quer seja no mercado energético, o desenvolvimento evolutivo de novas soluções mais abrangentes para esta aplicação estratégica no contexto nacional e mundial. 


\section{Referências Bibliográficas}

Ahlberg, C. Spotfire: an information exploration environment. SIGMOD Rec., v. 25, n. 4, p. 25-29, 1996.

AkkayA, A.; Tiker, M. L. Estimating parameters in autoregressive models in nonnormal situations: symmetric innovations. Communications in Statistics - Theory and Methods, v. 30, n. 3, p. 517-536, 2001.

Alencar, A. B.; G., A. F. M.; Paulovich, F. V.; Minghim, R.; Oliveira, M. C. F. Mineração visual de séries temporais: um estudo de caso com séries de vazões de usinas hidrelétricas (to appear). In: XVII Simpósio Brasileiro de Recursos Hídricos, Anais do XVII Simpósio Brasileiro de Recursos Hídricos, 2007, p. 20.

Andrade, M. G. Estimação bayesiana para processos par(pm) com transformação de box-cox. Relatório Técnico 77, ICMC-Estatística, Universidade de São Paulo, 2004.

Andrade, M. G. Modelos de séries temporais para previsão de vazões médias mensais. Curso da ONS. Operador Nacional do Sistema., 2005.

Andrienko, G.; Andrienko, N. Visual exploration of the spatial distribution of temporal behaviors. In: Proceedings of the Ninth International Conference on Information Visualisation (IV'05), IEEE Computer Society, 2005, p. 799-806.

Andrienko, G.; Andrienko, N.; Gatalsky, P. Towards exploratory visualization of spatio-temporal data. In: Proceedings of the 3th AGILE Conference on Geographic Information Science, Academic Press, Inc., 2000a, p. 137-142.

Andrienko, G.; Andrienko, N.; Gatalsky, P. Visualization of spatio-temporal information in the internet. In: Proceedings of the 11th International Workshop on Database and Expert Systems Applications, IEEE Computer Society, 2000b, p. 577-585.

Andrienko, G.; Andrienko, N.; Gatalsky, P. Exploratory spatio-temporal visualization: an analytical review. Journal of Visual Languages and Computing, v. 14, n. 6 , p. 503-541, 2003a. 
Andrienko, G.; Andrienko, N.; Voss, H. Gis for everyone: the commongis project and beyond., cáp. Maps and the Internet. Elsevier Science, p. 131-146, 2003b.

ANNEL Agência nacional de energia elétrica. capacidade de geração do brasil. Disponivel em http://www.aneel.gov.br/aplicacoes/capacidadebrasil/capacidadebrasil.asp. Acessado em 09/07/2007., 2007.

Balinni, R. Análise e previsão de vazões utilizando modelos de séries temporais, redes neurais e redes neurais nebulosas. Tese de Doutoramento, Universidade de Campinas - Departamento de Engenharia Elétrica, Campinas-SP, 2000.

Bertin, J. Semiology of graphics diagrams networks maps. Madison: The university of Wisconsin Press, 415 p., 1983.

BLOK, C. Monitoring change: characteristics of dynamic geo-spatial phenomena for visual exploration. In: Spatial Cognition II, Lecture Notes en Artificial Intelligence, Springer, 2000, p. 16-30.

Box, G.; Cox, D. An analysis of transformations. Journal of the Royal Statistical Society, v. 26, n. 2, p. 211-252, 1964.

Box, G. E. P.; Jenkins, G. M. Time series analysis, forecasting and control. HoldenDay, San Francisco: Prentice Hall, 1976.

Box, G. E. P.; Jenkins, G. M.; Reinsel, G. C. Time series analysis: forecasting and control. 3nd edition. New Jersey: Prentice Hall, 1994.

Brian, F.; Pritchard, J. Visualisation of historical events using lexis pencils. in: Case studies of visualization in the social sciences. Disponivel em http://www. agocg.ac.uk/reports/visual/casestud/contents.htm. Acessado em 23/04/2007., 1997.

Card, S.; Mackinlay, J.; Shneiderman, B. Readings in information visualization - using vision to think. New York: Morgan Kaufmann, 712 p., 1999.

Carlis, J. V.; Konstan, J. A. Interactive visualization of serial periodic data. In: Proc. 11 annual ACM symposium on User interface software and tecnology, ACM Press, 1998, p. 29-38.

Chakrabarti, K.; Keogh, E.; Mehrotra, S.; Pazzani, M. Locally adaptive dimensionality reduction for indexing large time series databases. ACM Transactions on Database Systems, v. 27, n. 2, p. 188-228, 2002.

Dragicevic, P.; Huot, S. A continuous and no-intrusive display for upcoming events. In: Conference on Human Factors in Computer Systems, ACM Press, 2002, p. 604-605. 
Elvins, T. T. Visfiles - presentation techniques for time-series data. SIGGRAPH Computer Graphics, v. 31, n. 2, p. 14-16, 1997.

Ester, M.; Kriegel, H.; SAnder, J. Lecture notes in computer science, cáp. Knowledge Discovery in Spatial Databases Berlin: Springer, p. 61-74, 1999.

Fayad, U.; Grinstein, G.; Wiersem, A. Information visualization in data mining and knowledge discovery. New York: Morgan Kaufmaun, Academic Press, 2002.

Fortunato, L. M.; Araripe, T. N. Introdução ao planejamento da expansão e operação de sistemas de produção de energia elétrica. Niterói, RJ, Br: Eduff-Editora Universitária, 1990.

Grunwald, G. K.; Hyndman, R. J.; Tedesco, L.; Tweedie, R. L. Non-gaussian linear ar(1) models. Australian and New Zealand Journal of Statistics, v. 42, n. 4, p. 479-495, 2000.

HARRIS, R. Information graphics - a comprehensive illustrated reference. Oxford: Oxford University Press, 448 p., 1996.

Havre, S.; Hetzler, B.; Nowell, L. Themeriver: Visualizing theme changes over time. In: Proc. IEEE Symposium on Information Visualization 2000 (InfoVis'00), IEEE Computer Society, 2000, p. 115-123.

Hochheiser, H.; Shneiderman, B. Dynamic query tools for time series data sets: Timebox widgets for interactive exploration. In: Information Visualization IV'04, Palgrave Macmillan, 2004, p. 1-18.

HUtTer, C. Uma abordagem bayesiana para modelos auto-regressivos periódicos. Dissertação de Mestrado, Universidade de São Paulo - Instituto de Ciências Matemáticas e de Computação, São Carlos - SP, 1998.

INXIGHT Transforming text into actionable information. Disponivel em http://www.inxight.com/. Acessado em 25/04/2007., 2006.

KeIM, D. Designing pixel-oriented visualization techniques: Theory and applications. Visualization and Computer Graphics, v. 6, n. 1, p. 59-78, 2000.

KeIm, D. Visual exploration of large databases. Communications of the ACM, v. 44, n. 8, p. 38-44, 2001.

KEIM, D. Information visualization and visual data mining. Visualization and Computer Graphics, v. 8, n. 1, p. 1-8, 2002. 
Keogh, E.; Chakrabarti, K.; Pazzani, M.; Mehrotra, S. Dimensionality reduction for fast similarity search in large time series databases. Journal of Knowledge and Information Systems, v. 3, n. 3, p. 263-286, 2000.

KEOGH, E.; Lin, J. Clustering of time series subsequences is meaningless: Implications for previous and future research. Knowledge and Information Systems, v. 8, n. 2, p. $154-177,2005$.

Keogh, E.; Stefano, L.; Ratanamahatana, C. A.; Wei, L.; Lee, S.; Handley, J. Compression-based data mining of sequential data. Data Mining and Knowledge Discovery, v. 14, n. 1, p. 99-129, 2007.

Koussoulakou, A.; KraAk, M. J. Spatio-temporal maps and cartographic communication. The Cartographic Journal, v. 29, n. 2, p. 101-108, 1992.

KraAK, M. J. Geovisualization illustraded. ISPRS Journal of Photogrammetry and Remote Sensing, v. 57, n. 5-6, p. 390-399, 2003.

Lin, J.; KeOgh, E.; Lonardi, S.; Chiu, B. A symbolic representation of time series, with implications for streaming algorithms. In: DMKD '03: Proceedings of the 8th ACM SIGMOD workshop on Research issues in data mining and knowledge discovery, ACM Press, 2003, p. 2-11.

Lin, J.; Keogh, E.; Lonardi, S.; Patel, P. Finding motifs in time series. In: Proceedings of the Second Workshop on Temporal Data Mining, ACM Press, 2002, p. $370-377$.

MacEachren, A.; KraAk, M. Research challenges in geovisualization. Cartography and geographic Information Science, v. 28, n. 1, p. 3-12, 2001.

MacEachren, A.; Wachowicz, M.; Edsall, R.; Haug, D.; Masters, R. Constructing knowledge from multivariate spatiotemporal data: Integrating geographic visualization (gvis) with knowledge discovery en database (kdd) methods. International Journal of Geographic Informaion Science, v. 13, n. 4, p. 311-334, 1999.

MacEachren, A. M. How maps work: Representation, visualization, and design. New York: The Guilford Press, 1995.

Mackinlay, J. Automating the design of graphical presentations of relational information. ACM Transactions on Graphics, v. 5, n. 2, p. 110-141, 1986.

Minghim, R.; Paulovich, F.; Lopes, A. Content-based text mapping using multidimensional projections for exploration of document collections. In: Proceedings of the Visualization and Data Analysis 2006, SPIE, 2006, p. 60600S. 
Moretin, P. A.; Toloi, C. M. C. Análise de séries temporais. São Paulo: Editora Edgard Blucher LTDA, 564 p., 2004.

Muller, W.; Schumann, H. Visualization methods for time-dependent data - an overview. In: Procedings of the 2003 Winter Simulation Conference, Winter Simulation Conference, 2003, p. 737-745.

Oliveira, M. C. F.; Levkowitz, H. From visual data exploration to visual data mining: A survey. IEEE Transactions on Visualization and Computer Graphics, v. 9, n. 3, p. 378-394, 2003.

ONS Operador nacional do sistema. Disponivel em http://www.ons.com.br/. Acessado em 12/04/2007., 2007.

OverBye, T. J.; WeBer, J. D. New methods the visualization of electric power system information. In: IEEE Symposium on Information Visualization 2000, IEEE Computer Society, 2000, p. 131-136.

Pagano, M. On periodic and multiple autoregressions. The Annals of Statistics, v. 6, n. 6, p. 1310-1317, 1978.

Pereira, B.; Pais, M. B. Z.; SAles, P. R. H. Análise espectral de séries temporais - uma introdução para engenharia, economia e estatística. Rio de Janeiro: Arte Final Leasing Editora LTDA, 109 p., 1986.

Peuquet, D. J. It's about time: a conceptual framework for the representation of temporal dynamics in geographic information systems. Annals of the Association of American Geographers, v. 84, n. 3, p. 441-461, 1994.

Roddick, J. F.; Hornsby, K.; Spiliopoulou, M. Lecture notes in computer science, cáp. An Updated Bibliography of Temporal, Spatial and Spatio-Temporal Data Mining Research Berlin: Springer, p. 147-163, 2001.

Salvador, V. Desenvolvimento de um modelo para exploração em visualização científica usando som. Tese de Doutoramento, Universidade de São Paulo-ICMC, 2003.

Shneiderman, B. Dynamic queries for visual information seeking. IEEE Software, v. 11, n. 6 , p. 70-77, 1994.

Shneiderman, B. The eyes have it: A task by data type taxonomy for information visualizations. In: IEEE Simposium on Visual Languages, IEEE Computer Society, 1996, p. 336-343.

Slocum, T. A. Thematic cartography and visualization. New Jersey: Prentice-Hall, 293 p., 1999. 
Spence, R. Information visualization. New York: Addison-Wesley, 206 p., 2001.

Stevens, S. S. On the theory of scales of measurement. Science, v. 103, n. 2684, p. 677-680, 1946.

Stolte, C.; Tang, D.; Hanrahan, P. Polaris: A system for query, analysis, and visualization of multidimensional relational databases. IEEE Transactions on Visualization and Computer Graphics, v. 8, n. 1, p. 52-65, 2002.

Swayne, D. F.; Cook, D.; BujA, A. Xgobi: Interactive dynamic data visualization in the $\mathrm{x}$ window system. Journal of Computacional and Graphical Statistic, v. 7, n. 1, p. 113-130, 1998.

Thomas, H. A.; Fiering, M. B. Mathematical synthesis of stream flow sequeces for the analysis of river basins by simulation. Harvardy University Press, 1976.

Tominski, C.; Abello, J.; Schumann, H. Axes-based visualizations with radial layouts. In: Proceedings of the 2004 ACM symposium on Applied computing, ACM Press, 2004, p. 1242-1247.

Tufte, E. R. The visual display of quantitative information. CT: Graphics Press, 1983.

Tufte, E. R. Envisioning information. CT: Graphics Press, 126 p., 1990.

VeCCHIA, A. V. Maximum likelihood estimation for periodic autoregressive moving average models. Technometrics, v. 27, n. 4, p. 375-384, 1985.

WARD, M. O. Xmdvtool: Integrating multiple methods for visualization multivariate data. In: Proc. of Information Visualization (IV94), IEEE Computer Society, 1994, p. 326-336.

Weber, M.; Alexa, M.; Müller, W. Visualizing time-series on spirals. In: Proc. IEEE Symposium on Information Visualization 2001 (InfoVis '01), IEEE Computer Society, 2001, p. 7-13.

WiJK, J.; SElow, E. V. Cluster and calendar-based visualization of time series data. In: Proc. IEEE Symposium on Information Visualization, IEEE Computer Society, 1999, p. $4-9$.

Wong, P. Visual data mining. IEEE Computer Graphics and Aplications, v. 19, n. 5, p. 20-21, 1999.

Yi, B. K.; Faloutsos, C. Fast time sequence indexing for arbitrary lp norms. In: Proc. of the 26st Internation Conference on Very Large Databases, Morgan Kaufmann Publishers Inc, 2000, p. 385-394. 


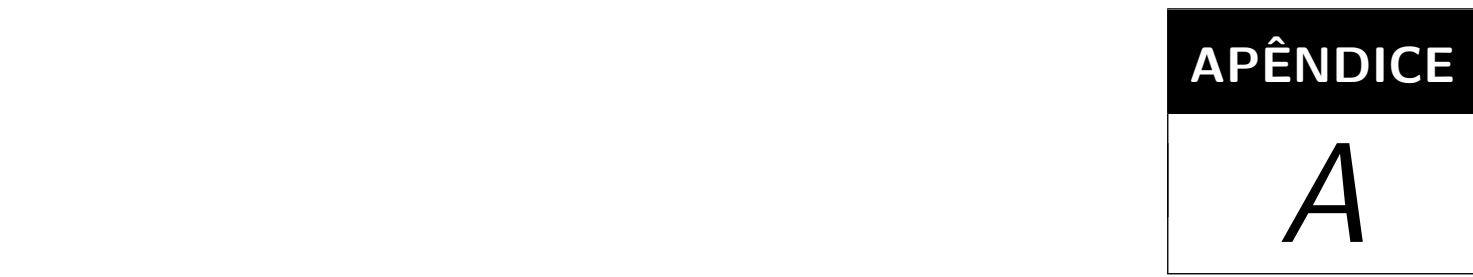

\section{Symbolic Aggregate ApproXimation -} SAX

O SAX é uma técnica de representação simbólica de séries temporais desenvolvido por Lin et al. (2003). O método consiste na conversão de séries temporais contínuas, que possuem valores reais, em um conjunto de seqüências discretas de símbolos especiais, preservando as características da série temporal original. Além disso, o SAX possibilita que uma série temporal de tamanho arbitrário n seja reduzida a uma string de tamanho $\mathrm{w}$, sendo w bem menor que n, como ilustrado na figura A.1.

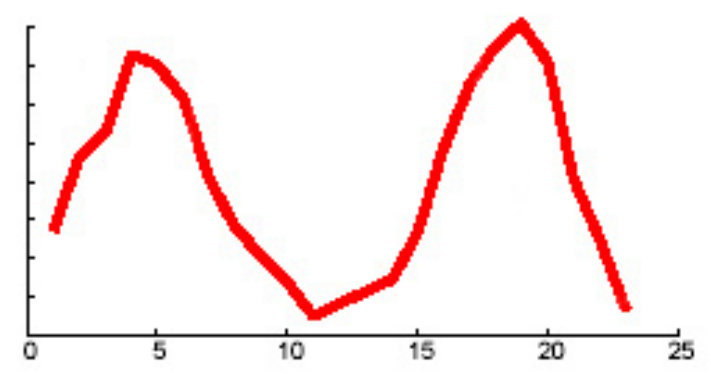

Figura A.1: SAX: uma série temporal de tamanho 24 foi reduzida em uma string de tamanho 8 (Lin et al., 2003).

No caso particular de séries temporais, o SAX pode ser dividido em três etapas: normalização, PAA (Picewise Aggregation Approximation) e discretização. Cada uma dessas etapas será detalhada a seguir. 
Na tabela A.1 são apresentadas algumas notações usadas para auxiliar a descrição das etapas.

\begin{tabular}{|c|c|}
\hline $\mathrm{C}$ & Uma série temporal $\mathrm{C}=c_{1}, \ldots, c_{n}$ \\
\hline $\bar{C}$ & Representação PAA da série temporal $C \times \bar{C}=\bar{c}_{1}, \ldots, \bar{c}_{w}$ \\
\hline$\widehat{C}$ & Representação simbólica da série temporal $C \times \widehat{C}=\widehat{c}_{1}, \ldots, \widehat{c}_{w}$ \\
\hline$w$ & Número de segmentos PAA representando a série temporal C \\
\hline$a$ & Tamanho do alfabeto na etapa de discretização (exemplo: para $a=3$, alfabeto $=$ "a","b","c") \\
\hline
\end{tabular}

Tabela A.1: Sumário de notações usadas no SAX.

\section{Normalização}

A normalização é a primeira etapa do SAX, e consiste basicamente na transformação dos elementos das séries temporais a serem discretizadas, a fim de que as séries temporais fiquem com média igual a 0 e desvio padrão igual a 1.

\section{Picewise Aggregation Approximation}

A PAA é uma etapa intermediária no algoritmo do SAX utilizada para a redução do tamanho da série temporal. O PAA consiste de um outro método para a representação de séries temporais introduzido por Keogh et al. (2000).

A idéia básica do PAA é dividir uma série temporal de tamanho $\mathrm{n}$ em $w$ segmentos de tamanhos iguais, a fim de reduzir o tamanho da série de n para $w$. Assim, é feita uma média aritmética dos valores dos elementos dentro de cada segmento, de modo que o vetor das médias dos segmentos torna-se a representação reduzida da série. A figura A.2 mostra a aplicação da etapa de PAA em uma série C normalizada, de tamanho igual a 128 para $w=8$ (número de segmentos).

Para calcular o vetor de $w$ segmentos, $\bar{C}=\bar{c}_{1}, \ldots, \bar{c}_{w}$ para uma série temporal $\mathrm{C}=$ $c_{1}, \ldots, c_{n}$, utiliza-se a seguinte equação para calcular cada um dos segmentos:

$$
\bar{c}_{i}=\frac{w}{n} \sum_{j=\frac{n}{w}(i-1)+1}^{\frac{n}{w} i} c_{j}
$$

As principais vantagens do uso dessa representação intermediária, segundo Lin et al. (2003), são:

- Redução de Tamanho: o PAA fornece uma representação da série temporal de tamanho igual a $w$, onde $w$ pode ser facilmente manipulado por um algoritmo de mineração enquanto ainda são mantidas as características da série temporal original. 


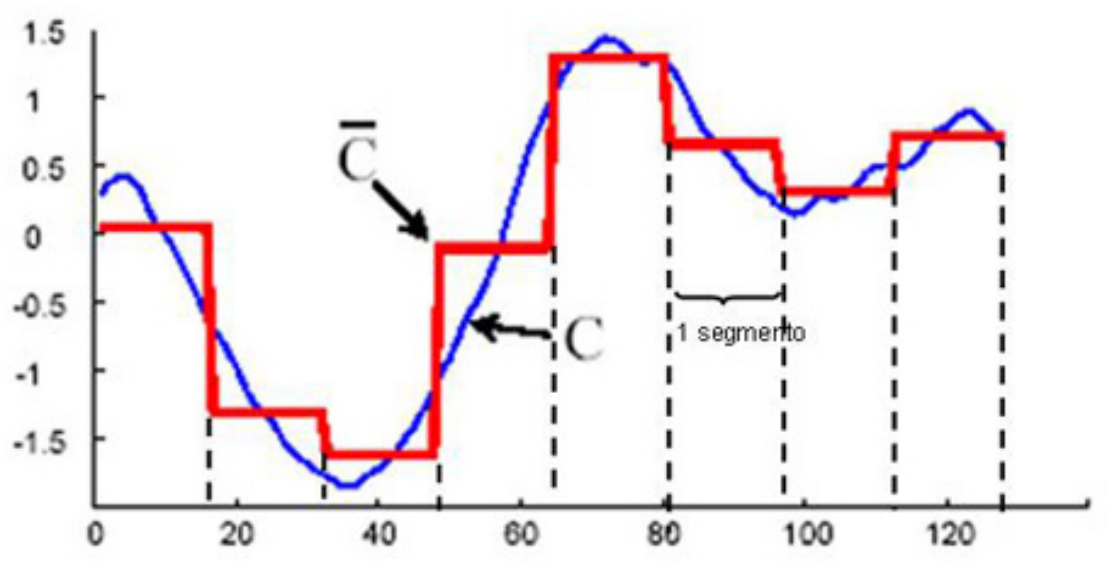

Figura A.2: Aplicação da etapa do PAA com $w=8$ a uma série temporal de tamanho $\mathrm{n}$ $=128$ (Lin et al., 2002).

- Limite Inferior: a distância entre duas representações PAA se aproxima bastante, mas nunca é maior que a distância entre as duas séries temporais originais que geraram essas representações. A existência do limite inferior é característica fundamental para a qualidade dos resultados dos algoritmos de mineração de dados sobre as representações das séries temporais.

\section{Discretização}

Uma vez transformado a série temporal na representação intermediária PAA, é possível aplicar uma outra transformação para se obter uma representação discreta. No caso de séries temporais normalizadas com distribuição Gaussiana, é possível produzir símbolos com eqüiprobabilidade (Lin et al., 2003). Assim, cada segmento da etapa anterior é convertido em um símbolo equiprovável.

Nesta etapa final, deve-se definir o valor de $a$, ou tamanho do alfabeto, que determinará quais símbolos serão utilizados no processo de discretização. O tamanho do alfabeto é um inteiro de tamanho arbitrário, em que $a>2$. Por exemplo, para $a=4$ os símbolos do alfabeto serão "a", "b", "c" e "d". Para determinar o processo de mapeamento dos segmentos em símbolos do alfabeto, utiliza-se uma lista de breakpoints, de acordo com a definição abaixo.

Definição 7. Breakpoints: é uma lista ordenada de números $\beta=\beta_{1}, \ldots, \beta_{a-1}$, tal que a área sob a curva Gaussiana $\mathrm{N}(0,1)$ de $\beta_{i}$ a $\beta_{i+1}$ é igual a $1 / a\left(\beta_{0}\right.$ e $\beta_{a}$ são definidos com $-\infty$ e $\infty$, respectivamente). 
Estes breakpoints podem ser determinados pela divisão da distribuição gaussiana em regiões equiprováveis. A tabela A.2 mostra os valores dos breakpoints para valores de $a$ de 3 a 10.

\begin{tabular}{|c|c|c|c|c|c|c|c|c|}
\cline { 2 - 9 } \multicolumn{1}{c|}{} & \multicolumn{7}{c|}{$a_{i}$} \\
\cline { 2 - 10 } & 3 & 4 & 5 & 6 & 7 & 8 & 9 & 10 \\
\hline$\beta_{1}$ & -0.43 & -0.67 & -0.84 & -0.97 & -1.07 & -1.15 & -1.22 & -1.28 \\
\hline$\beta_{2}$ & -0.43 & 0 & -0.25 & -0.43 & -0.57 & -0.67 & -0.76 & -0.84 \\
\hline$\beta_{3}$ & - & 0.67 & 0.25 & 0 & -0.18 & -0.32 & -0.43 & -0.52 \\
\hline$\beta_{4}$ & - & - & 0.84 & 0.43 & 0.18 & 0 & -0.14 & -0.25 \\
\hline$\beta_{5}$ & - & - & - & 0.97 & 0.57 & 0.32 & 0.14 & 0 \\
\hline$\beta_{6}$ & - & - & - & - & 1.07 & 0.67 & 0.43 & 0.25 \\
\hline$\beta_{7}$ & - & - & - & - & - & 1.15 & 0.76 & 0.52 \\
\hline$\beta_{8}$ & - & - & - & - & - & - & 1.22 & 0.84 \\
\hline$\beta_{9}$ & - & - & - & - & - & - & - & 1.28 \\
\hline
\end{tabular}

Tabela A.2: Tabela de breakpoints para a etapa de discretização de séries temporais normalizadas, com alfabeto variando de 3 a 10 .

Uma vez definidos os breakpoints, o passo seguinte consiste no mapeamento dos segmentos em símbolos. Os breakpoints dividem o eixo y em regiões equiprováveis, os segmentos menores ou iguais ao menor breakpoint são mapeados para o símbolo "a", todos os segmentos maiores que o menor breakpoint e menores ou iguais ao segundo menor breakpoint são mapeados para símbolo "b", e assim por diante. A concatenação dos símbolos obtidos pelo processo de discretização dos segmentos é chamado de "palavra". Esse processo de mapeamento para símbolos é ilustrado na figura A.3. O processo de discretização é aplicado segundo a definição abaixo (Lin et al., 2003):

Definição 8. Palavra $(\widehat{C})$ : Uma representação PAA com $w$ segmentos pode ser representada por uma "palavra", $\widehat{C}=\widehat{c_{1}}, \ldots, \widehat{c_{w}}$. Seja $a_{i}$ o i-gésimo elemento do alfabeto, ou seja, $a_{1}=\mathrm{a}, a_{2}=\mathrm{b}, a_{3}=\mathrm{c}$ e assim por diante. Então, a transformação da representação PAA $\bar{C}$ para uma "palavra" $\widehat{C}$ é obtida de acordo a seguinte equação:

$$
\widehat{c_{i}}=a_{j} \text {, se e somente se } \beta_{j-1} \leq \overline{c_{i}}<\beta_{j}
$$

Finalmente, aplicada essa transformação da representação PAA para uma representação discreta, tem-se uma seqüência de símbolos para representar a série temporal, que é o objetivo do SAX. 


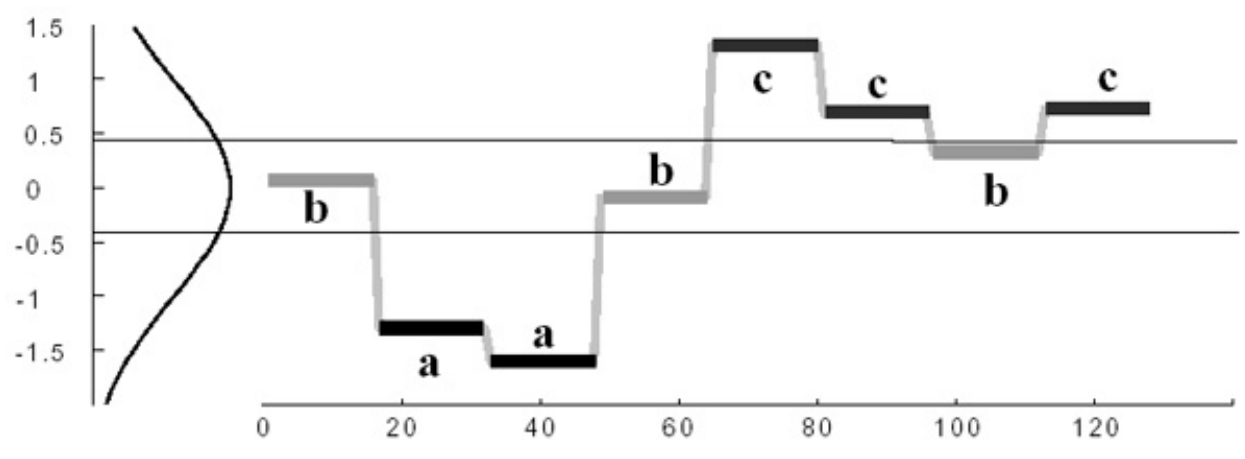

Figura A.3: Uma série temporal é discretizada, primeiramente obtendo uma representação PAA, e depois utilizando breakpoints para mapear os segmentos PAA em símbolos Lin et al. (2003). Neste caso, foi usado $w=8$ e $a=3$, obtendo-se a palavra $\widehat{C}=\widehat{c_{1}}, \widehat{c_{2}}, \widehat{c_{3}}, \widehat{c_{4}}$, $\widehat{c_{5}}, \widehat{c_{6}}, \widehat{c_{7}}, \widehat{c_{8}}=$ baabccbc (Lin et al., 2003). 


\section{APÊNDICE}

\section{$B$}

\section{Estrutura dos Arquivos XML}

Este apêndice apresenta a estrutura dos principais arquivos XML adotados pelo Power Map Explorer.

map.xml: este arquivo armazena as coordenadas para desenhar um mapa. O mapa é formado por um conjunto de regiões (tag region). Cada região é constituída por pontos limitadores (tag edge, formando um polígono) e pode ser colorida por uma cor específica através da tag color.

$$
\begin{aligned}
& <\text { map description }=\text { " "> } \\
& <\text { region name }=\text { " " nick }=" \text { "> } \\
& <\text { color red=" " green=" " blue=" " } /> \\
& <\text { edge } \mathrm{x}=\text { " " } \mathrm{y}=" \text { " } /> \\
& <\text { edge } \mathrm{x}=\text { " } \mathrm{y}=\text { " " / > } \\
& </ \text { region }> \\
& <\text { region name }=\text { " " nick=" "> } \\
& <\text { color red=" "green=" "blue=" " } /> \\
& <\text { edge } \mathrm{x}=\text { " " } \mathrm{y}=" \text { " } /> \\
& <\text { edge } \mathrm{x}=" \text { " } \mathrm{y}=" \text { " } /> \\
& </ \text { region }> \\
& </ \text { map }>
\end{aligned}
$$


rivers.xml: este arquivo armazena as coordenadas para desenhar os componentes de um mapa, por exemplo, rios ou linhas de transmissão. Cada componente é formado por um conjunto de pontos (tag edges) e pode ser colorido por uma cor específica. O componente pode ser lido pelo sistema como uma simples linha (type $=1$ ) ou um polígono $($ type $=0)$.

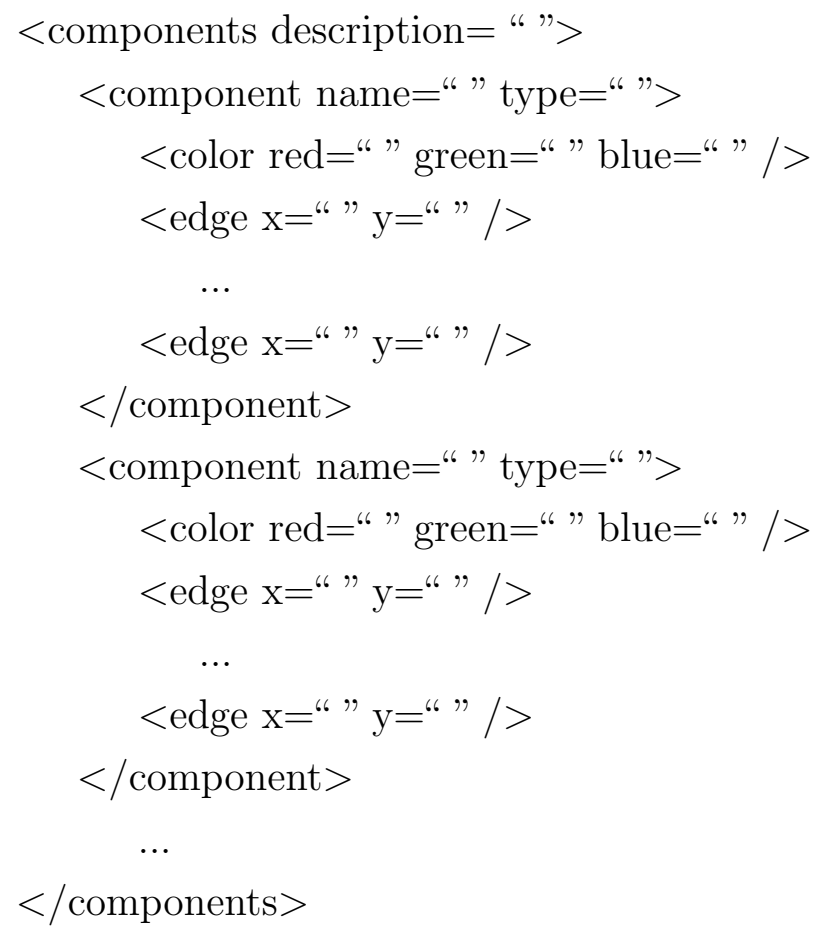

uhe.xml: este arquivo armazena os objetos espaciais a serem plotados no mapa. Cada objeto é identificado pela tag vertex e possui como propriedades: nome (tag label), classe que pertence ( $t a g$ class), latitude e longitude, e o nome do arquivo que contém a série temporal (tag url).

$$
\begin{aligned}
& <\text { graph description=" }> \\
& <\text { vertex id=" label=" }> \\
& <\text { class value=" } /> \\
& <\text { x-coordinate value=" " } /> \\
& <\text { y-coordinate value=" " } /> \\
& <\text { url value=" " } /> \\
& <\text { vertex }> \\
& \text {. } \\
& <\text { vertex id=" label=" }> \\
& <\text { class value=" } /> \\
& <\text { x-coordinate value=" } " /> \\
& <\text { y-coordinate value=" }=" />
\end{aligned}
$$


$<$ url value $=" " />$

$</$ vertex $>$

$</$ graph $>$

colortable.xml: este arquivo armazena a tabela de cores utilizada pelo sistema para mapear valores de um atributo em cores.

$<$ colortable description $=$ " $>$

$<$ value $>$

$<$ interval start=" " end=" " $/>$

$<$ color $\mathrm{r}=$ " " $\mathrm{g}=$ " " $\mathrm{b}=$ " " $/>$

$</$ value $>$

$\cdots$

$<$ value $>$

$<$ interval start=" " end=" " $/>$

$<$ color $\mathrm{r}=$ " " $\mathrm{g}=$ " " $\mathrm{b}=$ " " $/>$

$</$ value $>$

$</$ colortable $>$

Maiores detalhes sobre os arquivos XML adotados pelo sistema podem ser visto no manual do usuário disponibilizado em (http://infoserver.lcad.icmc.usp.br/infovis2/PowerMapExplorer). 